\title{
LA CERÁMICA ARGÁRICA EN LA ESTRATIGRAFÍA DE FUENTE ÁLAMO: CAMPAÑAS DE 1977-1982*
}

\section{THE ARGARIC CERAMICS IN THE STRATIGRAPHIC SEQUENCE OF FUENTE ÁLAMO. 1977-1982 SEASONS}

por

\author{
HERMANFRID SCHUBART
}

RESUMEN

ABSTRACT

Se presenta un estudio tipológico de las ocho formas clásicas de la cerámica argárica procedente del poblado de la Edad del Bronce de Fuente Álamo (Cuevas del Almanzora, Almería) en base a la secuencia estratigráfica documentada entre 1977 y 1982 en la cima y en la ladera este del asentamiento. Se contrastan las cerámicas domésticas estratificadas con los recipientes depositados en las sepulturas. Las reflexiones acerca de la evolución estilística de la cerámica argárica, entre los tiempos más antiguos y recientes, constituyen por ahora un resultado que solamente ha podido quedar puesto de manifiesto a tenor de la importante secuencia estratigráfica obtenida en el poblado de Fuente Álamo.

A typological analysis of the eight classical Argaric ceramic types from the Bronze Age settlement of Fuente Álamo (Cuevas del Almanzora, Almería) is presented, which is based upon the stratigraphical sequence documented between 1977 and 1982 on the summit and eastern slope of said settlement. The stratified domestic ceramic is compared to the recipients deposited in burials. These considerations about the systematic evolution of the Argaric ceramic, between the earliest and latest phases, can only be put forward due to the substantial stratigraphical sequence gained in the settlement of Fuente Álamo.

Palabras claves

Key words
Fuente Álamo. Poblado argárico. Cerámica argárica. Tipología. Cronología relativa. Desenvolvimiento de un estilo.

Fuente Álamo. Argaric settlement. Argaric ceramics. Typology. Relative chronology. Stylistic development.

* La versión alemana de este trabajo "Stratigraphisch geordnete Keramik der El Argar-Zeit aus den Grabungen 19771982 auf Fuente Álamo” se publicó en el volumen Iberia Archaeologica 4 (Schubart 2003). La traducción de la algo reducida versión española y una redacción muy competente en la temática se agradecen a la Dra. Anna-Maria Roos (Sevilla). 


\section{INTRODUCCIÓN}

La observación de las tendencias en la evolución tipológica de la cerámica argárica, la cual es decisiva para la cronología relativa de la Edad del Bronce Antiguo y Pleno en el sudeste de la Península, ocupa la investigación desde hace unas cuantas décadas. En un primer lugar, partiendo de distintos puntos de vista se analizaron los hallazgos procedentes de las tumbas, en especial los recipientes hallados en contextos cerrados. Estos estudios arrojaron importantes resultados acerca de un orden de sucesión, establecido en base a unas determinadas características evolutivas, y sobre la elaboración de una cronología relativa de la cerámica argárica (Schubart 1975; Ruiz-Gálvez 1977; Lull 1983; y otros) ${ }^{1}$. Pronto, sin embargo, se llamó la atención sobre el hecho de que estas observaciones sólo pueden ser válidas, en principio, para las cerámicas funerarias, ya que existen diferencias con los recipientes domésticos, por lo menos en parte (Schubart 1975: 89). A la hora de componer el ajuar sepulcral en una época concreta, era muy importante la selección de determinadas formas. Los intentos de comparar los resultados válidos para los contextos sepulcrales con la estratigrafía de la cerámica doméstica documentada en un poblado alejado del núcleo territorial de la Cultura de El Argar, resultaron poco satisfactorios (Schubart 1975: 89 s.). Así pues, en 1977 se pusieron en marcha las excavaciones sistemáticas en Fuente Álamo, "un yacimiento en la zona perteneciente a El Argar 'clásico' que Siret había definido en su época”, entre otras razones porque hasta entonces no fue posible comparar una secuencia de la cerámica doméstica con la funeraria (Arteaga y Schubart 1980: 248 s.).

En efecto, el principal resultado de la primera campaña de las excavaciones efectuadas en este asentamiento especialmente apto para realizar investigaciones estratigráficas sobre la historia del hábitat, fueron los conocimientos estratigráficos adquiridos, que fueron presentados inmediatamente el año siguiente en un informe preliminar (Schubart y Arteaga 1978: 31 ss.; Arteaga y Schubart 1980: 257 ss.). Después de la segunda campaña efectuada en 1979, aparte de establecer algunas indicaciones sobre las vasijas carenadas y las copas argáricas, se remitiría respecto de los resultados estratigráficos a un futuro estudio de los materiales mucho más ricos en cantidad (Arteaga y Schubart 1981: 13 s.).

Por otra parte, los hallazgos funerarios y en particular una selección de aquellas tumbas que estaban ubicadas en la secuencia estratigráfica del poblado, se trataron con detenimiento en estos informes preliminares y en los de las subsiguientes campañas de 1985 a 1999 (Schubart, Arteaga y Pingel 1985; 1988; 1989; Schubart, Pingel y Arteaga 1991; 1993; Pingel et al. 1998; 2003). De ello resultaron criterios novedosos respecto de la evolución tipológica de la cerámica argárica (cf. Schubart 2000c) $)^{2}$. El estudio de la cerámica doméstica - uno de los objetivos principales de las investigaciones en Fuente Álamo- tenía que ser relegado hasta después de finalizar la documentación gráfica y catalogación de todos los hallazgos.

Cuando los excavadores de Fuente Álamo encargaron el estudio de las cerámicas argáricas procedentes de las campañas realizadas entre 1985 y 1991 a Christine Sennewald, en primer lugar, y después de su marcha del Instituto Arqueológico Alemán de Madrid a Thomas Schuhmacher, las pusieron a disposición de unos prehistoriadores directamente comprometidos que participaron

1. Todas las vasijas de la Colección Siret accesibles en su momento son recogidas en Schubart y Ulreich (1991), ofreciendo una base para ulteriores estudios cerámicos.

2. Conforme a lo convenido hace tiempo entre el autor y el Dr. Hermann Ulreich (Viena, Austria), este investigador está preparando un amplio estudio de los numerosos hallazgos procedentes de contextos cerrados, mediante una estadística combinada, tomando como punto de partida la publicación común de la Colección Siret (Schubart y Ulreich 1991: VIII). Por separado, éstos y otros hallazgos funerarios de la Cultura de El Argar se tomarán en cuenta en la monografía que el autor tiene en preparación sobre las sepulturas de Fuente Álamo (Schubart e.p.). 
como estudiantes en la campaña de 1985, y luego como licenciados en la de 1991. Los resultados del estudio tipológico de Thomas Schuhmacher se presentaron como tesis doctoral en la Universidad de Tübingen (Alemania), siendo publicada en la serie Iberia Archaeologica como una tercera entrega de las investigaciones sobre Fuente Álamo (Schuhmacher 2003). En la primera monografía sobre Fuente Álamo se abarcaron en general las investigaciones realizadas entre 1977 y 1991 contando con la colaboración interdisciplinaria de destacados investigadores (Schubart, Pingel y Arteaga 2000). Y el segundo tomo fue dedicado al estudio de la industria lítica, presentado como tesis doctoral en la Universidad Autónoma de Barcelona por Robert Risch, siendo igualmente publicada en la serie Iberia Archaeologica (Risch 2002). Como próxima entrega está a punto de terminarse una monografía sobre las tumbas de Fuente Álamo (Schubart e.p.), a la cual han de seguir la publicación de las excavaciones en la ladera sur del poblado, así como la monografía sobre la ocupación post-argárica durante el Bronce Tardío.

Los directores de las excavaciones entre 1977 y 1982 -Oswaldo Arteaga y Hermanfrid Schubart- promovieron decisivamente el estudio de las cerámicas excavadas hasta entonces, intercalando concientemente una pausa en los trabajos de campo después de la conclusión de una primera fase de las excavaciones en Fuente Álamo. Todos los hallazgos materiales del inventario fueron catalogizados, dibujados y ubicados estratigráficamente. Los resultados obtenidos sobre la ordenación estratigráfica de las cerámicas argáricas y del Bronce Tardío estaban plasmados en representaciones gráficas. Ambos investigadores, sin embargo, tenían que cumplir en este momento con nuevas tareas, lo que impedía que terminaran el manuscrito por de pronto. Un adelanto al estudio de la tipología cerámica de Fuente Álamo fue presentado en 1984 en el congreso celebrado en homenaje a Luis Siret en el cincuentenario de su muerte (Schubart y Arteaga 1986: 294 s.).

Luego, después de la campaña de 1985, los nuevos datos sobre la ubicación cronológica del gran edificio $\mathrm{H}$ de planta cuadrangular y con ello sobre los estratos interrelacionados obligaron a revisar la secuencia y, en consecuencia, también la contrastación de numerosos complejos materiales. Así pues, un cierre de los trabajos sobre la cerámica de 1977-1982 continuaba prorrogándose, sin que se plasmaran en un manuscrito definitivo. Las tablas tipológicas elaboradas desde entonces, completando los estudios adelantos por Luis Siret, se incluyeron después de todo en la primera monografía publicada sobre Fuente Álamo (Arteaga y Schubart 2000).

En tales circunstancias, las reflexiones que siguen a continuación sobre los recipientes argáricos de las campañas de 1977-1982, en complemento del estudio realizado por Thomas Schuhmacher (2003), no pueden tener por objetivo repetir a base de un material muy parecido el pormenorizado trabajo de Schuhmacher, exigiendo consecuentemente una limitación razonable a lo esencial.

Como constataron las campañas efectuadas entre 1977 y 1982, las posibilidades en Fuente Álamo para la elaboración de una secuencia estratigráfica son de una índole muy especial, y sirven en general de base para la excavación de este poblado argárico. Aunque las prospecciones realizadas demostraron en seguida, que el hábitat no se limitaba a la cima del cerro, sino que incluía también las pendientes, las excavaciones se centraron en un principio en la cima y en la vecina ladera este, porque esta zona parecía en particular propicia para resolver las preguntas planteadas al comienzo de las excavaciones.

La cima de Fuente Álamo está formada por dos crestas rocosas, entre las cuales se conservan las estructuras arquitectónicas dentro de los sedimentos depositados en una gran potencia. En la pendiente superior de la ladera este, se ha podido documentar una estratigrafía de hasta $6 \mathrm{~m}$, que permite de una manera ejemplar distinguir 20 fases en toda la historia del hábitat (fig. 1). Estas fases pueden ser distribuidas sobre siete unidades mayores, referidas a la estratigrafía e incidencias deposicionales respecto a las construcciones de Fuente Álamo. Los cuatro primeros horizontes (I-IV) abarcan la Cultura de El Argar, conectando directamente con la ocupación post-argárica del

ISSN: 1133-4525 ISSN-e: 2255-3924 
Bronce Tardío (horizonte V). Después de esta secuencia prehistórica hay un largo hiatus temporal hasta que el cerro se vuelve a habitar en los tiempos de la República Romana (horizonte VI), y más tarde, después de otra interrupción, por la ocupación medieval árabe (horizonte VII). La secuencia argárica de los cuatro primeros horizontes, a su vez, podía ser respaldada por los ajuares funerarios integrados en la estratigrafía. De esta manera, los períodos A y B de la Cultura de El Argar podían ser subdivididos en 1 y 2, respectivamente, conforme con los horizontes I-IV de Fuente Álamo (Schubart 2000b: 39 ss., fig. 1).

Entre 1977 y 1982 se investigó por completo el gran 'eje' estratigráfico principal, orientado de este a oeste en la cima y la ladera este, alcanzando una longitud de $55 \mathrm{~m}$ con $4 \mathrm{~m}$ de ancho (Schubart 2000a). Fue proyectado en el área del poblado, donde la estructura del terreno permitía suponer la mayor potencia estratigráfica, correspondiendo los resultados a las esperanzas previstas. Aunque este eje iba dirigido con preferencia a la investigación de la estratigrafía, se proyectaba desde un principio con una anchura suficiente -junto con los vecinos cortes planteados hacia el norte y el sur- para poder investigar igualmente las estructuras arquitectónicas del asentamiento en su contexto.

La subdivisión de los estratos del 'eje' principal, quedando fraccionados en unas capas muy finas, posibilitaba una separación sistemática de los paquetes estratigráficos de una manera como no parece repetirse en otras áreas del asentamiento. Esto tiene aplicación incluso en relación con los tempranos horizontes I y II.

Era de especial importancia para los resultados que los estratos arqueológicos documentados en los perfiles principales pudieran ser perseguidos por amplias superficies de la cima y la ladera este, entrando también en los vecinos cortes hacia el norte y el sur, por lo que en la mayoría del área se consiguió elaborar una secuencia estratigráfica bastante uniforme.

Los cortes en la ladera este que están situados al norte y al sur del 'eje' principal, han sido investigados por completo durante las campañas efectuadas entre 1985 y 1991. Aquí la roca sube rápidamente hacia el norte y el sur, por lo que la potencia estratigráfica se va reduciendo y con ello la posibilidad de una subdivisión minuciosa de la estratigrafía, afectando en particular a los estratos antiguos (Schubart 2000b: 40 ss.). En consecuencia, la "ordenación estratigráfica de la cerámica argárica de Fuente Álamo. Campañas de 1977-1982" continúa siendo una fuente de información para la historia del asentamiento de Fuente Álamo así como también para el conocimiento de la Cultura de El Argar en general.

El estudio que aquí se presenta parte de los tipos cerámicos establecidos por Siret (Arteaga y Schubart 2000: fig. 1), utilizando su tabla tipológica que ha sido corregida y completada, pero sobre todo más diferenciada por Arteaga y Schubart (2000: figs. 2, 3) (figs. 2 y 3). La mayoría de los investigadores está de acuerdo en que la división de la cerámica funeraria en ocho tipos, como lo hicieron en su tiempo los hermanos Siret, tendría que ser conservada a pesar de sus defectos, atendiendo a varios motivos. Por un lado, con ello se podrá seguir trabajando con la documentación de Siret y también en el futuro establecer una comparación entre sus materiales y los nuevos hallazgos $y$, por otro lado, no se dificulta innecesariamente el entendimiento entre los investigadores que trabajan sobre esta temática. No obstante, múltiples esfuerzos demuestran que es preciso establecer una mayor diferenciación de los tipos de Siret, para poder contrastar los numerosos hallazgos procedentes de los poblados y las tumbas; en este sentido los penúltimos son de Arteaga y Schubart (2000) y los últimos de Schuhmacher (2003: 28 s., 95 ss.) $)^{3}$.

3. También Lull (1983: 52 ss.) sigue los tipos de Siret. Las estadísticas elaboradas por Lull, especialmente de las formas 1-3 (ibídem: 62 ss.) aportando unos resultados interesantes, se pueden apenas utilizar aquí tratándose en Fuente Álamo de recipientes fragmentados procedentes de un poblado. 
Así pues, bajo la condición de una limitación razonable, resultaron varias consecuencias, como p.ej. la necesidad de excluir del estudio numerosos fragmentos demasiado pequeños o poco característicos para poder identificarles con una forma concreta. Los recipientes o partes de ellos, ordenados por fases y horizontes estratigráficos en las figuras 4-16, ilustran en su valor informativo muy bien la utilidad de tal procedimiento. De esta manera se recurría a los fragmentos estratificados y a las pocas vasijas completas, que pudieron ser adscritos a las formas 1 a 8 , aunque la clasificación realizada en base a unos pequeños fragmentos sigue entrañando mucha dificultad. Los fragmentos no estratificados, cuyo número en comparación con los estratificados es en todo caso menor, se tomaron solamente en cuenta cuando se presentaron piezas únicas de importancia, como son: las vasijas conservadas por completo; los fragmentos decorados comparables con otros estratificados; o los recipientes funerarios procedentes de contextos cerrados.

La asignación exacta de un complejo material a una fase concreta es con frecuencia posible, pero no es la regla, de modo que se indican también dos o más fases como datación relativa. Los hallazgos adscritos a dos o tres fases se adjudican aquí a la más reciente, respectivamente. Los hallazgos que son relacionados con más fases aún, o sea, cuya datación relativa era evidentemente menos exacta, no se incluyeron en el estudio, aparte de algunas excepciones, para no aumentar una cierta falta de nitidez de la información que ya existe así y todo a causa del movimiento de fragmentos antiguos a estratos más recientes durante la vida del poblado. En un anexo se ponen en lista todos los fragmentos representados en las figuras 4-16, consignando el número del inventario y las fases.

Las figuras 4-16 se ordenan según la enumeración de las formas 1-8. Arriba a la izquierda aparecen los números romanos de los horizontes; arriba en el centro, los números arábicos de las fases. Los ejemplares pertenecientes a una misma fase están separados por líneas; los de un mismo horizonte por líneas más oscuras. Peculiaridades en la selección de los hallazgos y en su distribución en las figuras, serán señaladas en su momento cuando se discuta la forma en cuestión ${ }^{4}$.

\section{FORMAS 1-3}

Las formas 'clásicas' de la Cultura de El Argar, o sea las ollas de la forma 4, las características vasijas carenadas de las formas 5 y 6 , las llamativas copas de la forma 7, así como también los 'vasos' de la forma 8, son definidas claramente y pueden ser identificadas incluso a base de fragmentos. Esto es mucho más dificultoso en el caso de las escudillas, cuencos y ollas bajas. También en las publicaciones precedentes la poca diferenciación, y en parte inconsecuente, de la tabla tipológica de Siret contribuyó a ello. La identificación de las formas encontraba igualmente dificultades a la hora de elaborar un catálogo de las cerámicas de la Colección Siret, que tenía que basarse en la documentación de Siret y los tipos por él asignados (Schubart y Ulreich 1991: 62).

Así pues, en su tabla tipológica O. Arteaga y H. Schubart (2000: 101 ss., fig. 2) se esforzaron en definir más claramente estas formas 1-3, manteniendo intencionadamente reducido el número de los subtipos. Como recipientes de la forma 1 se incluyen cuencos cuyos perfiles dejan percibir

4. Los dibujos originales hechos a lápiz por los participantes en las excavaciones, sobre todo Miguel Requena, han sido pasados a tinta por los siguientes dibujantes: José Fernández Pérez (figs. 4-16, 17 a.b, 19-21); Elisa Puch Ramírez (figs. 2, 3); Miguel Requena (fig. 17 c); y Arno Eichler (fig. 18). Todos los hallazgos de Fuente Álamo son propiedad del Museo Provincial de Almería, donde se conservan en su gran mayoría. Debido a los problemas de almacenamiento por los que vienen pasando las instalaciones de dicho museo, una parte de los materiales se depositó de acuerdo con la Dirección General de Bienes Culturales en el propio Ayuntamiento de Cuevas del Almanzora.

ISSN: 1133-4525 ISSN-e: 2255-3924

SPAL 13 (2004)

http://dx.doi.org/10.12795/spal.2004.113.02 
una tendencia parabólica, o sea el cuerpo no está redondeado globularmente, por lo que más bien muestra una tendencia rectilínea hacia el punto más profundo del fondo. Los recipientes de la forma 2 se distinguen básicamente de los cuencos de la forma 1 por su perfil curvo que se aproxima a la forma circular o bien a segmentos circulares. En la forma 3 se trata de un perfil oval que se orienta horizontalmente, luego en las ollas de la forma 4 a verticalmente.

También la 'clasificación impresionista de las formas' presentada por Schuhmacher se apoya en las definiciones de Arteaga y Schubart, aunque introduce ciertos cambios y complementos (Schuhmacher 2003: 96 ss., 111 ss.). La sistematización de Arteaga y Schubart partía en primer lugar de la sistematización de Siret que estaba limitada a tres números. Además se basaba en los resultados estratigráficos de las campañas de 1977-1982 en Fuente Álamo y utilizaba los recipientes intactos procedentes de las sepulturas, publicados por Siret o posteriormente, que podían dar una idea de la forma completa, al contrario de la cerámica fragmentada hallada en los estratos del poblado. Aquí vale lo que también Schuhmacher encuentra como dificultad en el caso de los materiales incompletos a la hora de distinguir las formas. Y, finalmente, hay que añadir que las transiciones entre las formas 1,2 y 3 , así como también entre $2 \mathrm{~b} 2$ y $3 \mathrm{~b} 1$ y la olla de la forma $4 \mathrm{a}$, son difusas.

Por esa razón, los cuencos, las fuentes y ollas de las formas 1, 2 y 3 han sido reunidos conjuntamente en las figuras 4-6, y distribuidos según su posición estratigráfica, de modo que el usuario de las figuras puede hacerse una impresión independiente, aunque parta de otros criterios de ordenación. De todos modos, dentro de una misma fase se distribuye el material en lo posible con arreglo a los siguientes criterios formales: Arriba a la izquierda se comienza con los fragmentos de borde pertenecientes a los cuencos o fuentes de la forma 1, cuyos perfiles con una tendencia básica parabólica pueden mostrar a trechos también una tendencia rectilínea. Luego, hacia la derecha y hacia abajo, siguen los bordes de las formas 2 y 3 , cuyos perfiles curvos se aproximan a la forma circular o bien a segmentos circulares y al oval. Finalmente, abajo se ponen los cuencos y fuentes de borde entrante. Conforme a esta distribución, también los fragmentos de fondo se colocan en general hacia abajo y a la derecha.

Además, para no dejar crecer desmesuradamente la cantidad de las piezas reproducidas y con ello el número de las figuras, se tenía que elegir entre los materiales una selección ${ }^{5}$. De todos modos, las formas publicadas reflejan una sección representativa, tanto en lo que se refiere a los perfiles de los recipientes como a la frecuencia de una forma determinada, aunque no se escape del criterio individual de la selección del autor ${ }^{6}$.

Los fragmentos de borde de los cuencos de la forma 1 son relativamente frecuentes en todas las fases de los horizontes I-IV. También aparecen entre los pocos cuencos hallados en el horizonte I, donde hay dos fragmentos de esta forma, procedentes de la fase 5 (fig. 4, 2.3). No obstante, contemplando los dibujos, ya a primera vista se manifiesta en cualquier caso que los cuencos llanos de la forma 1a son muy raros. Solamente aparecen esporádicamente en las fases 7, 9, 10, 14 y 15 (figs.

5. A la hora de elaborar este trabajo, el fichero de los hallazgos de 1977-1982, con los dibujos de todos los fragmentos de borde y de pared que muestran una carena u otras características destacadas, incluyendo también las descripciones de los colores y las arcillas, estaba sólo en parte a disposición. En lo que concierne a las formas 1-5, había que escoger entre un contingente incompleto. En el caso de las formas 6-8 el contingente era completo.

6. Un posterior control, una corrección, un complemento o una revisión siempre serán posibles con la ayuda de la totalidad de los materiales.- Por ser una forma singular, para la publicación se seleccionó intencionadamente un fragmento de borde de un cuenco abierto (fig. 4, 1) procedente del horizonte I (fases 2-4). El borde macizo por encima de una pared fina recuerda a otro cuenco procedente de la tumba 777 de El Argar (Schubart y Ulreich 1991: 155, lám. 52, 777 a), a pesar de claras diferencias entre los dos perfiles. Según los excavadores, es probable que el cuenco de El Argar fue fabricado a molde (Siret y Siret 1890: 163, 175, lám. 19, 1 en el tomo de texto en p. 179; allí por equivocación se le hace proceder de la tumba 77). 
4,$5 ; 5,1.22 ; 6,39.69$ ), siendo sólo la escudilla de la fase 9 de la forma 1a1, mientras que parece que los otros cuencos son de la forma 1a2 algo más profunda. El caso es que la mayoría de los cuencos de la forma 1 pertenece a recipientes más profundos, como demuestra la orientación más inclinada de sus perfiles (figs. 4, 2.3.6-10.27-37; 5, 2-10.12.23-25.41-45; 6, 2-5.8-10.33.38.40-46).

Sólo muy pocos fragmentos pueden ser adscritos a la forma 2 , es decir a los cuencos con perfil curvo que se aproxima a segmentos circulares, y esto con toda reserva. Probablemente pertenecen a los siguientes subtipos: a la forma $2 \mathrm{~b} 2$ el fragmento de la fase 7 (fig. 4, 23); a la foma $2 \mathrm{a} 2 \mathrm{el}$ borde de la fase 9 (fig. 5, 13); a la forma 2 b2 el fragmento con decoración bruñida de la fase 12 (fig. 6, 31) y el fragmento amorfo de la fase 12/13 (fig. 6,35). Otro fragmento de borde sin decorar de la fase 12 (fig. 6,22 ) parece que procede de un cuenco de la forma $2 \mathrm{~b} 2$, así como el fragmento de la fase 14 (fig. 6,52 ) de un pequeño cuenco de la forma 2a2. Por lo tanto, la variante más cerrada, i.e. la forma $2 \mathrm{~b} 2$ que se depositó de una manera relativamente frecuente en las sepulturas, igualmente en Fuente Álamo (Pingel et al. 1998: figs. 10b; 14 = El Argar B2), se constata bastante raras veces entre los hallazgos procedentes del hábitat, lo que no obstante podrá ser a causa de las dificultades antes descritas que se encuentran cuando se juzga unos recipientes rotos de las cuales quedan sólo algunos fragmentos. Un ejemplo convincente para la forma $2 \mathrm{a} 2$ se halla en el pequeño cuenco descubierto en la tumba 75 de Fuente Álamo, en el enterramiento de un guerrero destacado por un brazalete de oro (Schubart, Arteaga y Pingel 1985: fig. 14 c).

En el caso de los cuencos u ollas de la forma 3, con un perfil oval que se orienta horizontalmente, de nuevo se documentan más ejemplares. Llama la atención que la mayoría de ellos pertenece a recipientes más abiertos que la forma 3a representada en la tabla tipológica de Arteaga y Schubart por un cuenco hondo con borde ligeramente entrante. El ejemplo de la tabla tipológica podría constituir una forma $3 \mathrm{a} 2$, mientras que los siguientes perfiles documentados en los estratos de Fuente Álamo serían característicos de una forma 3a1 presente en todos los horizontes argáricos: horizonte I (fig. 4, 4), horizonte II (figs. 4, 14.15.20.21.44; 5, 16-19), horizonte III (figs. 5, 3133.47.52.53; 6, 16-18), horizonte IV (fig. 6, 49-51). La mayoría de los fragmentos de borde citados, seguramente, se incluye como es debido entre la nueva forma $3 \mathrm{a} 1$ postulada para unos cuencos ovales más abiertos. Algunas piezas, si se hubiera podido seguir su perfil sobre un trecho más largo, posiblemente también podrían haber sido adscritas a la forma $2 \mathrm{a}$, lo que no obstante ha de quedar pendiente en estas circunstancias.

Después de introducir la forma 3a1, la anterior forma 3a constituye ahora la forma 3a2, para la cual se encuentran varios ejemplos en los horizontes II (fig. 4, 43.48) y III (figs. 5, 34.37.38; 6, 19.25).

También las ollas más cerradas de la forma $3 \mathrm{~b} 1$ aparecen reiteradas veces en distintos estratos, en particular en la fase 7 del horizonte II (fig. 4, 22.24-26), apreciándose justamente en estos perfiles un gran parentesco con otras formas de ollas, que haría posible la adjudicación de algún fragmento a variantes tanto de la forma 3 como también de la forma 4. El poblado de Cerro de Enmedio, un asentamiento de la época de El Argar A en la provincia de Almería, ofrece precisamente para semejantes formas de transición unos buenos ejemplos (Schubart 1980: 181, fig. 4 e.f).

La forma 3 b2 se describe por Arteaga y Schubart como una olla con perfil de tendencia oval y con borde ligeramente indicado, recto y entrante. Entre los cuencos y las ollas procedentes de la estratigrafía documentada entre 1977-1982 en Fuente Álamo, no obstante, esta forma tan característica no aparece. Solamente un cuenco perteneciente a la fase 12-14a, siendo claramente más abierto, presenta un borde más corto, eso sí, pero que está indicado, anguloso y entrante (fig. 6, 56).

Por otra parte, hay un grupo de cuencos y ollas que muestra otro tipo de borde digno de atención. En estos casos el borde entrante es arqueado, estrechándose con frecuencia por la parte de

ISSN: 1133-4525 ISSN-e: 2255-3924

SPAL 13 (2004) 
arriba, sin que se apreciara una indicación como en la forma $3 b 2$. No parece que este tipo esté presente en las fases antiguas, apareciendo hacia fines del horizonte II en la fase 9 (fig. 5, 15), luego con más frecuencia en el horizonte III en la fase 11 (fig. 5, 54-57.59) y en la fase 12 (fig. 6, 13.14.20.21.23.32). Tampoco falta en el horizonte IV en las fases 13-15 (fig. 6, 34.36.54.71). Si de acuerdo con el autor se considera que los fragmentos escogidos son característicos para unos cuencos y ollas de esta forma en las distintas fases, parece que se trate de un tipo relativamente tardío, que se manifiesta por primera vez en la fase 9 , o sea a fines del horizonte II, para luego en los horizontes III y IV tener más importancia, en especial en las fases 11 y 12.

Varios cuencos de distintas formas presentan una decoración bruñida. Esta técnica decorativa se observa también en otros recipientes de la Cultura de El Argar: tanto en las vasijas carenadas de la forma 5 (fig. 18) (Schubart, Arteaga y Pingel 1985: 95, fig. 10 b; Schubart y Ulreich 1991: lám. 50, 765 a), como en las copas de la forma 7 (Schubart y Ulreich 1991: láms. 16, 209 a, decoración en el exterior del pie; 121, 5, decoración en el interior del cuenco; 141, 152.153.159, decoración en el exterior del cuenco). En comparación con estas pocas piezas, se conocen en Fuente Álamo trece cuencos con decoración bruñida, y de ellos diez fragmentos provienen de las excavaciones de 1977 1982 (figs. 5, 57-59; 6, 29-32.73; 17 a.b).

En la cerámica argárica cuidada se observa a menudo una superficie bruñida, percibiéndose las marcas del bruñido orientadas en paralelo las más de las veces, pero sin trazar ningún dibujo. La decoración bruñida, al contrario, se basa en una agrupación bien visible de varias líneas, y en el caso de la cerámica argárica se aplica siempre sobre un fondo brillante. Por lo que no resalta tanto como en otras vasijas decoradas del Bronce Final y del Hierro Antiguo, donde la decoración bruñida se emplea sobre un fondo alisado mate que aparenta de este modo más claro. Por eso, la decoración bruñida argárica es más difícil de detectar en ciertas circunstancias, aunque está hecha intencionadamente trazando unos dibujos característicos, repetidos varias veces.

De este modo, en el caso de los fragmentos con decoración bruñida procedentes de las excavaciones de 1977-1982 en Fuente Álamo, se repiten unos determinados patrones simples. Así pues, las líneas bruñidas pueden ser paralelas guardando unas equidistancias menores o mayores (figs. $5,58 ; 6,31)$; pueden presentar una disposición radial, siendo una solución ideal para el interior de un cuenco (figs. 5, 57.59; 6, 29); pueden cruzarse en ángulo recto o también diagonalmente (fig. 6, 30.32); o pueden formar líneas agrupadas, cambiantes en la orientación (fig. 6, 73). Por regla general, los dibujos bruñidos adornan el interior de los cuencos. Solamente un recipiente estratificado muestra una decoración por ambas caras (fig. 6, 32), como se la conoce sólo en otra pieza adicional (fig. 17 a) procedente del área nordeste de la cumbre de Fuente Álamo. Lamentablemente no puede ser conectado con las zonas estratificadas de la cima y la ladera este. Del mismo complejo FA 77/68, excavado en el corte 9, proviene un segundo fragmento decorado por el interior (fig. 17 b), que se parece mucho a la otra pieza por la forma y el diámetro calculado, pero que tendrá que pertenecer a un recipiente distinto, ya que el segundo cuenco se decoró sólo por el interior, presentando una ordenación radial de las líneas. El fragmento decorado por ambas caras (fig. 17 a) muestra en el interior por debajo del labio una franja bruñida y luego un dibujo irregular de arcos apuntados; en el exterior, las líneas bruñidas son en principio paralelas y verticales, que después, hacia un fondo redondeado, también tendrían una ordenación radial.

Los ocho fragmentos estratificados con decoración bruñida, procedentes de las excavaciones de 1977-1982, pertenecen al período El Argar B, y en su mayoría precisamente a las fases 11 y 12 del horizonte III de Fuente Álamo; sólo una pieza es de la fase 15 del horizonte IV.

No se han encontrado recipientes con una decoración bruñida pertenecientes a los horizontes I y II de Fuente Álamo, o sea del período El Argar A, de modo que esta técnica decorativa es un elemento más bien reciente y por lo visto no sólo en Fuente Álamo, ya que las dos vasijas carenadas 
(Schubart, Arteaga y Pingel 1985: 95, fig. 10 b; Schubart y Ulreich 1991: lám. 50, 765 a) y las cuatro copas con decoración bruñida (Schubart y Ulreich 1991: láms. 16, 209 a; 121, 5; 141, 152.153.159)7, mencionadas anteriormente, son variantes recientes de las formas 5 y 7 . Tampoco el cuenco decorado procedente de un enterramiento doble en covacha de la tumba 80 de Fuente Álamo (fig. 17 c), no contradice tal cronología, aunque las sepulturas en covacha y en particular las tumbas de mayores dimensiones, pertenezcan al período El Argar A (fig. 1) (Arteaga y Schubart 1981: 17 ss.), ya que en Fuente Álamo este tipo de sepultura sigue apareciendo en El Argar B, igual que las enterramientos en cista (Pingel et al. 1998: 30 s.). En la tumba 80, no sólo el cuenco con decoración bruñida y con el borde entrante, algo arqueado, sino también la forma del puñal hablan a favor de una datación en el período El Argar B.

Igual que el cuenco de la tumba 80 , cinco de los seis fragmentos de borde procedentes de las excavaciones de 1977-1982, son de cuencos con borde entrante y arqueado (figs. 5, 57.59; 6, 32; 17 a.b), así como también uno de los cuencos enteros hallados en posteriores campañas (Schuhmacher 2003: lám. 14, 3). Por lo que este tipo de borde tardío de los cuencos, en su gran mayoría pertenecientes a El Argar B, coincide con la decoración bruñida que igualmente data en El Argar B. Semejantes criterios de datación pueden ser aplicados en especial a la cerámica cuidada, tratándose en el caso de las vasijas argáricas de unos recipientes de paredes más bien finas que muestran unas superficies cuidadas, frecuentemente alisadas.

Por último, las figuras 4-6 incluyen también varios fragmentos de fondos planos presentes en las distintas fases de Fuente Álamo (figs. 4, 19.49; 5, 20.21.39.40; 6, 28.58.59), cuya pertenencia a una forma concreta por de pronto no puede ser determinada. No obstante, es muy probable que pertenecieran a cuencos o grandes fuentes. También hay fondos planos en otras formas argáricas, aunque sólo esporádicamente ${ }^{8}$. Por lo demás, para la gran mayoría de todos los recipientes argáricos son característicos los fondos redondos (p.ej. fig. 4, 21).

En consecuencia, acerca de las formas 1-3 hay que consignar en resumen, que es sumamente difícil de adscribir con seguridad los fragmentos de borde conservados a formas completas, cuando el resto del perfil sólo puede ser inferido y cuando sólo en los casos más favorables de una mejor conservación puede ser determinado. Además, los resultados sobre la cronología, en base a la estratigrafía, son relativamente escasos, lo que en gran parte tiene que ver con las condiciones de conservación antes descritas. Por lo mismo, preguntas concretas que resultaron de otras observaciones, no podían ser respondidas a base del material. No se podía observar una tendencia en la evolución, p.ej., de unos recipientes más cerrados, en especial ollas, como los que pudieran estar en una tradición aún más antigua ${ }^{9}$, a unos cuencos más abiertos; pero tampoco la supuesta tendencia a cuencos 'cónicos' (Schubart 2000c: 108, 112), que entonces deberían corresponder a la forma 1. Por otra parte, el material ordenado estratigráficamente permitía la fijación cronológica de unas

7. Salvo en el caso de la copa de la lám. 141, 159, se trata de copas tardías de la forma 7c con pie esbelto, en parte presentando un vástago macizo de la forma 7c2 (lám. 16, 209 a; por lo visto también lám. 121, 5), en parte con una peana alta de la forma 7c1 (lám. 141, 153; parece también lám. 141, 152). En el caso de la copa de la lám. 141, 159 la forma del pie no puede ser determinada y por ello tampoco su datación relativa.

8. Véase p.ej. El Oficio, tumba 223: Schubart y Ulreich 1991: lám. 96, 223 b; Fuente Álamo, tumba 11: ibídem: lám. 115, 11 a; tumba 86: Pingel et al. 1998: 24 s., figs. 8 e; 14, 86. También las pequeñas ollas globulares de la forma 2 b2, con mamelones perforados verticalmente, poseen en ocasiones un pequeño fondo plano: Schubart y Ulreich 1991: láms. 3, 22 a; 6, $51 \mathrm{~g} ; 50,766$ f; 55, 823 b. Las últimas cuatro ollas formaron parte del ajuar de unas inhumaciones en urna, respectivamente.

9. Entre los materiales del Cerro de Enmedio, que pertenecen por lo visto a El Argar A, existen unas ollas cerradas (Schubart 1980: fig. 4 e.f) al lado de los cuencos abiertos que no obstante predominan. La tumba 202 de El Argar que contenía dos ollas parecidas, unos botones perforados en 'V'y un punzón (Schubart y Ulreich 1991: lám. 16, 202), aboga por una cronología antigua.

ISSN: 1133-4525 ISSN-e: 2255-3924

SPAL 13 (2004)

http://dx.doi.org/10.12795/spal.2004.113.02 
determinadas innovaciones: la formación del borde entrante y arqueado, así como la aparición de la decoración bruñida. Ambas manifestaciones no se observan en las tempranas fases de la estratigrafía de Fuente Álamo, pero luego son características para los horizontes III y IV, o sea para el período El Argar B, corriendo en parte parejas.

Una comparación de los materiales procedentes de las excavaciones de 1977-1982 con las cerámicas documentadas en las campañas de 1985-1991, evidencia que los cuencos con borde entrante y arqueado (Schuhmacher 2003: fig. 56, forma 2.1.2.0) aparecen también aquí no antes de los estratos de los horizontes III y IV ${ }^{10}$, siendo ambos estudios complementarios y confirmatorios. Ya se indicó anteriormente, que en las últimas campañas se encontraron sólo escasos fragmentos con decoración bruñida. Dos cuencos decorados empleando esta técnica (Schuhmacher 2003: láms. 14, $3 ; 22,9)$, no obstante, pertenecen igualmente a las fases 12 y 14 que son más recientes ${ }^{11}$.

\section{FORMA 4}

Las grandes ollas de la forma 4 se conservaron muy bien en las sepulturas, pero entre las cerámicas domésticas se encontraron sólo fragmentos, por lo que la identificación de los fragmentos de borde está asociada a una cierta inseguridad. Los restos de vasijas panzudas con borde entrante pueden pertenecer tanto a ollas de la forma 3 (fig. 4, 22.25) como a ollas de la forma 4a con borde entrante. Si el estado de conservación de los fragmentos permite reconstruir el perfil completo de la vasija, la forma concreta de la olla se determina por la altura. Mientras que en el caso de la forma 3 se trata de un perfil oval que se orienta horizontalmente, en el caso de la forma $4 \mathrm{a}$ el perfil oval se orienta verticalmente teniendo estas vasijas una mayor altura (fig. 2). Las ollas de la forma $4 \mathrm{~b}$, con borde indicado, se identifican más fácilmente, aunque los pequeños fragmentos de borde tampoco permiten una clasificación con seguridad (Arteaga y Schubart 2000: 103, fig. 2). La forma 4 se menciona en este lugar solamente para completar esta reseña tipológica, ya que fue imposible realizar un estudio detallado a causa de no poder manejar en su momento la documentación de la mayor parte de los materiales ${ }^{12}$.

Para la fase 1 de Fuente Álamo, que es la más antigua, se reproduce aquí sólo una olla globular de borde indicado y decorado con digitaciones (fig. 7, 1), la cual está en la transición a la forma 10 (fig. 3).

Para completar la noción sobre la forma 4, se ilustran también las dos ollas con borde indicado procedentes de la tumba 68 (fig. 7, 10.12), porque la posición estratigráfica de esta sepultura esta fijada con seguridad en la fase 14. Estas tres ollas de la forma 4 b (fig. 7, 1.10.12) son todas globulares, lo que de acuerdo con los hallazgos funerarios habla más bien a favor de una forma antigua en la tendencia general de la evolución tipológica (Schubart 2000c: 107), aunque las ollas de la tumba 68 pertenezcan a un enterramiento de El Argar B. Por otra parte, una olla procedente de un contexto más antiguo del Cerro de Enmedio (Schubart 1980: fig. 4 d), también es más ancho (proporción entre altura y anchura = 5:6) que las dos ollas de la tumba 68 (1:1).

10. Schuhmacher 2003: fase 10 (lám. 7, 7); fase 11 (lám. 10, 9?); fase 12 (lám. 14, 3.6.12.13); fase 13 (19, 9-12); fase 14 (lám. 23, 10.11).

11. También Schuhmacher (2003: 111 ss., 125 s.) considera en base a su estudio tipológico independiente que el borde entrante es una evolución tardía, tanto en lo que concierne a las formas 1 y 2 , como a la forma 3 , aunque en ese caso con restricciones.

12. A la hora de realizar este estudio, no eran accesibles ni las fichas originales con los dibujos a lápiz y las descripciones de las pastas, ni los dibujos a tinta, de modo que no era posible ofrecer una cantidad representativa de la forma 4 , aparte de los pocos ejemplares de la figura 7. 
A base de la publicación de Schubart y Ulreich (1991) se puede examinar la distribución de las distintas formas de ollas sobre los enterramientos en cistas y en urnas de inhumación: En el asentamiento de El Argar, donde son bastante válidas las adscripciones de las sepulturas en cista, en fosa y en covacha al periodo El Argar A, y de las inhumaciones en urnas al período El Argar B -en otros yacimientos, como p.ej. en Fuente Álamo, los enterramientos en cistas y en covachas perduran en El Argar B- se encontraron en las tumbas de cista 340, 363, 449, 463 y 541 cinco ollas, que causan la impresión de ser globulares, aunque en dos de ellas la altura prima sobre el ancho y en tres de ellas el ancho sobre la altura. Las dos ollas procedentes de las tumbas 340 y 541 de aspecto más estirado, no son ovoides como las de la tumba 9 de Fuente Álamo (ibídem: láms. 113, 9 e; 114, $9 \mathrm{v}$ ). En los enterramientos en urnas, que son más tardíos, aparecen sólo pocas ollas de la forma 4a, sin presentar un borde especial (p.ej. El Argar, tumbas 163 y 615). La mayoría de las ollas corresponden a la forma con borde indicado, para las cuales se hacía constar ya en 1975 (Schubart 1975: 84) "una clara preponderancia en la fase de los enterramientos en pithos" (57:8). Observando las tumbas de El Argar, entre las ollas provenientes de las inhumaciones en urnas predominan las más bien ovoides sobre las más bien globulares $(4: 3) .{ }^{13}$

En fin, en lo que respecta a la ordenación estratigráfica o tal vez incluso a la evolución cronológica de la forma 4, no es posible dar informaciones a base de los materiales de las excavaciones de 1977-1982 examinados por el autor.

\section{FORMA 5}

Las vasijas carenadas de la forma 5 constituyen junto con las copas los exponentes si cabe más característicos de la cerámica argárica. Todas las vasijas de la forma 5 presentan una carena más o menos acusada, siendo la amplitud de las variaciones del perfil sumamente grande. Arteaga y Schubart (2000: 103 s.; fig. 2) incluyen en su tabla tipológica sólo tres subtipos característicos, sin embargo, en el intermedio es posible imaginarse cualquier forma de transición (fig. 2).

Como referencias cronológicas pueden ser de importancia las siguientes observaciones tipológicas: la carena situada a la mitad del recipiente, aproximadamente, o en la parte inferior a una altura más o menos baja; la parte superior o inferior curvilínea de la vasija carenada; o la parte superior o inferior estirada más cónicamente, como en el caso de la forma $5 \mathrm{c}$. En consecuencia, estos distintos elementos de los perfiles tienen que ser considerados a la hora de dar una referencia cronológica para una vasija carenada en sí, respectivamente, y para las posibles formas de transición. Por ello ya en ocasiones anteriores (Schubart 2000c: 107 ss.) se hacia constar que la datación de los recipientes carenados no puede ser obtenida por medio de puros cálculos de la altura de la carena (Schuhmacher 2003: 188, 128 s.), sino que para la datación es esencial la configuración completa del cuerpo. En el período El Argar A, la forma se caracteriza sobre todo por un cuerpo más ancho que alto, con la parte superior curvilínea cóncava y la inferior curvilínea convexa. En el Argar B, en cambio, la carena está situada más bien baja y conforme a ello la parte superior es relativamente más alta, presentando el cuerpo con frecuencia unas paredes más estiradas que pueden llegar a ser cónicas.

Entre todos los restos cerámicos excavados entre 1977 y 1982, se cuentan más de 300 fragmentos de pared de vasijas carenadas, de los cuales un alto porcentaje está estratificado. A estos 'fragmentos de carena' se añaden los fragmentos de borde saliente, cuyo perfil curvilíneo cóncavo de la parte superior del recipiente permite con cierta probabilidad adscribirles a la forma 5, aunque no se con-

13. Este resultado puede ser válido de momento sólo para las cerámicas funerarias procedentes de El Argar.

ISSN: 1133-4525 ISSN-e: 2255-3924 
serva la carena. Entre estos fragmentos de borde hay vasijas de muy distinto tamaño, desde muy pequeñas hasta francamente grandes, y también de distintas calidades, desde la cerámica cuidada hasta los grandes recipientes de la forma 5 utilizados incluso como urnas de inhumación.

En lo que concierne al horizonte I, en las tempranas fases 1-3, cuyos estratos podían ser documentados sólo en pequeñas zonas, se hallaron dos fragmentos (fig. 8, 1.2); en las fases 4-6 el número de los fragmentos de borde con carena aumenta a once (fig. 8, 3-5.7-14). La vasija completa procedente de la tumba 69 (fig. 8,6 ) sirve de ejemplo para la clásica forma 5 a del período El Argar A. En su punto más ancho, el diámetro excede considerablemente la altura del recipiente, de modo que la vasija se parece casi a una fuente; muy al contrario de las formas tardías de El Argar B, que más bien causan la impresión de un 'vaso'. La forma 5a de la tumba 69 muestra la parte superior curvilínea cóncava y la inferior igualmente curvilínea convexa. La carena se encuentra bastante exacta a media altura. Un segundo ejemplar completo procede de la fase 6 (fig. 8, 13), ofreciendo un aspecto bastante similar, aunque se trata de una variante mucho más pequeña de esta forma de El Argar A. Aquí, la carena se sitúa algo por debajo de la media altura del recipiente. La mayoría de las otras vasijas, conservadas solamente en parte, corresponde por lo visto también a estas formas anchas, caracterizadas por sus perfiles curvilíneos y una carena relativamente alta.

Aunque las formas estiradas $5 \mathrm{~b}$ ó $5 \mathrm{c}$ faltan del todo entre los hallazgos del horizonte I, hay que hacer observar que en algunos fragmentos la parte superior no es tan curvilínea cóncava como en el prototipo de la forma $5 \mathrm{a}$, lo que tiene aplicación en especial a uno de los fragmentos reproducidos, procedente de la fase $5 \mathrm{c}$ (fig. 8,12 ), así como también hasta cierto grado al único fragmento de una vasija carenada de la fase 1 (fig. 8, 1). Aquí, la carena tiene que haber estado situada relativamente alta, en cualquier caso en la parte superior de la vasija, y está menos marcada que en los otros ejemplos de la forma $5 \mathrm{a}$, lo que está condicionado, entre otras cosas, por la parte superior menos cóncava que en las restantes piezas de este horizonte antiguo.

En el horizonte II, el número de los fragmentos que conservan tanto el borde como la carena (fig. 9) es el doble que en el horizonte I, lo que no sorprende a la vista de la mayor cantidad antes mencionada de los fragmentos carenados, aunque de nuevo se hallaron solamente dos vasijas completas, ambas de la fase 7 . Una de estas vasijas procede de la tumba 54 que puede haber sido instalada ya en una de las últimas fases del horizonte I, pero que es considerada como muy tarde perteneciente a la fase 7, en la cual por tanto se la incluye aquí. La vasija carenada de la tumba 54 (fig. $9,2)$ no es tan ancha como la de la tumba 69 y aparenta ser más estirada. En las proporciones, la altura ha aumentado algo en relación con la mayor anchura del recipiente, sin embargo, la carena se encuentra tanto como antes a media altura, aproximadamente, e incluso algo por encima. Además, las partes superior e inferior siguen siendo muy curvilíneas. La segunda vasija completa, procedente de la fase 7d (fig. 9, 6), es otra vez una variante pequeña de la forma ancha. Mientras que la máxima anchura excede claramente la altura, baja la carena: Las partes superior e inferior del recipiente están en la proporción de 2:1, encontrándose la carena fuertemente marcada aún en el tercer cuarto desde arriba. Otro ejemplo para el tipo antiguo de la forma ancha - y también en este caso la carena se mueve algo hacia abajo desde la media altura de la vasija (fig. 19 a) - procede de un contexto cerrado de la fase 9 , adscrito a la tumba 95 (fig. 1).

Parece que también 19 de los 26 fragmentos de borde con carena pertenecen a esta forma ancha, y juzgando por sus medidas corresponden a las variantes pequeñas y medianas de la forma $5 \mathrm{a}$. En general, estas vasijas ya son algo más altas. En el horizonte I, sólo dos vasijas, mencionadas como atípicas, ofrecieron unas distancias mayores entre el borde y la carena; en el horizonte II, en 10 de las vasijas la medida de esta distancia excede $\operatorname{los} 6,0 \mathrm{~cm}$, lo que no es un valor llamativo, pero que deja percibir una cierta tendencia en la evolución tipológica. 
Observando la figura 10, que está dedicada a las vasijas carenadas del horizonte III, se nota a primera vista una coexistencia de los distintos perfiles. Cerca de la mitad de todos los ejemplos, cuyo aspecto podía ser reconstruido por completo o al menos aproximadamente en base al estado de conservación de los bordes y carenas, pertenece a las formas más anchas con una carena relativamente alta, que aún corresponden a una tradición antigua. Junto a estas vasijas, aparecen ya formas más estiradas con una parte superior más alta siendo la respectiva carena más baja, que nos hablan de una coexistencia conforme con un proceso que dura algún tiempo. Si, al lado de las formas que se distinguen claramente por seguir una tradición antigua (fig. 10, 1.7.10.13-16.22.23), las formas identificadas con seguridad como más recientes, con el perfil más estirado, de momento continúan estando en la minoría (fig. 10, 2-4.26.30), es seguramente a causa del problema de conservación. En las formas cerámicas estiradas aumenta la distancia entre el borde y la carena, con frecuencia incluso muchísimo, de modo que cuando se rompe la vasija, hay más probabilidad de que en los fragmentos de un tamaño medio el borde se separa de la carena, o sea de que ya no se conservan conjuntamente en un solo fragmento, lo que se puede reconocer fácil en los fragmentos de pared seleccionados (p.ej. fig. 10, 11.25). Varios de estos fragmentos de carena tendrían que presentar en el lugar donde por encima de la carena sigue aún subiendo la pared, en el caso de las formas antiguas, más anchas, ya el borde del recipiente a una determinada distancia. Estas condiciones de conservación tienen una influencia decisiva sobre la composición de los materiales ilustrados en la figura 10. Para corregir este cuadro al menos parcialmente, respecto de los recientes horizontes III y IV era imprescindible incluir en las figuras 10 y 11 una mayor cantidad de fragmentos que conservan sólo la carena.

Las tres vasijas completas del horizonte III reflejan igualmente la coexistencia de distintas formas. Se trata de tres versiones pequeñas de la forma 5 , de las cuales dos formaron parte del ajuar de las tumbas de cista 52 y 65 y pueden ser adscritas al estrato $10 \mathrm{~b}$ (fig. 10, 2.3). La tercera fue hallada en el estrato $11 \mathrm{~b}$ y es sólo algo más reciente (fig. 10,15). Este último recipiente, de por sí estratigráficamente más reciente, es sin embargo de forma ancha de tradición antigua. Su mayor anchura es a la altura como 3:2. Esta proporción cambia a favor de una mayor altura en lo que respecta las dos vasijas funerarias que pertenecen ya a la forma más estirada (fig. 10, 2.3). En el caso de la vasija de la tumba 52, la mayor anchura es a la altura como 3:2,7. Y en el caso del recipiente de la tumba 65 , la proporción es de 3:3, quedando la medida de la mayor anchura incluso algo por debajo de la altura. Las dos vasijas funerarias se clasifican de todos modos como la forma $5 \mathrm{~b}$, característica de El Argar B, aun cuando la pieza de la tumba 65 evoque ya la forma 5 c (fig. 10, 2).

Además de estas dos vasijas, hay en el horizonte III algunos fragmentos carenados con borde que presentan un cuerpo estirado, siendo la carena en su mayoría más baja. Varios de ellos muestran en la parte superior un perfil cónico o sea que ya no es curvilíneo cóncavo (fig. 10, 8.9.18.26). Destaca en esta línea evolutiva un fragmento carenado de una vasija cuidada de tamaño menor, cuya parte superior ofrece una pared recta, estrechándose hacia arriba; debajo de la carena muy baja, el cuerpo inferior está consecuentemente muy llano (fig. 10, 30). Aunque este recipiente no puede ser adscrito a una fase concreta del horizonte III, representa por su aproximación a la forma $5 \mathrm{c}$ el ejemplo más evolucionado de una vasija carenada tardía.

En el horizonte IV, la cantidad de fragmentos procedentes de vasijas carenadas (fig. 11, 1-17) desciende notablemente en comparación con los horizontes II y III. Por eso y también por motivo de las ya citadas dificultades en la conservación de los perfiles reconstruibles en el caso de las vasijas más estiradas, se explica que en el horizonte IV se conserven sólo dos recipientes enteros, y ningún fragmento carenado de borde, como sí los había en los horizontes I-III.

En la pequeña vasija carenada de la tumba de cista 68 (fig. 11, 13), la cual se adscribe a la fase 14, la altura excede mucho la mayor anchura. En comparación con la vasija procedente del estrato

ISSN: 1133-4525 ISSN-e: 2255-3924

SPAL 13 (2004)

http://dx.doi.org/10.12795/spal.2004.113.02 
$11 \mathrm{~b}$, que se describió anteriormente (fig. 10, 15), casi se invierte la proporción entre anchura y altura. Se puede establecer un paralelo con otras dos vasijas pequeñas, aunque no conserven el borde: una procede del estrato 14 (fig. 11, 14) y la segunda del estrato 15b (fig. 11, 16), encontrándose ésta última tipológicamente entre los recipientes de las tumbas 65 y 68 .

Parece que los fragmentos de pared con carena, hallados en el horizonte IV, corresponden en suma a las formas estiradas, características del período El Argar B: con la parte superior alta, menos curvilínea cóncava, y una carena más bien baja sobre la parte inferior del cuerpo respectivamente baja. Varias de estas vasijas presentan la parte superior rectilínea cónica (fig. 11, 2.5.10.14.17), aproximándose al perfil de la forma $5 \mathrm{c}$.

Schuhmacher (2003: 115 ss., 128 s.) pudo identificar tipológicamente sólo 12 vasijas carenadas. Las "en forma de cuenco o fuente" (forma 5a) prevalecen en su número sobre las "en forma de olla" (forma 5b), sin que la ordenación estratigráfica permitiera sacar unas "conclusiones cronológicas amplias". En efecto, para poder señalar algo con seguridad, la cantidad de los fragmentos clasificados es demasiado escasa. No obstante, algunas de las vasijas carenadas aportan datos sobre la tendencia observada en la evolución tipológica en otras ocasiones. Es cierto que algunas formas no pueden ser identificadas con seguridad, como p.ej. las de mayor tamaño procedentes de las fases 9-10 (Schuhmacher 2003: láms. 6, 5; 9, 3), que tienden a formas estiradas, pero de todos modos siguen siendo anchas, de modo que podrían ser características de una fase de transición. Un recipiente de la fase 13 (ibídem: lám. 21,2) es igualmente difícil de clasificar por su mala conservación. Más información aportan otras dos vasijas anchas de la forma $5 \mathrm{a}$, procedentes de la fase 7 (ibídem: lám. 3, 9.10), y una vasija claramente estirada de la forma 5b, procedente de la fase 10 o sea de inicios del horizonte III que es equiparado a El Argar B. Otra vasija de la forma 5b (ibídem: lám. 7, 3) está relacionada con las fases 7-12, sin poder concretar la fase en este amplio espacio de tiempo que abarca los horizontes II-III, aunque es bastante probable que pertenezca más bien al horizonte más tardío. No es de extrañar que una vasija carenada como la ilustrada en la lámina 13, 7 de Schuhmacher, siendo tipológicamente más bien de la forma 5a, aún aparezca en la fase $11 / 12$, i.e. en el horizonte III, teniendo a la vista las distintas formas del horizonte III reproducidas en nuestra fig. 10. En la ladera sur de Fuente Álamo se excavó un ejemplo completo y fehaciente de la forma 5a (ibídem: lám. 29, 4), cuya complicada ubicación estratigráfica no vamos a tratar aquí con detenimiento. Solamente apuntamos que ha sido hallado conjuntamente con una peana ancha de una copa de la forma 7 b2 (ibídem: lám. 29, 5), por lo que según la ordenación estratigráfica de las copas que expondremos más adelante, este complejo material difícilmente podrá pertenecer al horizonte I, pero muy probablemente a los horizontes II y III, aunque tampoco puede excluirse el horizonte IV. ${ }^{14}$ Acerca de las vasijas carenadas procedentes de las excavaciones de 1985-1991 se puede concluir que, aunque hay algunas referencias que confirman la hipótesis de 1975, son escasas en comparación con las informaciones aportadas por los materiales de 1977-1982.

En resumen se puede consignar que los materiales de las campañas de 1977-1982 permiten constatar una evolución tipológica de las vasijas carenadas de la forma 5 , que va desde unas formas antiguas, más anchas, con la carena más alta y la parte superior del cuerpo curvilínea cóncava, hasta formas más estiradas, con la carena más baja y la parte superior menos o apenas

14. La cazuela de carena alta (Schuhmacher 2003: lám. 23, 14) que en su día fue adscrita por error a la fase 14, es sin duda del Bronce Tardío. Esta cazuela fue excavada junto al muro gg (FA 91/3198/1) a una profundidad de $-4,37 \mathrm{~m}$, lo que la sitúa en el ámbito del complejo material FA 91/3199 (profundidad: -4,20 a -4,60 m), para el cual se anota en el catálogo: "fosa / ¿alteración?”, por lo que la ubicación estratigráfica del complejo FA 91/3199 en las fases 14-17 está igualmente válida para el complejo FA 91/3198. 
cóncava. Así pues, se confirman las primeras observaciones publicadas en 1975, que hablaron de una evolución de las vasijas carenadas en la misma línea (Schubart 1975: 79 ss., 85 ss., figs. 2-4), aunque en su día se podían basar sólo en algunos contextos cerrados procedentes de las sepulturas. A continuación, esta hipótesis pudo ser confirmada reiteradas veces por otros hallazgos funerarios (Schubart 1979; 2000c: 107 ss.), hasta que ahora está firmemente fundamentada mediante la secuencia estratigráfica documentada en el poblado de Fuente Álamo, en particular en las campañas de 1977-1982.

\section{FORMA 6}

El recipiente bicónico de la forma 6 representa una variante especial de la vasija carenada, de proporciones más anchas que altas y sin un labio modelado en particular. Al contrario de las vasijas procedentes de las tumbas, que se conservan por completo y son frecuentemente de gran tamaño, la identificación de la forma a base de los fragmentos encontrados en los estratos del poblado es a menudo difícil, cuando no se trate de fragmentos de borde o de carena. En la tabla tipológica de Arteaga y Schubart (2000: 104, fig. 2) se distinguen dos subtipos (fig. 2): La forma 6a se caracteriza por mostrar una carena muy alta por encima del cuerpo panzudo de la vasija, inclinándose sólo algo la parte superior. Con el diámetro de la boca mayor, la parte superior de la forma $6 \mathrm{~b}$ presenta una mayor altura y el hombro curvilíneo convexo por encima de una carena respectivamente más baja. Como en las otras formas cerámicas, también en este caso se escogieron conscientemente dos variantes muy opuestas de la forma bicónica, existiendo entre estos dos extremos numerosas formas de transición.

Sobre la base de los hallazgos funerarios conocidos en su momento, se elaboró la hipótesis de que las vasijas bicónicas de la forma 6 pertenecerían en lo esencial al período El Argar A, y de que continuarían apareciendo todavía en El Argar B1 o sea en el horizonte III de Fuente Álamo. En cambio, en lo que concierne al período El Argar B2 (horizonte IV), parecía que estarían ausentes, de todos modos hasta entonces (Schubart, Arteaga y Pingel 1985: 99). Los ajuares funerarios y las cerámicas domésticas como las de las campañas de 1977-1982, que en su día aún no estaban publicados, han modificado esta idea. Así pues, la vasija bicónica de la forma 6 sí está presente en el horizonte IV, como p.ej en la tumba 678 de El Argar (Schubart 2000c: 111, notas 56 y 61). Además, la línea evolutiva desde la vasija con carena alta (El Argar, tumba 975) hasta la forma con el hombro curvilíneo convexo y la carena más baja (Fuente Álamo, tumba 52), no es tan recta como parecía (Schubart, Arteaga y Pingel 1985: 98, nota 45), aunque se confirma la tendencia entonces observada como tal.

Como demuestran igualmente los hallazgos de los años 1977-1982, la forma 6 no era muy frecuente, de modo que el número de los ejemplares estratificados es bastante escaso, lo que también en parte podría ser a causa de la ya citada dificultad de identificar con seguridad fragmentos de pared e incluso de borde de estas vasijas bicónicas.

Un fragmento de pared procedente del horizonte I muestra por encima de una carena bien marcada el hombro curvilíneo convexo (fig. 12,1), siendo por tanto la parte superior del cuerpo alta, de modo que no puede pertenecer a una vasija carenada de la forma 5a, que es la variante en uso durante el horizonte I, sino por lo visto a un recipiente bicónico de la forma 6b: con el hombro curvilíneo convexo y un perfil rectilíneo por debajo de la carena. Por lo tanto, esta forma $6 \mathrm{~b}$ considerada como la más reciente se documenta ya en el horizonte I, aunque sea en una de sus últimas fases $(5 \mathrm{c} 1)$.

ISSN: 1133-4525 ISSN-e: 2255-3924 
Otros tres fragmentos carenados de menor tamaño (fig. 12, 2-4) datan en la fase 7 a principios del horizonte II. A pesar de su pequeño tamaño que dificulta su clasificación, podrán permitir hablar de la presencia de la forma $6 \mathrm{~b}$ en el horizonte II. Hay que añadir otros tres fragmentos carenados que por encima de la carena apenas conservan algo de la pared (fase 5c: FA 79/1061/10; fase 7d: FA 77/505/5 y 505/8). Es probable que estos tres últimos puedan ser adscritos a la forma 6 (b?), pero no es seguro.

Siempre que los fragmentos estén correctamente orientados en el dibujo lo que condiciona su clasificación, estos resultados sobre las fases 5 y 7 contrastan con las observaciones que hubo hasta la fecha, porque demostrarían la presencia de la forma 6 b ya en los horizontes I y II de Fuente Álamo, o sea en el período El Argar A, mientras que hasta ahora faltan por completo en los tempranos estratos del poblado (horizontes I-II) unos fragmentos de borde o de carena de la forma $6 \mathrm{a}$, considerada como la más antigua. No obstante, a base de los hallazgos funerarios, la mayor antigüedad de la forma $6 \mathrm{a}$ está bien contrastada. Una variante característica, con el hombro algo inclinado y la carena muy alta (fig. 13, 1), sirve de modelo para la forma 6a de la tabla tipológica, siendo por lo visto muy antigua, probablemente del horizonte I de Fuente Álamo (Schubart, Arteaga y Pingel 1985: 98 s., fig. 14 a; Schubart y Ulreich 1991: lám. 59, 975). Entre este 'extremo' y la forma 6b, plenamente evolucionada a comienzos del horizonte III (figs. 12, 5.6; 13, 3) ) $^{15}$, parece que existían formas de transición (fig. 13, 2) que deberían datar en el horizonte II $^{16}$.

Estas observaciones se completarían ahora por la temprana presencia de la forma $6 \mathrm{~b}$ a fines del horizonte I e inicios del horizonte II, lo que parece confirmar una coexistencia de ambas formas. Igualmente se podría suponer que la evolución entre ambas formas, o sea de la forma $6 \mathrm{a}$ a la $6 \mathrm{~b}$, se efectuaría ya durante el horizonte I, y que para el ajuar de las sepulturas se seleccionaría unas vasijas especiales que darían la impresión de una evolución tipológica más lenta. En todo caso, es preciso no perder de vista la referencia aún poco segura, aportada por los fragmentos carenados relativamente pequeños de los horizontes I y II (fig. 12, 1-4), y verificar la situación aquí expuesta en base a otros hallazgos ${ }^{17}$.

De la fase 10b, o sea de comienzos del horizonte III, proceden las dos vasijas bicónicas de las tumbas 52 y 65 (fig. 12, 5.6) ${ }^{18}$, que son características de la forma $6 \mathrm{~b}$, a la cual pertenecen también dos fragmentos carenados: uno adscrito sólo globalmente a los horizontes II/III (fig. 12, 9) y el otro al horizonte III (fig. 12, 11). Hay que añadir otros dos fragmentos carenados (fig. 12, 10: horizonte II/III; 12, 13: horizonte III, fase 12), que presentan un hombro menos convexo que las piezas antes mencionadas, es decir un hombro algo curvilíneo (fig. 12,13) o más bien cónico (fig. 12, 10), comparable a la forma por lo visto más antigua ${ }^{19}$. Una de las piezas reproducidas (fig. 12, 12), procedente de la fase 12a, representa una variante excepcional, con la carena muy redondeada.

Más difícil es la identificación de los fragmentos de borde como forma 6 y tanto más como uno de los subtipos 6a ó 6b. Mientras que uno de los fragmentos de borde ilustrados puede ser clasificado

15. Arteaga y Schubart 1980: 267 s., fig. 9 g; Schubart 2000c: 110 ss., fig. 3 f. De la fosa de la tumba 52 de Fuente Álamo, igualmente datada en la fase 10b, procede un fragmento de borde (FA 77/566/4) que pudiera pertenecer a una olla o también a una vasija bicónica. En este último caso se trataría de una forma comparable a la vasija de la tumba 678 de El Argar (Schubart y Ulreich 1991: lám. 45, 678; Schubart 2000c: 111, nota 56).

16. Schubart, Arteaga y Pingel 1985: 98, nota 45, fig. 15; Pingel et al. 1998: 28, figs. 13, 14. Un aspecto parecido mostrarían también las vasijas bicónicas procedentes de la tumba 7 de Fuente Álamo (Schubart y Ulreich 1991: lám. 113, 7 d) y de la tumba 244 de El Argar (ibídem: lám. 18, 244 g), en las cuales el resto del ajuar sugiere una fecha más reciente. Según el dibujo insuficiente de Siret, posiblemente se podrá añadir la vasija de la tumba 1 de Fuente Álamo (ibídem: lám. 112, 1 h). Eventualmente se pudiera admitir la hipótesis de una mayor perduración también de esta variante.

17. Véase más adelante acerca de las campañas de 1985-1991.

18. Cf. supra nota 15.

19. Cf. supra nota 16. 
con cierta seguridad como forma 6 , aunque ofrezca el labio engrosado de una manera no observada en otras piezas (fig. 12, 8: fase 10b/11), los otros dos fragmentos de borde se incluyen aquí sólo con probabilidad (fig. 12, 7: fase 11b; 12, 14: fase 12). Eventualmente podrían pertenecer también a otras formas, como p.ej. a grandes ollas muy cerradas.

Es probable que la forma 6 sigue existiendo hasta el horizonte IV, porque aunque hay pocos fragmentos, son característicos, si no se supone de que se trate de un traslado de fragmentos antiguos a estratos más recientes; una posibilidad que no se puede excluir nunca totalmente. Dos fragmentos de pared, que tenían que haber pertenecido a la forma $6 \mathrm{~b}$, datan en la transición del horizonte III al IV (fig. 12, 15.16: fase 12/13) $)^{20}$ y un tercer fragmento de carena, igualmente de un recipiente bicónico de la forma $6 \mathrm{~b}$ (fig. 12, 17), proviene de la fase 14a del horizonte IV. En las sepulturas de Fuente Álamo, las vasijas de la forma 6 ya no aparecen a fines del horizonte III y tampoco en el horizonte IV, siendo excepcional la tumba 678 de El Argar (Schubart y Ulreich 1991: lám. 45, 678). El ajuar de esta inhumación en urna habla de una cronología tardía; además, el aspecto de esta vasija bicónica parece ser más evolucionado tipológicamente (Schubart 2000c: 111, nota 56), teniendo en cuenta las proporciones entre altura y anchura frente a las vasijas de las tumbas 52 y 65 de Fuente Álamo. El fragmento de carena antes mencionado que data en el horizonte III (fig. $12,11)$, también está emparentado con esta vasija tardía. Si en el futuro se observase más a menudo este tipo de perfil, la variante de la vasija bicónica hallada en la tumba 678 de El Argar debería ser introducida en la tabla tipológica como forma $6 c^{21}$.

En resumen es de subrayar que las vasijas bicónicas de la forma 6 están presentes en todos los cuatro horizontes de la secuencia estratigráfica documentada entre 1977-1982 en el poblado de Fuente Álamo, aunque con frecuencia y aspectos diferentes. De todos modos, el escaso número de los hallazgos limita el valor informativo de las observaciones. En este sentido, se pueden citar p.ej. los horizontes I y II, en los cuales se conocen vasijas de la forma 6 a en las sepulturas, mientras que procedentes de los estratos del poblado se mencionaron aquí solamente fragmentos carenados que parecen pertenecer a la forma $6 \mathrm{~b}$.

Por otro lado, en los horizontes III y IV carecemos de datos que confirmasen la presencia de la forma $6 \mathrm{a}$ en los contextos funerarios o domésticos, ni siquiera se conoce un fragmento carenado característico, lo que hay que destacar explícitamente, porque puede respaldar una datación antigua de esta forma. No obstante, una conclusión ex silentio siempre incluye una inseguridad como demostró el anterior ejemplo.

Las excavaciones de 1985-1991 aportaron lamentablemente muy pocos fragmentos estratificados de la forma 6 (Schuhmacher 2003: 118, 129, fig. 60)22. Un gran fragmento de la parte superior de una vasija bicónica (ibídem: lám. 35, 1; cf. lám. 35, 2-4) representa claramente la forma 6a, con el hombro rectilíneo, muy poco inclinado, y una carena francamente alta. Este pieza no procede de la secuencia estratigráfica documentada en la cima y la ladera este, que se discute aquí, sino de la ladera sur de Fuente Álamo, cuyas unidades estratigráficas no pueden ser equiparadas sin más a las de la cima. Fue encontrada junto con los fragmentos de dos copas: una de la forma 7a1 y la otra de

20. Acerca de fig. 12, 15 cf. Schubart, Arteaga y Pingel 1985: 99; Schubart 2000c: 111.

21. La designación como forma $6 \mathrm{c}$ caracteriza mejor la clara evolución en el aspecto de la vasija, que como forma $6 \mathrm{~b} 2$ (cf. todavía Arteaga y Schubart 2000: 104, nota 13). La tumba 133 de El Argar ofrece una de las observaciones exigidas, a realizar sobre otros ejemplos tardíos de esta forma. Esta inhumación en urna contenía como ajuar cerámico un recipiente pequeño de la forma 6c y una copa de la forma 7c1, igualmente del período El Argar B (Schubart y Ulreich 1991: lám. 11, 133 b.c. La reproducción de la vasija bicónica -según Siret forma 5- se tomó de Siret y Siret 1890: lám. 55, 133).

22. El estudio de las cerámicas procedentes de las campañas de 1977-1982 de momento se realizó concientemente por separado del estudio de los materiales de las excavaciones de 1985-1991 y de los resultados obtenidos en tales investigaciones, en lo que respecta a ésta y al resto de las formas.

ISSN: 1133-4525 ISSN-e: 2255-3924 
la forma 7c1. Esta última forma es de cronología más reciente, como se demostrará en el próximo apartado. Si este complejo material se considera como un contexto cerrado - todavía está pendiente el estudio concluyente de la estratigrafía de la ladera sur, que podrá responder a esta cuestión - se data en cualquier caso por el elemento más reciente, de modo que el fragmento de la forma 6a tendría que ser más reciente que su supuesta datación antigua o ser de deposición secundaria.

Otros dos fragmentos de la forma 6 (ibídem: láms. 27, 5; 38, 5) proceden igualmente de la ladera sur, pero no existen elementos en los respectivos complejos materiales, que aportasen unas referencias cronológicas más concretas. La posición estratigráfica de los complejos tampoco ofrece una base sólida para poder establecer un parangón con los hallazgos de la cima y la ladera este, ordenados estratigráficamente.

En lo que respecta a la ladera este de Fuente Álamo, las excavaciones de 1985-1991 aportaron tres fragmentos estratificados de la forma 6. Del horizonte II procede un fragmento de borde de una vasija bicónica (ibídem: lám. 6, 4), que concuerda con la forma del recipiente de la tumba $71^{23}$, encontrándose entre las formas $6 \mathrm{a}$ y $6 \mathrm{~b}$. Su pertenencia al horizonte II confirma la datación propuesta para esta forma de transición. Otros dos fragmentos, esta vez del horizonte III (fase 11/12), son de la forma 6b. El fragmento de borde (ibídem: lám. 13, 9) perfila un cuerpo más bien ancho, mientras que el otro fragmento con una carena bien marcada (ibídem: lám. 13, 10) muestra una forma más estirada, que se aproxima a la forma (6c) representada por la vasija bicónica de la tumba 678 de El Argar (Schubart y Ulreich 1991: lám. 45, 678 i). El caso es que este cuerpo estirado de la vasija bicónica constituye una forma característica del período El Argar B.

Así pues, los pocos hallazgos estratificados en los años 1985-1991 corroboran en lo esencial los resultados sobre la forma 6 , aportados por los hallazgos funerarios y la secuencia estratigráfica de 1977-1982.

\section{FORMA 7}

Junto con las vasijas carenadas, las copas pertenecen a las formas 'clásicas' de la Cultura de El Argar. En su mayoría forman parte de la cerámica cuidada, sobre todo las copas de pie esbelto. En la tabla tipológica de Arteaga y Schubart (2000: 104, fig. 3) se distinguen tres formas con dos variantes, respectivamente, como sigue a continuación (fig. 3). La forma 7a: copas con fondo en forma de anillo (7a1) o de pie muy bajo (7a2). La forma 7b: copas de pie ancho, medianamente alto (7b1) o alto (7b2). La forma 7c: copas de pie alto y esbelto, que puede estar hueco en toda su longitud (7c1), a veces modelado alrededor de una varilla acaso de madera eliminada posteriormente, o con el pie macizo enteramente o en parte (7c2). Los prototipos para las formas $7 \mathrm{c} 1$ y $7 \mathrm{c} 2$ de la tabla tipológica admiten distintas formas mixtas. No obstante, la adscripción a una u otra variante, con la peana hueca o maciza, se realizará según los criterios establecidos sobre la configuración del pie.

La mayor frecuencia de las copas en los enterramientos en urna llevaba a la suposición de que las copas pertenecerían en su mayoría al período El Argar B (Schubart 1975: 85, figs. 6-7), pero las observaciones estratigráficas realizadas ya en las dos primeras campañas de Fuente Álamo demostraron que las copas de pie esbelto, la mayoría de las veces macizo en su parte superior, en efecto no aparecen antes de los estratos argáricos tardíos, mientras que desde los estratos más antiguos en adelante hay que contar con formaciones de un pie en los más distintos tipos cerámicos, aunque

23. Véase supra nota 16; cf. Pingel et al. 1998: 33 Zusatz. 
en principio sólo en forma de anillo (Arteaga y Schubart 1980: 265 ss., fig. 11; Arteaga y Schubart 1981: 14).

Las investigaciones que se fundamentan en la estratigrafía de las campañas de 1977-1982 son en general de gran importancia para la evolución tipológica de las copas de la forma 7. Por ello se ofreció un resumen ya en otro lugar (Schubart 2000c: 112) como sigue: "Aún durante El Argar A, o sea durante los horizontes I y II de Fuente Álamo, aparecen las formas predecesoras de las copas. En un principio presentan una base en forma de un anillo o un pie todavía bajo y ancho, aunque ya hueco, mientras que los pies esbeltos de la clásica forma 7 , como se conocen de los contextos funerarios, todavía no se encuentran en los horizontes antiguos de Fuente Álamo. Sin embargo las copas de pie ancho y abierto (tipo 7bis de Siret, ahora forma 7b) experimentan una evolución en los horizontes III y IV de Fuente Álamo, es decir, en El Argar B. Ahora, los pies son más altos y al mismo tiempo más anchos, mostrando un perfil cónico (forma 7b1) o cóncavo (forma 7b2). Según la estratigrafía de Fuente Álamo es evidente, que las copas del tipo 7bis siretiano (hoy forma 7b) aparecen algo antes que las del tipo 7 (ahora forma 7c) de pie esbelto; que en su mayoría no se presenta antes de El Argar B2, aunque las dos formas coexistían al menos por algún tiempo, como documenta p.ej. la tumba 9 de Fuente Álamo".

Este resumen escrito en 1997 sigue siendo válido para la gran línea de las tendencias en la evolución tipológica. No obstante, después de consultar todos los hallazgos estratificados procedentes de las excavaciones de 1977-1982, cabe puntualizar lo dicho sobre la fecha de la aparición de las nuevas formas $7 \mathrm{~b}$ y $7 \mathrm{c}$, como se expone a continuación. Hay que tener en cuenta que este estudio ha de dedicarse casi exclusivamente a las peanas de las copas, conservándose pocos ejemplares completos de la forma 7 y quedando los fragmentos de las partes altas de las mismas en su mayoría sin la posibilidad de atribuirlas con seguridad a esta forma. Puesto que la configuración de los pies es muy variada, siendo característicos de distintas formas de copa, los mismos prometen un estudio de gran valor informativo.

En las primeras fases 1-3 del horizonte I, no se conocen restos de fondos en forma de anillo o de pies lo que no sorprende ante el pequeño número de los hallazgos de estas fases, y no debe inducir a una conclusión precipitada que estas formas estén ausentes en la época temprana de Fuente Álamo. También en tiempos avanzados del horizonte I, en las fases 4-6, la cantidad de los fragmentos sigue siendo escasa en comparación con los horizontes II-IV, cuando por lo visto se fabricaron copas con mayor frecuencia.

Ya entre los más antiguos recipientes con pie, que no se encuentran antes de la fase 4, o sea del horizonte I avanzado, se documentan paralelamente un fondo en forma de anillo, como forma temprana de un pie ya presente en otro ejemplar (fig. 14, 2), así como un pie bajo (fig. 14, 1) que por lo visto pertenecía a un cuenco hondo o a una fuente. Semejantes pies bajos y curvados hacia afuera son igualmente típicos en las siguientes fases 5-6 del tardío horizonte I, así como también al principio del horizonte II (fase 7) (fig. 14, 4-29).

En la siguiente fase 8 aparecen al lado de los fragmentos que en su mayoría pertenecen a la forma $7 \mathrm{a}$-entre otros seguramente los restos ilustrados en la figura 14, 30.39-41.43.44- los primeros exponentes característicos de las copas de pie más alto de la forma $7 \mathrm{~b}$, entre los cuales se cuenta un fragmento de pared del cuenco superior con arranque del pie ancho y más alto (fig. 14, 32), o el recipiente con un pie por lo visto más alto, cuyo aspecto puede ser reconstruido por lo menos en parte (fig. 14, 36).

Como se observó anteriormente en otros tipos de la cerámica argárica, las antiguas variantes de una forma perduran al lado de las más modernas que están en evolución. Hay circunstancias en las cuales las antiguas incluso predominan de momento sobre las innovaciones que se imponen paulatinamente. Este es el caso también de las copas de la fase 8 .

ISSN: 1133-4525 ISSN-e: 2255-3924 
En concordancia con lo antes dicho, en la fase 9 al final del horizonte II, siguen existiendo las copas con fondo en forma de anillo (fig. 14, 47) o de pie muy bajo (fig. 14, 49-51), pero igualmente aparecen fragmentos que posiblemente pertenecen ya a las formas $7 b$ (fig. 14, 46.48). Una copa de la forma $7 \mathrm{~b}$ conservada por completo (fig. 19 b), procedente de esta fase 9 , constituye junto con una vasija carenada de la forma $5 \mathrm{a}$, igualmente bien conservada, un hallazgo de un contexto cerrado, que posiblemente pertenece a un ajuar depositado al exterior de la tumba $95^{24}$ y que en cualquier caso es de la misma cronología que este enterramiento en covacha.

Hablando de las copas de la forma $7 \mathrm{~b}$, se hace observar un fragmento hallado en la ladera occidental de Fuente Álamo en 1996, que procede por lo visto de una variante 7 b2 (fig. 20). El recipiente se rompió justamente en el punto donde el pie conecta con el cuenco superior. En la rotura se notan unas incisiones para facilitar la conexión entre ambas piezas que fueron modeladas por separado y después juntadas. Más frecuentes son los fondos - provisionales- de los 'cuencos' superiores que muestran incisiones correspondientes.

En la fase 9 -como también en todas las fases siguientes, dicho sea de paso- merecen de atención los fragmentos en aumento que proceden del borde inferior de los pies, y que sólo pueden haber pertenecido a unas copas. Entre ellos, un fragmento con un pequeño diámetro del borde inferior (fig. 14, 52) insinúa la reconstrucción de un pie alto y esbelto que concordaría con la forma $7 \mathrm{c}$, por lo cual es probable que esta forma aparezca por primera vez en la fase 9 .

Además, en la siguiente fase 10, ya en el temprano horizonte III, contamos con más pruebas para este tipo de pie: Cuatro fragmentos del borde inferior del pie pertenecen con toda probabilidad, rayando en la seguridad, a unas copas de la forma 7c (fig. 15, 1.7.10.11). El escaso diámetro y la única reconstrucción posible como pie alto difícilmente permitirían una clasificación diferente de estas piezas. Todos los otros fragmentos procedentes de este potente paquete estratigráfico de la fase 10, y que pueden ser identificados con seguridad, pertenecen a los tipos de pie conocidos ya desde las fases más antiguas, es decir a la forma 7 a (fig. 15, 2.13.14.16) y a la forma $7 \mathrm{~b}$ (fig. 15, 15 (= 7b1). 18. tal vez 4). El mayor diámetro de un fragmento procedente del borde inferior de un pie (fig. 15, 6) le adscribe a una copa más bien de la forma $7 \mathrm{~b}$ (2) que de la forma $7 \mathrm{c}$, cuya presencia en la fase 10 podía ser inferida mediante las cuatro pruebas importantes antes mencionadas.

Los fragmentos de la fase 11, cuya cantidad es algo menor que en la anterior fase $10 \mathrm{y}$ en la siguiente fase 12, pueden ser adscritos sólo en parte con seguridad a determinadas formas o variantes, aunque todos están identificados como copas (forma 7a: fig. 15, 21.24.25; forma 7a/b: fig. 15, 19.23; forma 7b/c: fig. 15, 20). El fragmento de vástago de una peana (fig. 15, 22) es la primera prueba de hecho segura sobre la presencia de la esbelta forma 7c, y precisamente con el pie hueco de la forma $7 \mathrm{c} 1$. Según los resultados estratigráficos, la forma $7 \mathrm{c}$ es claramente de evolución tardía y falta en los estratos antiguos de Fuente Álamo, salvo los fragmentos de borde de pies encontrados en las fases 9 y 10 que muy probablemente son de esta forma. Pero ahora, desde la fase 11 en adelante, la forma 7c se halla en todas las fases de El Argar B como una forma característica que es especialmente útil a la hora de discutir la cronología relativa de los complejos materiales.

Parece que en la fase 12 disminuye el porcentaje de las copas de pie bajo, característico de la forma $7 \mathrm{a}$. Sea como sea, en los estratos de la fase 12 no se encontraron unas pruebas contundentes. Y luego, sólo en la fase 13 siguen todavía apareciendo fragmentos de la forma 7a (fig. 16, 1.2), para después desaparecer por completo. En consecuencia, la forma 7a es característica de los horizontes I y II, en particular, y luego todavía para la época de transición del horizonte III.

24. Acerca de las circunstancias del hallazgo cf. Schubart e.p. 
Por otro lado, en la fase 12 crece claramente la diversidad de los recipientes con pie esbelto. La forma $7 \mathrm{c} 1$, que se comprobó con seguridad en la anterior fase 11, aporta en la fase 12 dos piezas características (fig. 15, 32.34). Como innovación se añaden los fragmentos de peanas igualmente esbeltas, pero macizas (fig. 15, 31.35.36.39). También se cuentan entre esta forma 7c2 las peanas que presentan solamente la parte superior del vástago macizo (fig. 15, 31). En el caso de otros dos fragmentos de vástago macizo, en uno de los pies se trata de una pieza mediana (fig. 15,39 ) y en el otro de un vástago especialmente esbelto, casi cilíndrico (fig. 15, 35). El cuarto fragmento, finalmente, que por su forma también podría pertenecer a una copa de la forma $7 \mathrm{a}$, a causa de su muy pequeño diámetro tiene que ser interpretado como una forma $7 \mathrm{c}$ y precisamente como $7 \mathrm{c} 2$ por el cierre del vástago aún reconocible (fig. 15, 36). Aparte de este fragmento que no se identifica con la misma seguridad que los otros, se demuestra claramente en la fase 12 el comienzo de la forma $7 \mathrm{~b} 2$ con vástago macizo.

Además, hay algunos fragmentos de borde de los pies de la forma $7 \mathrm{c}$; y debe quedar pendiente si pertenecen a la forma $7 \mathrm{c} 1$ ó $7 \mathrm{c} 2$ (fig. 15, 38.42.43.45). Cuando no se puede determinar el diámetro, semejantes fragmentos podrían pertenecer igualmente a la forma $7 \mathrm{~b}$ (posiblemente fig. 15, 37.46).

No obstante, al lado de la forma 7c sigue estando en uso la forma 7b. Algunos fragmentos se identifican con seguridad (fig. 15, 33.44), otros con cierta probabilidad (fig. 15, 26.27.29.30.37.40).

En las fases 13-15 del horizonte IV, coexisten ambas formas 7b (fig. 16, 4.20.21.27.29.32) y 7c (fig. 16, 3.6-12.17-19.23.26.31), prevaleciendo algo la forma $7 \mathrm{c}$ en número, en cualquier caso entre las piezas aquí tratadas. Solamente algunos fragmentos de vástago pueden ser diferenciados entre las variantes 7c1 (fig. 16, 3.10.11) y 7c2 (fig. 16, 8.9. probable 23. quizás 26.31). Dos copas enteras proceden de las tumbas 68 (fig. 16, 11) y 102 (fig. 16, 8) de Fuente Álamo, respectivamente. Se trata de enterramientos en cista (tumba 68) y en urna de inhumación (tumba 102), que han sido instalados después del abandono del gran edificio $\mathrm{O}$ y pertenecen al período El Argar B2, por lo que han sido adscritos aquí a la fase 14. Ya se ha señalado en otros escritos que las copas incluidas en el ajuar de las sepulturas de El Argar B eran por lo visto de una especial importancia bajo el punto de vista social (Pingel et al. 2003: 202, fig. 13) y también ritual (Schubart 1975: 84; 2000c: 112).

Mirando el número no muy abundante de fragmentos adscritos a las copas, procedentes de las excavaciones de 1985-1991, se advierten varias copas en el horizonte II, entre ellas una de la temprana forma 7a1 (Schuhmacher 2003: lám. 4, 4). Otro fragmento, con el pie conservado sólo en parte, se encuentra en el medio de las formas 7a2 y $7 \mathrm{~b} 1$ (ibídem: lám. 4, 3). En cualquier caso, un tercer recipiente puede ser identificado como forma $7 \mathrm{~b} 1$ (ibídem: lám. 4, 5) y está adscrito a la fase $7 / 8$, lo que confirma el momento antes enunciado para la presencia de la forma $7 \mathrm{~b}$ en la fase 8 . Puesto que un cuarto fragmento no conserva el pie, no puede ser identificado con seguridad como forma $7 \mathrm{a} 2$ ó $7 \mathrm{~b} 1$ (ibídem: lám. 4, 2).

También entre estos materiales de 1985-1991 aparecen todavía en el horizonte III formas de pie bajo, y precisamente tanto en la fase 11 (ibídem: lám. 13, 3) como en la fase 12 (ibídem: lám. 17, 8), donde estos pies entre los materiales de 1977-1982 estaban ausentes.

Un hallazgo importante respecto de la cronología de las copas representa la peana completa de la forma 7c1 procedente de la fase 10 (ibídem: lám. 9, 2). Los materiales de 1977-1982 aportaron de esta fase sólo fragmentos de los bordes inferiores de los pies, que podían comprobar la existencia de la forma $7 \mathrm{c}$ con toda probabilidad rayando en la seguridad. Esta pieza de la fase 10 se destaca además por mostrar restos de una decoración bruñida dentro del cuenco. Confirma la primera aparición de la forma 7c1 con una variante de copa, cuyo pie todavía es de efecto bastante comprimido en comparación con las posteriores copas con el vástago estirado y esbelto, lo que igualmente revelaría su antigüedad (fig. 21). Dos fragmentos de copas de la fase 12, ambas tal vez de la forma 7c1 (ibídem: lám. 17, 7.8), van bien con los otros de esta fase anteriormente presentados.

ISSN: 1133-4525 ISSN-e: 2255-3924 
Los hallazgos de las campañas de 1985-1991 encajan bien con los resultados obtenidos del estudio de los materiales más abundantes de 1977-1982 y aportan con el importante hallazgo de la fase 10 la seguridad sobre la aparición en este momento de la forma $7 \mathrm{c}$ en su variante $7 \mathrm{c} 1$.

Resumiendo se puede apuntar que las copas con fondo en forma de anillo y las de pie bajo de la forma 7a aparecen en el horizonte I durante las fases 5-6. En el horizonte II -posiblemente ya en la fase 7, en cualquier caso desde la fase 8- se añaden las copas de pie más alto, muy saliente, de la forma $7 \mathrm{~b}$. En el horizonte III aparece por primera vez en la fase 10 una copa de pie más esbelto con el vástago hueco (forma 7c1). Luego, en la fase 12, se incorporan a su lado las copas de pie esbelto y macizo de la forma 7c2, mientras que las formas antiguas de los horizontes I-II aún siguen existiendo durante el horizonte III, para luego en el horizonte IV decrecer en cantidad en comparación con las formas más recientes.

Las copas poseen un especial valor informativo en lo que concierne a las cuestiones cronológicas, lo que sin duda guarda relación con la gran variedad de las formas. Tanto el cuenco superior como el pie, cuyo aspecto cambia mucho con el tiempo, son elementos influenciados por las citadas tendencias. El conjunto de ambos elementos podía ser observado sólo en los pocos recipientes completos, por lo que no puede ser incluido en el estudio de las cerámicas procedentes de los estratos del poblado de la misma manera como en el caso de los hallazgos funerarios.

\section{FORMA 8}

Después de que los pies reutilizados de la forma 7b2, que Siret definió como tipo $8 \mathrm{a}$ y que en diferentes ocasiones aparecen en el ajuar funerario como 'vasos', tienen que ser considerados tipológicamente entre las copas, el número de los verdaderos vasos ha decrecido mucho. Entre las cerámicas de 1977-1982 se encontraron solamente pocos fragmentos que podían ser identificados como vasos ${ }^{25}$. En Arteaga y Schubart (2000: 104, fig. 2) se distingue entre los vasos de la forma 8 a con el fondo plano y de paredes rectas, verticales o inclinadas, y los vasos de la forma $8 \mathrm{~b}$ con el fondo igualmente plano, pero de paredes algo cóncavas. Además, la forma $8 \mathrm{~b}$ podía ser subdividida en la forma $8 \mathrm{~b} 1$, en la cual el borde no sobresale del diámetro del fondo, y en la forma $8 \mathrm{~b} 2$ de borde más saliente (fig. 2).

Acerca de la evolución tipológica de los vasos de la forma 8a, que resultan menos numerosos y además están menos diferenciados, hasta ahora no se podía decir nada en concreto. En cambio, los contextos cerrados de las sepulturas, donde se depositaron vasos de la forma $8 \mathrm{~b}$, permitían hacer la observación, de que los vasos de la forma 8 b1 están presentes en varios enterramientos más antiguos en cista y solamente en una inhumación en urna, mientras que los vasos de la forma $8 \mathrm{~b} 2$, con el borde sobresaliendo del diámetro del fondo, se hallan con más frecuencia en los enterramientos en urna que son de cronología más reciente. Por lo que los vasos de borde menos saliente pudieran representar una forma relativamente más antigua, y los de borde más saliente una forma reciente (Schubart 2000c: 112). A la hora de formular esta hipótesis se advirtió al mismo tiempo que este 'modelo' de evolución requeriría para su consolidación hallazgos adicionales procedentes de contextos cerrados.

Solamente nueve fragmentos de los materiales recuperados en las excavaciones de 1977-1982, podían ser adscritos a las formas de vaso y a los estratos del poblado, de modo que aportan muy poca información. De los cuatro vasos del horizonte II, tres presentan las paredes rectas (fig. 13,

25. Entre los materiales de 1985-1991 no se identificó ni un solo fragmento de un auténtico vaso (Schuhmacher 2003: 119). 
4.5.7) perteneciendo por lo tanto a la forma 8a. Dos de los últimos muestran un reforzamiento exterior del fondo algo rehundido (fig. 13, 4.5). Mientras que las paredes de dos de los vasos son rectas y verticales, poco más o menos (fig. 13, 4.7), las de los otros dos son salientes (fig. 13, 5.6). En ambos casos no se conservó el borde, sin embargo, parece que sobresaldría del diámetro del fondo, respectivamente. En el caso de la forma 8a esto no cobra importancia, aun cuando uno de los fragmentos con la pared muy poco cóncava (fig. 13,6) no tendrá que ser adscrito a la forma $8 \mathrm{~b}$, sino más bien a la forma $8 \mathrm{a}$.

Lo mismo tiene aplicación a un vaso de la fase 12 (horizonte III) que presenta la pared igualmente muy poco cóncava y el borde sobresaliendo del diámetro del fondo (fig. 13,9). Sería de examinar a base de una mayor cantidad de vasos, si posiblemente los vasos de esta forma constituyan una transición entre formas antiguas y más recientes. Otro vaso procedente del horizonte III, adscrito a las fases $9 / 10$, muestra la pared muy cóncava y saliente, careciendo otra vez de borde (fig. 13, 8). El fragmento puede ser clasificado como forma $8 \mathrm{~b} 2$ confirmando la hipotética cronología más reciente de esta forma.

Dos de los tres vasos adjudicados al horizonte IV ofrecen las paredes más o menos rectas (fig. $13,10.11$ ) perteneciendo por lo tanto a la forma $8 \mathrm{a}$, mientras que el tercer fragmento muestra la pared algo curvilínea, posiblemente entrante en la parte superior (fig. 13, 12) ${ }^{26}$. Por motivo de la escasa cantidad de los fragmentos recuperados, lamentablemente no se pueden dar más informaciones sobre las formas y tendencias en la evolución de los vasos.

\section{EPÍLOGO}

El texto ofrecido en las páginas precedentes se basa solamente en una selección representativa y esencial de los ricos hallazgos hechos en los estratos del asentamiento de Fuente Álamo durante las excavaciones de 1977-1982. Se concentra este análisis en las cerámicas procedentes de la cima y la ladera este, que podían ser integradas en la amplia secuencia estratigráfica. Por consiguiente renuncia a la presentación de los materiales no estratificados, excepto de algunos fragmentos o hallazgos funerarios para establecer un paralelo. El estudio abarca los 'clásicos' tipos 1-8 de Siret, que se recuperaron en distintas cantidades lo que determina tanto el ritmo de la investigación y sus resultados como la diferenciación de las respectivas formas y la posibilidad de acusar unas tendencias en la evolución tipológica, que existieron andando los siglos en las distintas formas y de manera muy diferente.

Las causas de la necesaria concentración del estudio ya se exponían en la introducción. Los resultados de los distintos apartados no pueden ser resumidos de nuevo en este lugar; esto se realizó al final de cada apartado cuando los resultados de las investigaciones lo justificaron. A continuación, se hará observar cuestiones y tendencias más generales, que se declararon en el curso de este estudio tipológico basado en la secuencia estratigráfica. Por lo que incluso habrá que volver en el futuro a considerar de nuevo ciertas cuestiones ahora planteadas (Schubart e.p.).

Las líneas de la evolución tipológica observadas se manifiestan como una tendencia que en la forma de un proceso continuo se percibe gradualmente durante todos los horizontes y en parte incluso en las fases. Por lo que solamente con la ayuda de nuestra división en fases y horizontes se hace matizable en cortes artificiales, para hacerla tangible en etapas sucesivas y para que de esta manera los resultados del estudio puedan ser útiles en futuras investigaciones. En esta apreciación

26. Este último fragmento de vaso (FA 79/989/9) pertenece, junto con el muro bh, ya al horizonte V (= fases 16/17), y no a la fase 15 como se indicó en la versión alemana por equivocación.

ISSN: 1133-4525 ISSN-e: 2255-3924

SPAL 13 (2004)

http://dx.doi.org/10.12795/spal.2004.i13.02 
comparativa se fundan también las reflexiones realizadas sobre las respectivas formas en los apartados anteriores; y ellas seguirán siendo admisibles siempre que aquí y en el futuro se tenga que trabajar con estos cortes artificiales de nuestra división.

En lo que atañe a los horizontes I y II de Fuente Álamo, que concuerdan con el período El Argar A, se hace patente la existencia de un conjunto de formas que está constantemente sujeto a pequeños cambios en la combinación y en la evolución de las formas. Innovaciones en el aspecto de los cuencos -aquí también en las decoraciones-y de las ollas, pero en particular de las vasijas carenadas y copas, aparecen con más fuerza no antes del horizonte III, aunque se perciben en piezas únicas o en formas precursoras ya durante los tiempos tardíos del horizonte II. Los cambios se manifiestan en los cuencos en unas formas abiertas con el borde arqueado entrante y con una decoración bruñida; en las ollas en una mayor tendencia 'oval colocada verticalmente' y la evolución de la forma ovoide; en las vasijas carenadas en una forma más estirada, con la carena al mismo tiempo más bien baja; en las vasijas bicónicas en una tendencia parecida, a pesar de ser una forma muy diferente; y, finalmente, en las copas en la evolución del pie que se hace cada vez más alto y más esbelto.

Estas innovaciones no se presentan espontáneamente como conceptos acabados, sino pueden ser rastreadas en su evolución mediante unas formas precursoras y tempranas, hasta que en el horizonte III nos encontramos delante de las nuevas formas maduradas. Parece que durante las fases de este horizonte se imponen en el número a las formas antiguas que predominaban en los horizontes I y II. No obstante, estas formas antiguas no se abandonan, sino al mismo tiempo que las formas nuevas, estas formas tradicionales siguen estando en uso y seguramente también continúan en la fabricación. En las fases del horizonte III se hace patente una larga coexistencia, hasta que en el horizonte IV las formas antiguas escasean -lo que, sin embargo, se podía observar sólo en algunos de los tipos estudiados- y pasan a un segundo término detrás de los perfiles cerámicos característicos del período El Argar B.

Desde hace tiempo es sabido que a la hora de componer los ajuares funerarios se seleccionaron vasijas de la cerámica cuidada. Las investigaciones en Fuente Álamo demostraron pronto, que esta cerámica cuidada estaba igualmente presente en los contextos domésticos (Arteaga y Schubart 1980: 248 s.). Una de las preguntas planteadas al comienzo de las excavaciones de Fuente Álamo fue si para los ajuares se escogerían unos recipientes determinados y, luego, cuáles serían. Esta cuestión será abordada en detalle por la publicación monográfica de las sepulturas de Fuente Álamo (Schubart e.p.). De todos modos, en base a los materiales estratificados es de indicar que por lo visto se llegarían a seleccionar como ofrendas no sólo unas vasijas de la cerámica cuidada sino también las de la tendencia en boga (cf. arriba lo dicho sobre la forma 5). Esto se manifiesta tanto en las piezas con decoración bruñida, que son muy raras en general y a pesar de ello relativamente frecuentes en las tumbas (Schubart y Ulreich 1991: lám. 50, 765 b) ${ }^{27}$, como en las vasijas carenadas. Posiblemente cumpliendo una función especial, unos recipientes carenados de pequeño tamaño a la moda de su tiempo han sido depositadas en las tumbas 52 y 65 de la fase 10; en la tumba 111 que probablemente pertenece al horizonte IV (Schubart 2004); y, finalmente, en la tumba 68 de la fase 14 (horizonte IV), siendo este último el más estirado (cf. arriba lo dicho sobre la forma 5; Pingel et al. 2003: 206, fig. 10 y). Las pequeñas vasijas carenadas de las tumbas 68 y 111 contenían un aceite vegetal extraído de la adormidera, o al menos con adición de la adormidera ${ }^{28}$.

27. También la vasija carenada del Museo de Almería (fig. 18) debería proceder de un enterramiento.

28. El análisis de las dos muestras fue realizado hace poco por el Dr. Jordi Juan i Tresseras (Universidad de Barcelona), por mediación de la Dra. Corina Liesau von Lettow-Vorbeck (Universidad Autónoma de Madrid), la excavadora 
Esta propensión a escoger las formas cerámicas más evolucionadas o sea las más novedosas para la composición del ajuar funerario, se puede seguir de cerca igualmente en el caso de las copas: En las tumbas 68 y 102 de la fase 14 -la primera un enterramiento en cista, la segunda una inhumación en urna-se depositaron unas copas de la forma 7c; en la tumba 111 que eventualmente es algo más antigua, una copa de la forma 7b2 (Pingel et al. 2003: 206, fig. 10 z; Schubart e.p.). Las antiguas vasijas carenadas de aspecto más ancho o las formas anteriores de las copas, que, sin embargo, continuaban estando en uso en los contextos domésticos según nos dice la secuencia estratigráfica, ya no aparecen en las tumbas tardías. El gusto por el estilo de la época era claramente un criterio que contribuía a la decisión en la selección de las formas, siendo por lo visto independiente de la edad del difunto ${ }^{29}$. Por otra parte, la posición social del difunto habrá sido de una gran importancia. Si partimos del supuesto de que las sepulturas con un ajuar más ostentoso y rico pertenecieron a una capa social mejor situada, justamente este sector de la población podría entrar con más facilidad en posesión de las 'creaciones a la moda'.

En los apartados sobre las distintas formas, se presentó cada una de por sí, estudiando siempre a base de la secuencia estratigráfica su frecuencia y posibles tendencias en la evolución tipológica, dándose unos resultados diversos: Unas formas más simples eran menos susceptibles a los cambios; unos tipos más diferenciados dejaron percibir en el transcurso de las fases unos cambios menores, pero en parte también muy marcados. Echando una mirada retrospectiva sobre las diversas líneas de la evolución, se pueden constatar unas tendencias comunes en los cambios ocurridos durante siglos, que en un sentido más amplio pueden ser entendidos como una evolución del estilo.

Así pues, las vasijas carenadas de la época temprana muestran un aspecto ancho, las de la época tardía un acabado estirado de la misma forma original. Las copas antiguas tenían solamente un pie bajo, frente a los cuales se hallan luego los pies altos de las copas en suma más esbeltas de la época tardía. También las vasijas bicónicas presentan en su confección antigua un aspecto en que la anchura excede la altura, mientras que en las formas tardías esta proporción se vuelve al revés a favor de la altura. Finalmente, las ollas ovoides más esbeltas pertenecen en su mayoría a la época tardía. En general, por tanto, y sobre todo en las formas más diferenciadas, se puede advertir un estiramiento de los cuerpos, que en cualquier caso constituye para las formas 4-7 una evolución común: el desenvolvimiento de un estilo.

En la figura 21 se intenta plasmar gráficamente esta evolución estilística. Aquí se contrastan unas vasijas antiguas con otras tardías de las formas 4-7, respectivamente, para lo cual no se escogieron unos ejemplos excepcionales, sino unos exponentes muy característicos de las distintas formas. Puesto que el cuadro no está a escala, para todos los exponentes de una misma forma se convierten las mayores anchuras, respectivamente, a un mismo formato. De este modo, queda manifiesta la diferencia entre las antiguas formas anchas y las posteriores formas estiradas.

Los habitantes de Fuente Álamo, y además de ellos otra gran parte de la población argárica, podemos afirmar que tenían un sentido estético que se refleja no sólo en sus creaciones cerámicas muy características, sino también en las tendencias de la evolución tipológica, que fueron comunes a las muy diversas formas, y que aún hoy en día nos deleitan con unos trabajos alfareros equilibrados y estéticamente logrados.

Estos aspectos comunes en la producción de un conjunto asombrosamente uniforme de formas cerámicas, junto con los objetos metálicos característicos, la arquitectura y los ritos funerarios tan

\footnotetext{
de la tumba 111. El autor queda muy agradecido a los dos colegas. La gran importancia de la adormidera (Papaver sp.) como droga y en relación con las creencias de ultratumba se tratará en Schubart e.p.

29. Partiendo del estudio antropológico de M. Kunter (2000), cf. otro estudio del mismo autor sobre las tumbas 108112 de Fuente Álamo, incluyendo además unas nuevas observaciones sobre las tumbas 49-70 (Kunter 2004).
}

ISSN: 1133-4525 ISSN-e: 2255-3924 
típicos -sepulturas dentro del hábitat, en cistas, covachas o en grandes vasijas- sirven de base para la definición de la Cultura de El Argar. Precisamente las formas características de la cerámica argárica permiten observar la expansión argárica, y también su irradiación más allá del propio núcleo territorial. Aún hay que revisar detenidamente, si estos aspectos comunes en las tendencias evolutivas de las cerámicas características son admisibles sólo para Fuente Álamo y para el territorio argárico 'clasico' del Bajo Almanzora, donde los hallazgos funerarios del mismo El Argar sí aportan pruebas fehacientes para ello. En cualquier caso, las investigaciones en los yacimientos argáricos de las provincias de Almería y Granada revelan rasgos paralelos de la evolución. Así pues, de las repuestas que la cerámica estratificada de Fuente Álamo puede dar, se abren cuestiones nuevas.

\section{BIBLIOGRAFÍA}

ARTEAGA, O. y SCHUBART, H. (1980): "Fuente Álamo. Excavaciones de 1977", Noticiario Arqueológico Hispánico 9: 245-289. Madrid.

__(1981): "Fuente Álamo. Campaña de 1979", Noticiario Arqueológico Hispánico 11: 7-32. Madrid.

(2000): "Formas de la cerámica argárica de Fuente Álamo", en Schubart, Pingel y Arteaga 2000: 99-106.

KUNTER, M. (2000): "Los restos de esqueletos humanos hallados en Fuente Álamo durante las campañas de 1985, 1988 y 1991", en Schubart, Pingel y Arteaga 2000: 265-282.

_ (2004): "Die menschlichen Skelettreste aus den Grabungskampagnen 1996 und 1999 in Fuente Álamo", Madrider Mitteilungen 45: 88-96. Mainz.

LULL, V. (1983): La 'cultura' de El Argar (Un modelo para el estudio de las formaciones económicosociales prehistóricas). Madrid.

PINGEL, V.; SCHUBART, H.; ARTEAGA, O. y KUNST, M. (1998): "Fuente Álamo. Vorbericht über die Grabung 1996 in der bronzezeitlichen Höhensiedlung", Madrider Mitteilungen 39: 1434. Mainz.

PINGEL, V.; SCHUBART, H.; ARTEAGA, O.; ROOS, A.M. y KUNST, M. (2003): "Excavaciones arqueológicas en la ladera sur de Fuente Álamo. Campaña de 1999”, Spal 12: 179-229. Sevilla.

RISCH, R. (2002): Recursos naturales, medios de producción y explotación social. Un análisis económico de la industria lítica de Fuente Álamo (Almería), 2250-1400 antes de nuestra era. Iberia Archaeologica 3, Mainz.

RUIZ-GÁlVEZ, M. (1977): "Nueva aportación al conocimiento de la Cultura de El Argar", Trabajos de Prehistoria 34: 85-110. Madrid.

SCHUBART, H. (1975): "Cronología relativa de la cerámica sepulcral en la cultura de El Argar", Trabajos de Prehistoria 32: 79-92. Madrid.

-(1979): "Nuevas fuentes para la Cultura de El Argar", en XV Congreso Nacional de Arqueología (Lugo 1977): 297-308. Zaragoza.

_(1980): "Cerro de Enmedio. Hallazgos de la Edad del Bronce en el Bajo Andarax (Prov. Almería)", Cuadernos de Prehistoria de la Universidad de Granada 5: 175-192. Granada.

_ (2000a): "Las excavaciones arqueológicas entre 1977 y 1991", en Schubart, Pingel y Arteaga 2000: 25-37.

- (2000b): "La estratigrafía en la cima y en la ladera Este del poblado: Secuencia de los estratos y de las fases", en Schubart, Pingel y Arteaga 2000: 39-61. 
-(2000c): "Acerca de la evolución formal de la cerámica argárica", en Schubart, Pingel y Arteaga 2000: 107-116.

(2003): "Stratigraphisch geordnete Keramik der El Argar-Zeit aus den Grabungen 1977-1982 auf Fuente Álamo", en T.X. Schuhmacher y H. Schubart, Fuente Álamo. Iberia Archaeologica 4: 297-366. Mainz.

(2004): "Das reiche Grab einer jungen Frau aus dem El Argar-zeitlichen Fuente Álamo", Madrider Mitteilungen 45: 57-78. Mainz.

(e.p.): Die Gräber von Fuente Álamo. Ein Beitrag zur Chronologie und zu den Grabriten der El Argar-Kultur. En preparación.

SCHUBART, H. y ARTEAGA, O. (1978): "Fuente Álamo. Vorbericht über die Grabung 1977 in der bronzezeitlichen Höhensiedlung", Madrider Mitteilungen 19: 23-51. Heidelberg.

_-(1986): "Fundamentos arqueológicos para el estudio socio-económico y cultural del área de E1 Argar", en Homenaje a Luis Siret 1934-1984 (Cuevas del Almanzora 1984): 289-307. Sevilla.

SCHUBART, H.; ARTEAGA, O. y PINGEL, V. (1985): "Fuente Álamo. Informe preliminar sobre la excavación de 1985 en el poblado de la Edad del Bronce", Ampurias 47: 70-107. Barcelona.

_ (1988): "Fuente Álamo. Informe preliminar sobre la excavación realizada en 1988 en el poblado de la Edad de Bronce", Anuario Arqueológico de Andalucía 1988-II: 171-178. Sevilla.

_ (1989): "Fuente Álamo. Vorbericht über die Grabung 1988 in der bronzezeitlichen Höhensiedlung", Madrider Mitteilungen 30: 76-91. Mainz.

SCHUBART, H.; PINGEL, V. y ARTEAGA, O. (1991): "Informe preliminar sobre la excavación realizada en 1991 en el poblado de la Edad del Bronce", Anuario Arqueológico de Andalucía, 1991-II: 24-27. Sevilla.

_ (1993): "Fuente Álamo. Vorbericht über die Grabung 1991 in der bronzezeitlichen Höhensiedlung", Madrider Mitteilungen 34: 1-12. Mainz.

- (2000): Fuente Álamo. Las excavaciones arqueológicas 1977-1991 en el poblado de la Edad del Bronce. Junta de Andalucía, Sevilla.

SCHUBART, H. y ULREICH, H. (1991): Die Funde der Südostspanischen Bronzezeit aus der Sammlung Siret. Madrider Beiträge 17, Mainz.

SCHUHMACHER, T.X. (2003): "Fuente Álamo. Die Siedlungskeramik der Grabungen 19851991. Untersuchungen zur Chronologie und zum Siedlungsschema der El Argar-Kultur", en T.X. Schuhmacher y H. Schubart, Fuente Álamo. Iberia Archaeologica 4: 15-295. Mainz.

SIRET, E. y L. (1890): Las Primeras Edades del Metal en el Sudeste de España. Barcelona. 


\begin{abstract}
ANEXO:
Inventario de los dibujos representados en las figuras 4-16

Entre paréntesis se pone el número del inventario que se levantó con una enumeración correlativa durante todas las campañas realizadas en Fuente Álamo desde 1977 en adelante. Las primeras cifras designan el complejo material; las segundas el número individualizado de cada pieza. Después de los dos puntos sigue la ubicación estratigráfica dentro de la secuencia de fases de Fuente Álamo. Las fases que se añaden a veces entre paréntesis señalan las posibilidades de una cronología más amplia cuando eventualmente se cortó un estrato más antiguo o más reciente en una zona limitada, siendo las fases mencionadas fuera del paréntesis las mucho más probables.

Fig. 4 1 (1499/2): 2-4; 2 (323/3): 5c1; 3 (323/2): 5c1; 4 (266/2): 5b2; 5 (514/6): 7c/d; 6 (775/6): 7d; 7 (452/11): 7d; 8 (452/6): 7d; 9 (513/13): 7d; 10 (505/9): 7d; 11 (452/2): 7d; 12 512/5): 7d; 13 (513/5): 7d; 14 (515/1): 7d; 15 (507/1): 7d; 16 (515/5): 7d; 17 (514/1): 7c/d; 18 (507/4): 7d; 19 (513/7): 7d; 20 (514/4): 7c/d; 21 (517/3): 7d; 22 (511/3): 7d; 23 (454/3): 7d; 24 (452/7): 7d; 25 (513/12): 7d; 26 (505/10): 7d; 27 (456/1): 7d/8; 28 (1409/43): 7/8; 29 (379/6): 8; 30 (617/11): 8; 31 (622/4): 8; 32 (379/1.2): $8 ; 33$ (381/14): 8; 34 (617/6): 8; 35 (617/17): 8; 36 (617/14): $8 ; 37$ (437/1): $8 ; 38$ (377/16): 8; 39 (622/6): 8; 40 (622/13): 8; 41 (379/12): 8; 42 (622/6a): 8; 43 (622/12): 8; 44 (381/2): 8; 45 (381/17): 8; 46 (379/10): 8; 47 (432/3): 8; 48 (387/2): 8; 49 (437/4-8): 8.
\end{abstract}

Fig. 51 (423/2): 9b; 2 (589/19): 9; 3 (589/14): 9; 4 (335/8): 9(a/)b; 5 (597/3): 8/9; 6 (500/1): 8/9; 7 (500/10): 8/9; 8 (500/9): 8/9; 9 (500/5): 8/9; 10 (383/2): 8/9; 11 (378/1): 8/9; $12(500 / 2.13): 8 / 9 ; 13$ (421/3): 9; 14 (587/3): 8/9; 15 (589/27): 9; 16 (589/13): 9; 17 (386/1): 8/9; 18 (385/1): 9a; 19 (391/1): 9; 20 (383/4): 8/9; 21 (500/20): 8/9; 22 (303/2): 10; 23 (581/22): (9b/)10; 24 (581/21): (9b/)10; 25 (584/4): 9/10; 26 (584/3): 9/10; 27 (295/1): 9/10; 28 (581/11): (9b/)10; 29 (581/5): (9b/)10; 30 (581/23): (9b/)10; 31 (581/27): (9b/)10; 32 (584/2): 9/10; 33 (499/2): 10b; 34 (621/6): 9/10; 35 (295/2): 9/10; 36 (303/1): 10; 37 (581/17): (9b/)10; 38 (581/6): (9b/)10; 39 (578/2): 10b; 40 (295/7): 9/10; 41 (580/2): 11b; 42 (580/10): 11b; 43 (498/4): $11 \mathrm{~b} ; 44$ (580/5): 11b; 45 (497/8-11.13.14): 11b; 46 (580/6): 11b; 47 (497/10): 11b; 48 (193/10): 11a; 49 (580/8): 11b; 50 (497/15): 11b; 51 (198/5): 10/11a; 52 (497/12): $11 \mathrm{~b} ; 53$ (565/1): 10b/11; 54 (193/8): 11a; 55 (193/2): 11a; 56 (198/2): 10/11a; 57 (1179/2): 1-11; 58 (1406/17) 11b; 59 (1020/3): 10/11a.

Fig. 61 (433/4): 11b-12b; 2 (495/45): 12; 3 (495/45a): 12; 4 (495/11): 12; 5 (433/3): 11b-12b; 6 (495/23): 12; 7 (495/43): 12; 8 (495/30): 12; 9 (495/16): 12; 10 (430/4): 11b/12; $11(495 / 35): 12 ; 12$ (495/20): 12; 13 (495/2): 12; 14 (430/8): 11b/12. 15 (495/55): 12; 16 (519/1): 10a-12a; 17 (495/6): 12; 18 (433/1): 11b-12b; 19 (495/12): 12; 20 (438/2): 11b/12a; 21 (519/5): 10a-12a; 22 (495/25): 12; 23 (495/53): 12; 24 (1426/7): 7-12; 25 (496/7): 12; 26 (495/14): 12; 27 (1294/4): 12b; 28 (438/1): 11b/12a; 29 (240/3): 12; 30 (1251/9): 10-12; 31 (1434): 12b1; 32 (1444/1): 12b1; 33 (431/2): 12/13; 34 (402/4): 12/13; 35 (1046/4): 12/13; 36 (401/2): 12/13; 37 (944/3): 14; 38 (404/17): 13/14; 39 (130/11): 12-14a; 40 (130/23): 12-14a; 41 (404/18): 13/14; 42 (494/5): 14; 43 (130/22): 12-14a; 44 (482/8): 12-14; 45 (130/15): 12-14a; 46 (130/9): 12-14a; 47 (130/2): 12-14a; 48 (404/10): 13/14; 49 (130/27): 12-14a; 50 (404/6): 13/14; 51 (404/1a): 13/14; 52 (494/3): 14; 53 (130/14): 12-14a; 54 (130/6): 12-14a; 55 (130/18): 12-14a; 56 (130/5): 12-14a; 57 (130/17): 12-14a; 58 (1272/3): 14; 59 (143/5): 13/14; 60 (888/7): 13/14; 61 (404/2a): 13/14; 62 (130/4): 12-14a; 63 (494/4): 14; 64 (404/1): 13/14; 65 (404/2): 13/14; 66 (130/12): 12-14a; 67 (586/3): 15b; 68 (586/1): 15b; 69 (586/4): 15b; 70 (586/2): 15b; 71 (586/6): 15b; 72 (759/11): 15b; 73 (1392/2): 14/15.

Fig. 71 (964/5): 1; 2 (505/1): 7d; 3 (541/3): 7d; 4 (515/6.7): 7d; 5 (379/15): 8; 6 (422/3): 9/10; 7 (1168/2): 10b; 8 (195/1-3): 11a; 9 (495/18): 12; 10 (1432/1; tumba 68): 14; 11 (130/29): 12-14a; 12 (1432/2; tumba 68): 14.

Fig. 81 (1001/7): 1; 2 (1540/1): 2/3; 3 (1524/1-11): 4b; 4 (1525/1-3): 4b; 5 (1139/1): 4b; 6 (1496/1; tumba 69): $1-4 ; 7$ (1566/ 1.4.5.7): 5c3; 8 (1127/3): 5c2; 9 (958/17): 5c2; 10 (958/14): 5c2; 11 (958/7.16 ss.): 5c; 12 (1135/2): 5c; 13 (1344/44): 6; 14 (1357/1): 1-6. 
Fig. 91 (506/1): 7d; 2 (1494/4; tumba 54): (4-)7; 3 (1247/1-4): 7; 4 (1230/1): 7d; 5 (1305/1.2): 7d; 6 (1557/1): 7d1; 7 (1343/1.10): 7b; 8 (359/1): 7; 9 (775/8): 7d; 10 (1410/6): 7; $11(392 / 1): 7 \mathrm{~d} ; 12$ (1225/56): 7d; 13 (511/2): 7d; 14 (1229/1): 7d; 15 (851/1): 7d; 16 (1409/7): 7/8; 17 (1222/32): 7d/8; 18 (1003/1): 8; 19 (623/1): 8; 20 (384/1): 7d/8; 21 (1221/11): 8; 22 (930/13): 5-9; 23 (1520/1): 8/9; 24 (845/27): 9; 25 (199/4): 7-9.

Fig. 101 (312/1): 10b; 2 (1313/2; tumba 65): 10b; 3 (600/2; tumba 52): 10b; 4 (1277/4): 10b; 5 (1322/7): 10b; 6 (1021/15): 10b; 7 (1058/2): 10b; 8 (1266): 10b; 9 (1022/1): 10b; 10 (584/31): 9/10; 11 (499/4): 10b; 12 (1058/3): 10b; 13 (1326/1): 10b/11; 14 (1407/7): 10b/11a; 15 (1549): 11b; 16 (194/1): 11a; 17 (525/1-3): 1-11a; 18 (1321/5): $11 \mathrm{~b} ; 19$ (957/3.6.11): 12a; 20 (1251/1.5.11): 10-12; 21 (192/1.2): 11b/12; 22 (496/3): 12; 23 (496/1): 12; 24 (973/9): 12b; 25 (1294/3): 12b; 26 (495/13): 12; 27 (973/2): 12b; 28 (974/1): 12; 29 (973/6): 12b; 30 (1251/10): 10-12.

Fig. 11 (319/1): 13; 2 (1161/3): 11b-13; 3 (86/1): 13a; 4 (188/7): 14; 5 (1394/5): 13/14; 6 (582/1): 12-14; 7 (1394/17): 13/14; 8 (1197/2): 11b-14; 9 (130/7): 12-14a; 10 (87/1): 14a; 11 (940/16): 14; 12 (98/3): 14a/b; 13 (1432/4; tumba 68): 14; 14 (940/33): 14; 15 (920/1): 14/15; 16 (586/5): 15b; 17 (823/4): 15; 18 (10/2): 20; 19 (170/1): 18; 20 (2/5): 20; 21 (1/14): 20.

Fig. 12 1 (1137/8.9.14): 5c1; 2 (505/7): 7d; 3 (1494/4): 7; 4 (1555/2-4): 7c/d; 5 (600/1; tumba 52): 10b; 6 (1313/1; tumba 65): 10b; 7 (497/7): 11b; 8 (1326/3): 10b/11; 9 (1429/1.2.5): 7-12; 10 (1429/4): 7-12; 11 (519/3): 10-12a; 12 (916/1-4): 12a; 13 (496/2): 12; 14 (829/3): 12; 15 (720/3): 12b/13; 16 (750/2): 11-13; 17 (87/3): 14a.

Fig. 131 (1816/4; tumba 75): probable 1-6; 2 (2584/1; tumba 71): probable 7-9; 3 (1261/1; tumba 56): probable 10-12; 4 (514/5): 7c/d; 5 (336/1): 7-9; 6 (597/5): 8/9; 7 (500/12): 8/9; 8 (584/3a): 9/10; 9 (495/50): 12; $10(572 / 2 \mathrm{a}): 12-14 ; 11(494 / 6): 14 ; 12(989 / 9): 16 / 17$.

Fig. 141 (1500/1): (2-4); 2 (1126/6): 2-4; 3 (424/2): (3/)4; 4 (1234/1): 4a/5; 5 (1495/1-3): 5a; 6 (1137): 5c1; 7 (1496): 5a; 8 (1149/1): 4b/5: 9 (1453): 5c; 10 (1457/5): 5c; 11 (958/18): 5c2; 12 (1343/2; 1344/1): 6 ; 13 (1344/63): 6; 14 (923/1): 1-6; 15 (1452/2): 5b-6a; 16 (1356/1): 1-6; 17 (1344/66): 6; 18 (1344/3): 6; 19 (1225/38): 7d; 20 (851/10): 7d; 21 (395/1): 7d; 22 (1229/6): 7d; 23 (1223/15): 7d; 24 (774/10): 7d; 25 (507/6): 7d; 26 (775/9): 7d; 27 (851/14a): 7d; 28 (452/12): 7d; 29 (775/3): 7d; 30 (1467/1): 8; 31 (437/4.8): 8: 32 (848/5): (7d/)8; 33 (1221/22): 8; 34 (437/10): 8; 35 (381/1): 8; 36 (1220/26): 8; 37 (1222/35): 7d/8; 38 (1221/37): 8; 39 (381/24): 8; 40 (393/2): 8; 41 (390/1): 8; 42 (1220/1): 8; 43 (773/2): 7d/8; 44 (1026/3): 8b; 45 (1082/4): 5-9; 46 (845/13): $9 ; 47$ (595/2): 8/9; 48 (867/1): 8b/9; 49 (364/1; 367/1): 8/9; 50 (335/5): 9; 51 (589/4): 9; 52 (335/4): 9; 53 (845/9): 9.

Fig. 15 1 (303/2): 10; 2 (1284/2): 10b; 3 (1341/4): 10b; 4 (1277/9): 10b; 5 (289/4): 10b; 6 (1334/6): 8b10a; 7 (844/7-9): 9/10; 8 (581/20): 9/10; 9 (499/7.8): 10b; 10 (1338/2.4): 10b; 11 (1057/3): 10b; 12 (581/10): 10; 13 (1266/15): 10b; 14 (1190): 10b/c; 15 (581/2): 10; 16 (1266/12): 10b; 17 (1023/3): 10a; 18 (844/6): 9/10; 19 (1407/10): 10b/11a; 20 (804/8): 9-11a; 21 (1527/10.15): 11b; $22(1321 / 9)$ : 11; 23 (193/5): 11a; 24 (1407/1): 10b/11a; 25 (1407/15-17): 10b/11a; 26 (130/13): 12; 27 (1251/7): 10-12; 28 (1251/14): 10-12; 29 (861): 12: 30 (435/1): 11b/12; 31 (1275/1): 11/12; $32(192 / 3)$ : 11b/12; 33 (1402/6): 12b; 34 (1012/1): 10-12; 35 (1414/2): 12b; 36 (495/31): 12; 37 (973/16): 12b; 38 (1231/8): 10-12; 39 (180/2): 12b; 40 (1462/13): 12b; 41 (495/54): 12; 42 (1289/4a): 12b; 43 (495/32): 12; 44 (520/1): 12b; 45 (240/2): 12; 46 (518/1): 12.

Fig. 161 (768/1): 13; 2 (987/3): 13b; 3 (564/3): 13; 4 (564/2): 13; 5 (730/1): 12/13; 6 (564/17): 13; 7 (564/18): 13; 8 (3196/2.3; tumba 102): 14; 9 (403/1): 12-14; 10 (858/14): 14; 11 (1432/3; tumba 68): $14 ; 12$ (858/11): $14 ; 13$ (130/20): 12-14a; 14 (130/21): 12-14a; 15 (858/5): $14 ; 16(105 / 18): 12-14 ; 17$ (927/6): 11b-14; 18 (940/26): 14; 19 (940/19): 14; 20 (858/2.16): 14; 21 (858/10.15): 14; 22 (481/1): 14; 23 (1394/2): 13/14; 24 (1087/8): 14/15; 25 (837/1): 15a; 26 (1392/4): 14/15; 27 (1395/2): 13-15; 28 (48/1): 13-15; 29 (1393/7): 14/15; 30 (1392/18): 14/15; 31 (902/13): 15; 32 (759/21): 15b.

ISSN: 1133-4525 ISSN-e: 2255-3924 


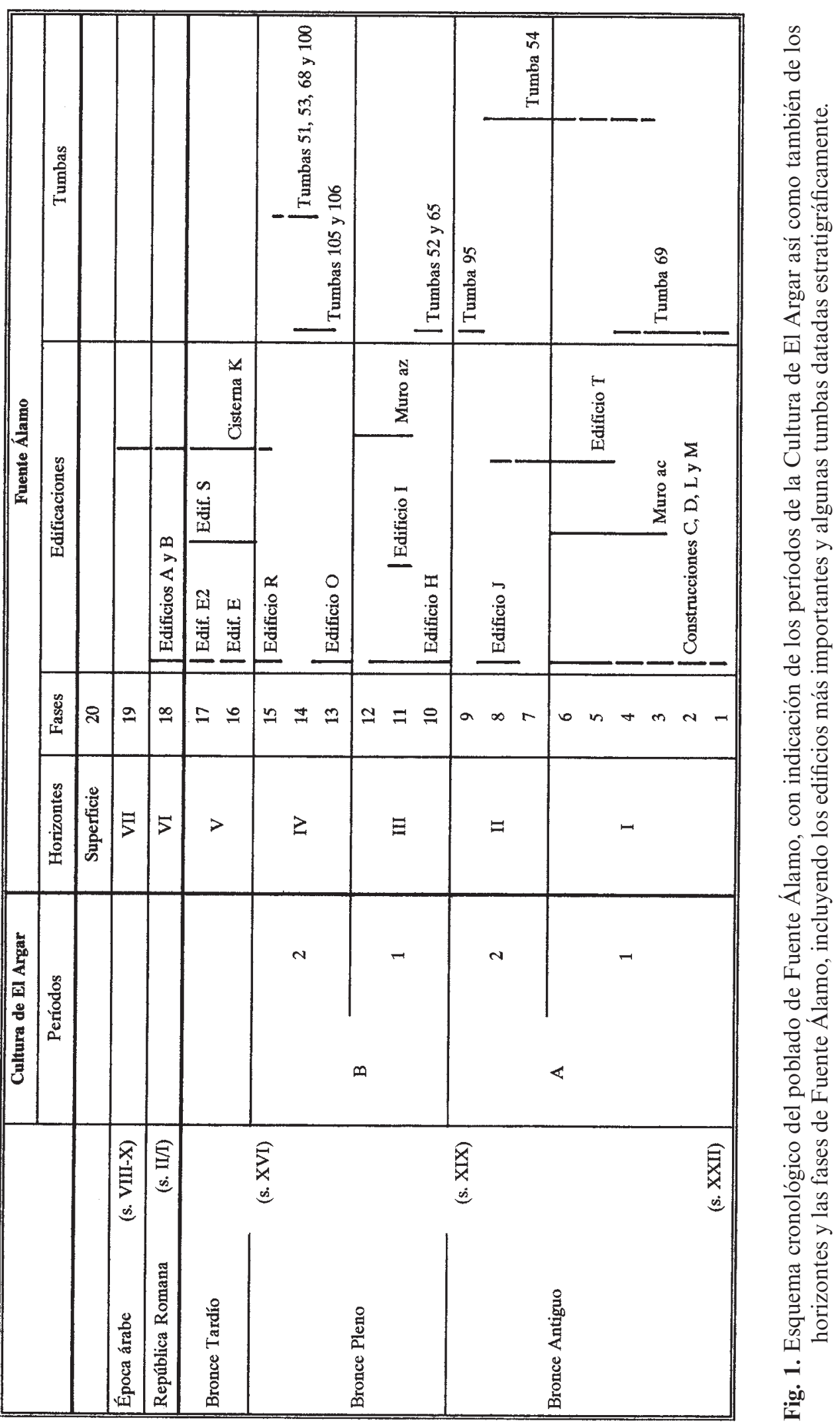


1 a1

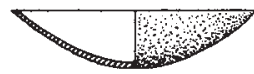

a2

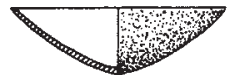

b1

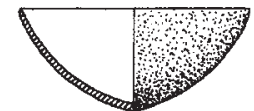

b2

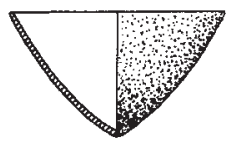

c1

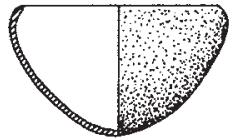

c2

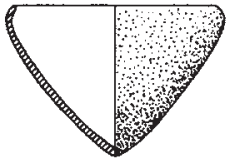

d

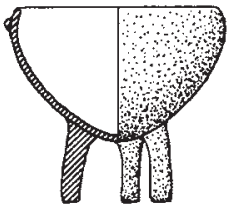

2 a1

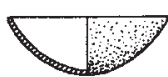

a2

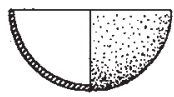

b1

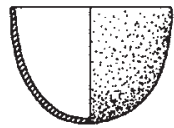

b2

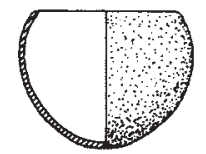

3 a

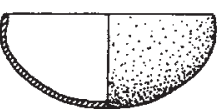

b1

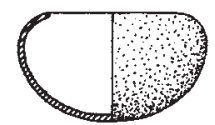

b2

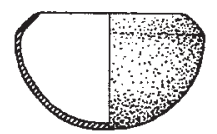

c1

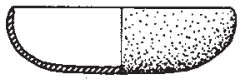

c2

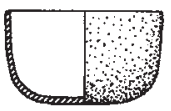

c3

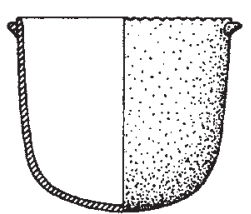

4 a1

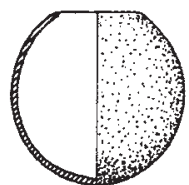

a 2

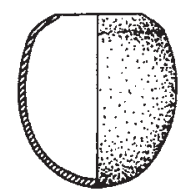

b1

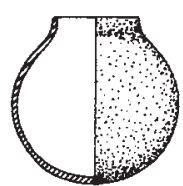

b2

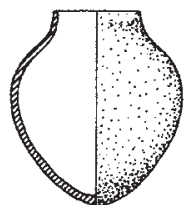

5 a
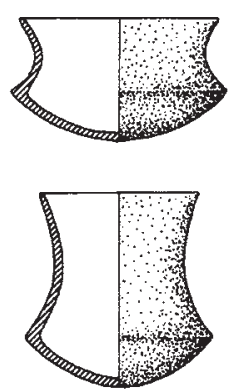

c

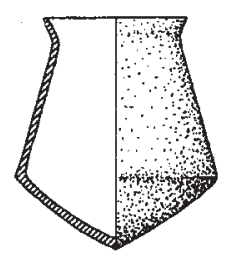

6 a
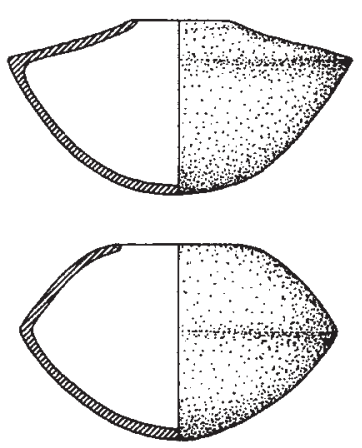

8 a

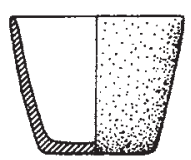

bl

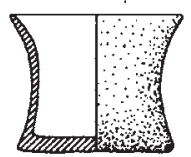

b2

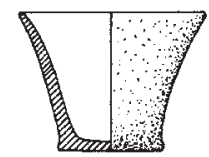

Fig. 2. Formas 1-6 y 8 de la cerámica argárica de Fuente Álamo. 
7 a

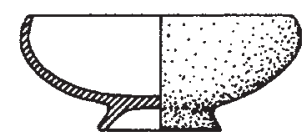

a 2

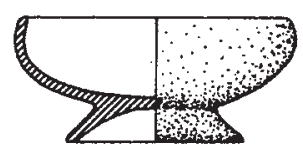

b1

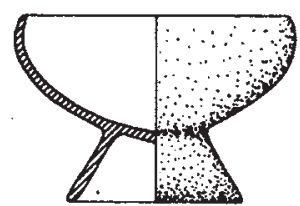

b2

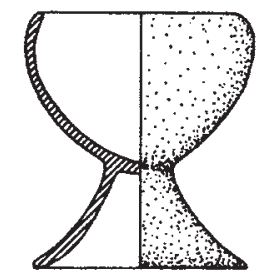

01

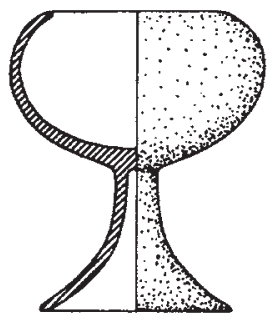

c2

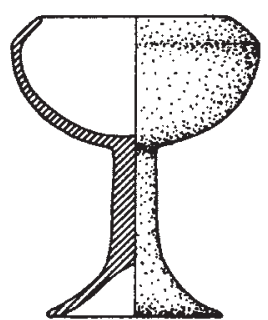

9

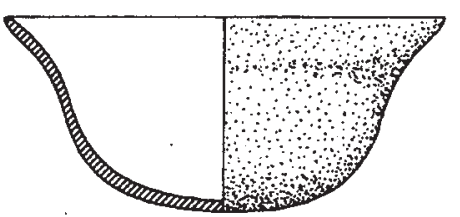

10. a

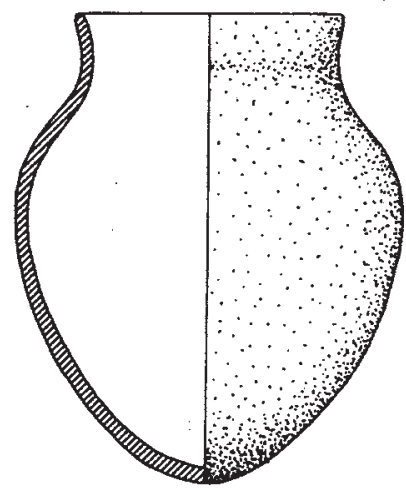

b1

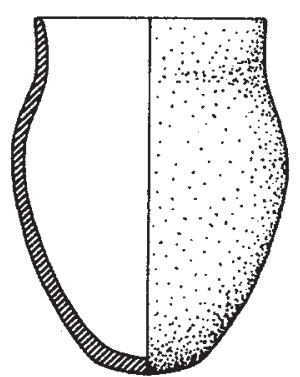

b2

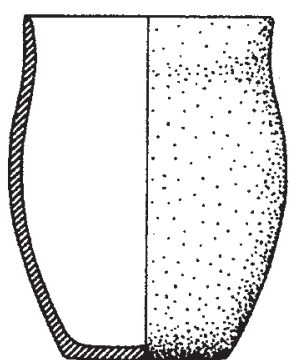

Fig. 3. Formas 7, 9 y 10 de la cerámica argárica de Fuente Álamo. 

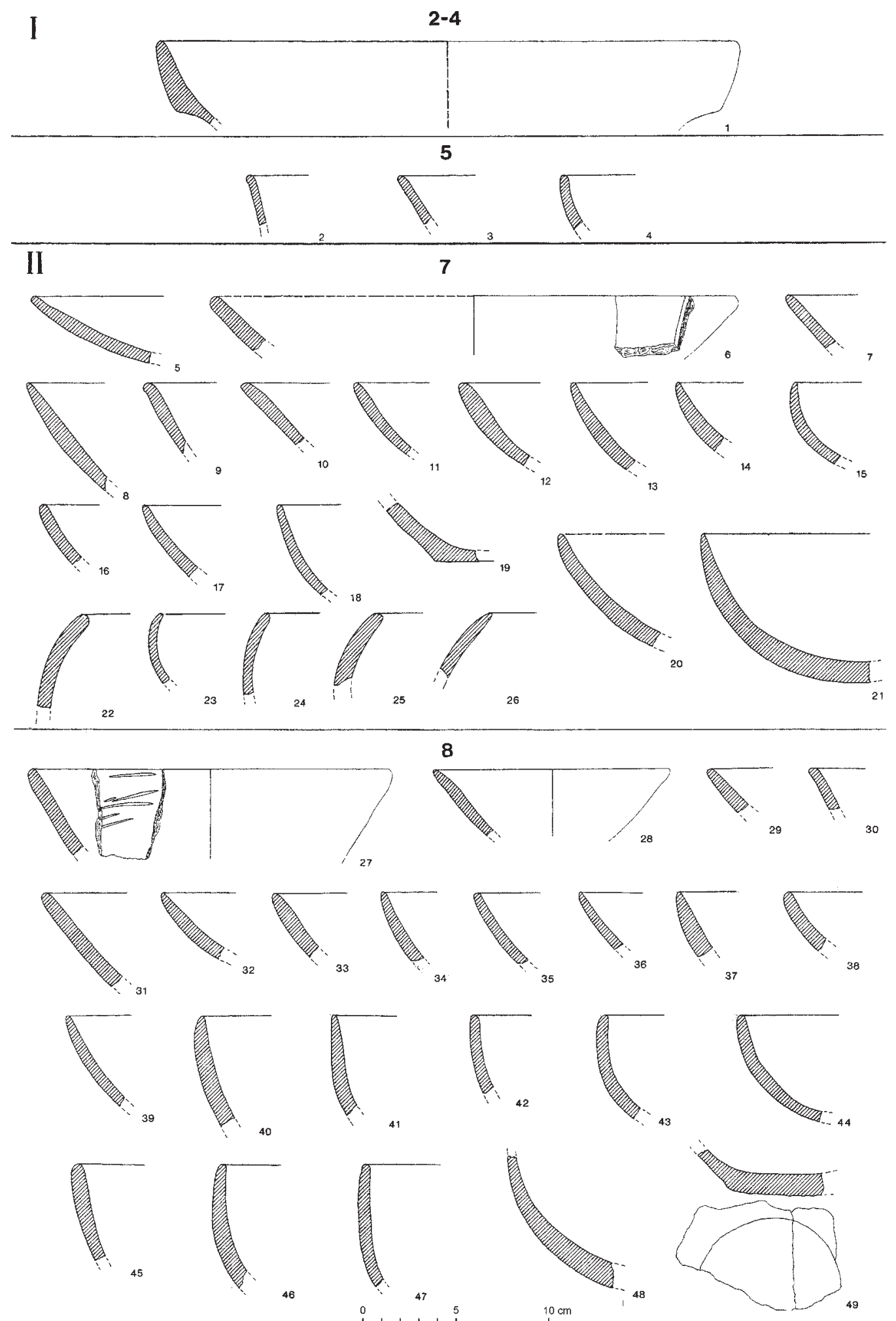

Fig. 4. Fuente Álamo 1977-1982. Hallazgos de cuencos y ollas de las formas 1-3, ordenados por fases y horizontes estratigráficos. 


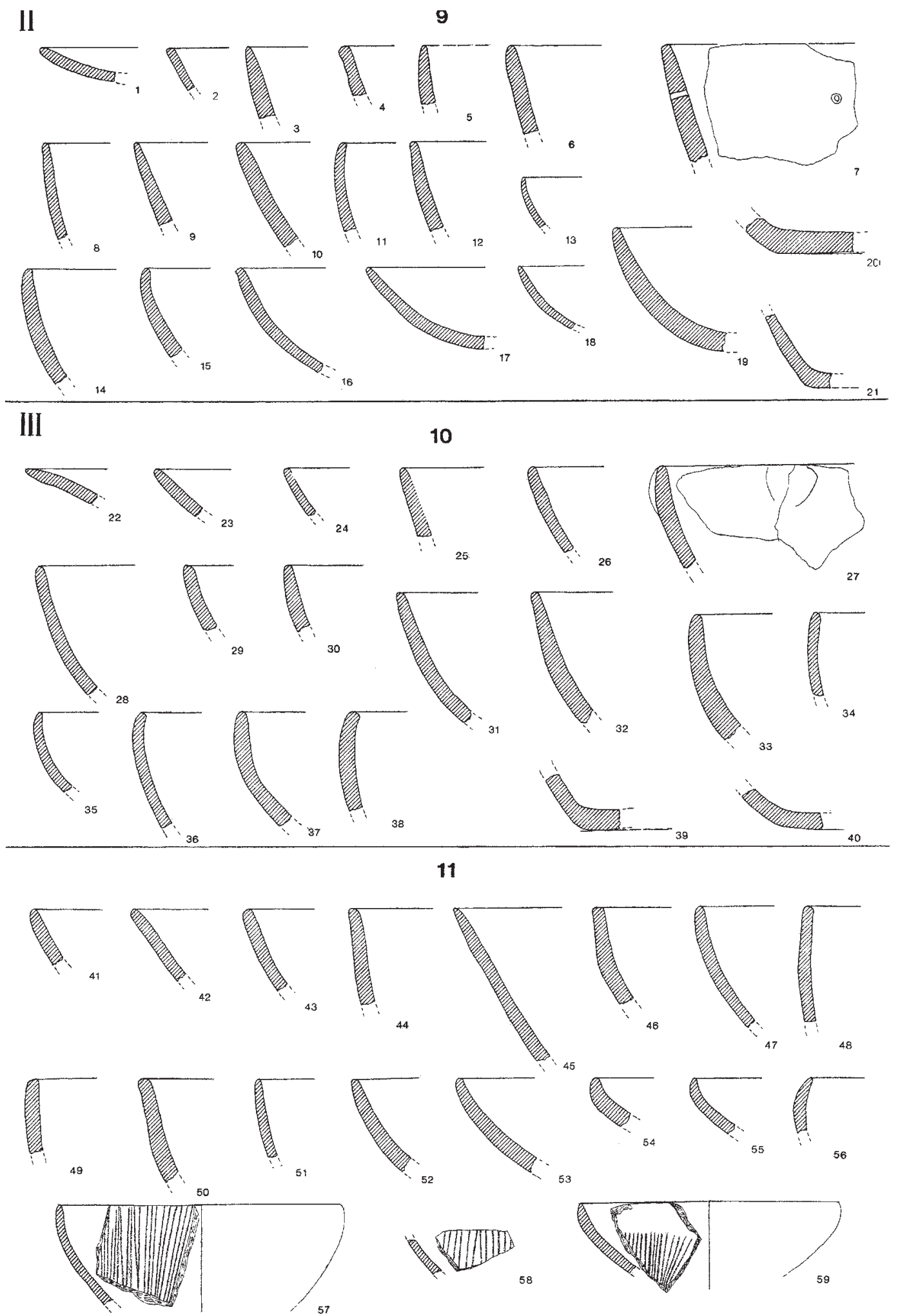

Fig. 5. Fuente Álamo 1977-1982. Hallazgos de cuencos y ollas de las formas 1-3, ordenados por fases y horizontes estratigráficos. 
III
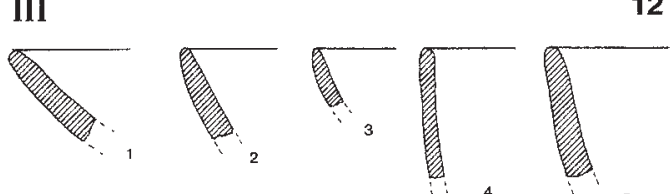

$\frac{0002}{2}$
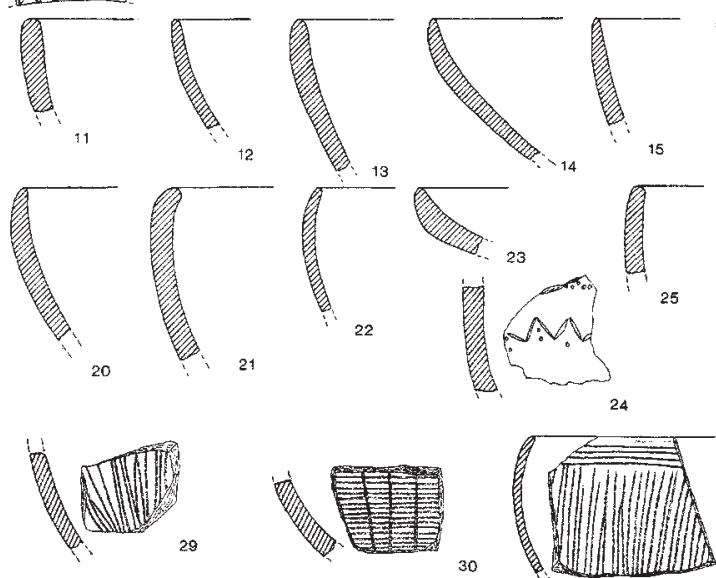

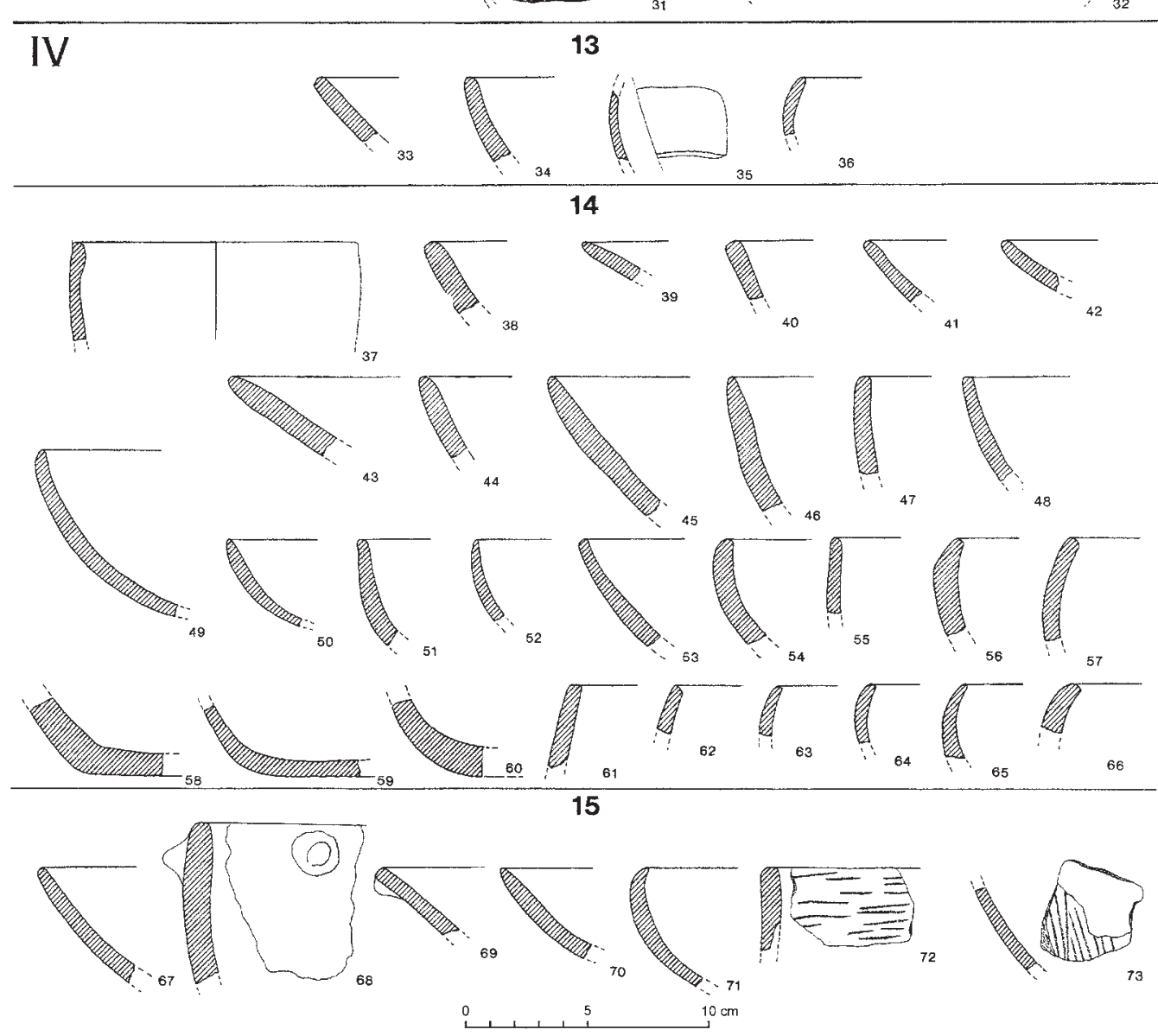

Fig. 6. Fuente Álamo 1977-1982. Hallazgos de cuencos y ollas de las formas 1-3, ordenados por fases y horizontes estratigráficos. 

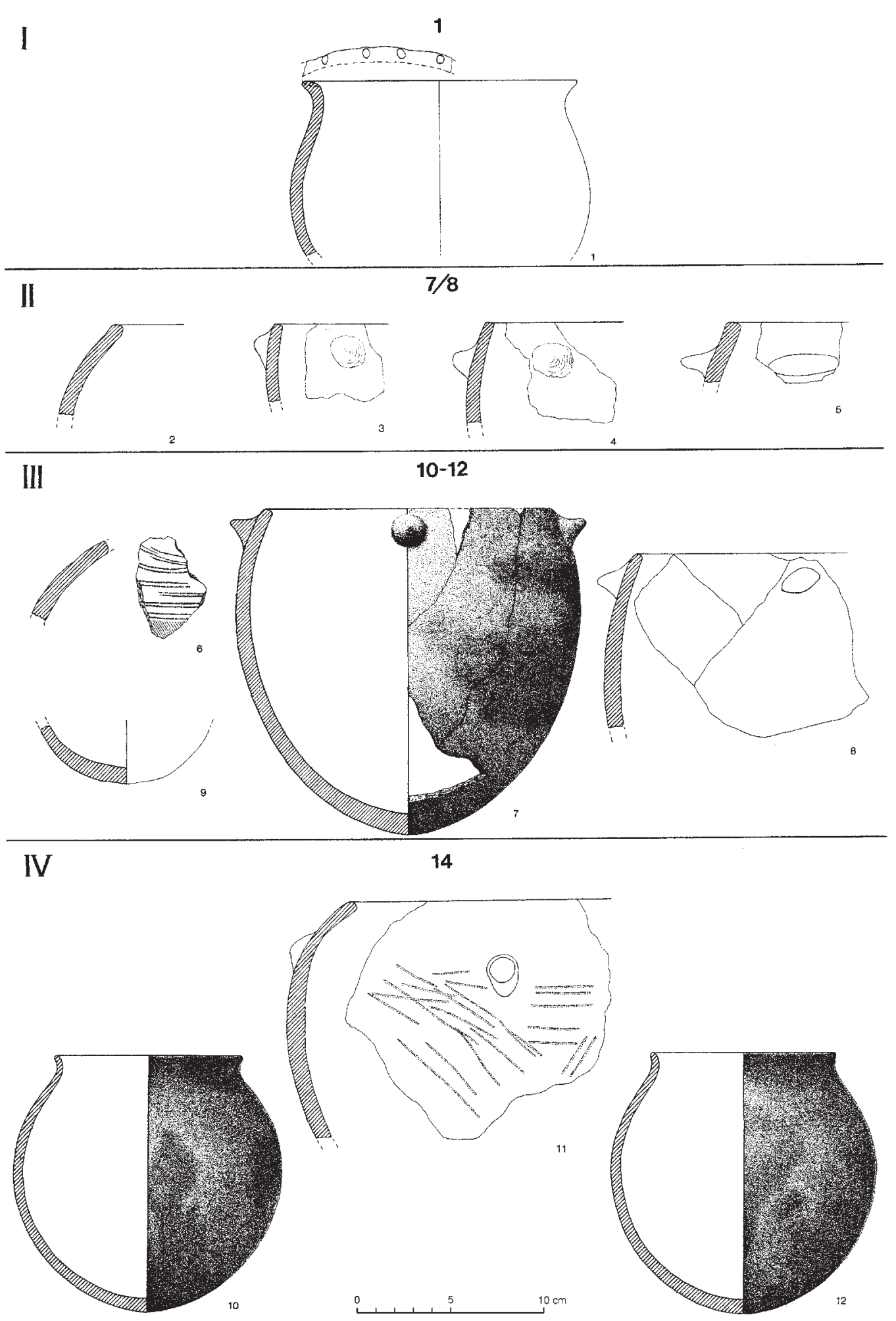

Fig. 7. Fuente Álamo 1977-1982. Hallazgos de ollas de la forma 4, ordenados por fases y horizontes estratigráficos. 
I

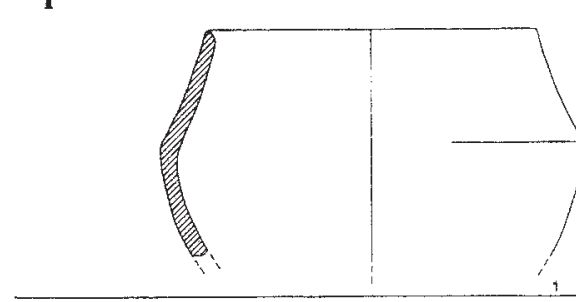

$1-3$

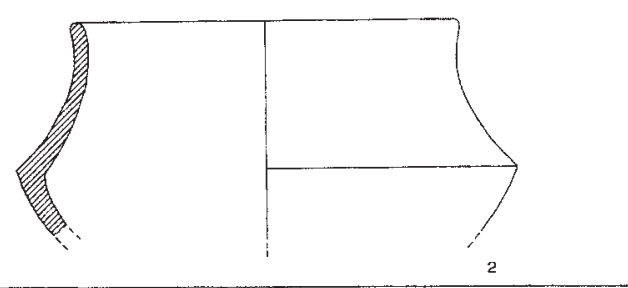

4

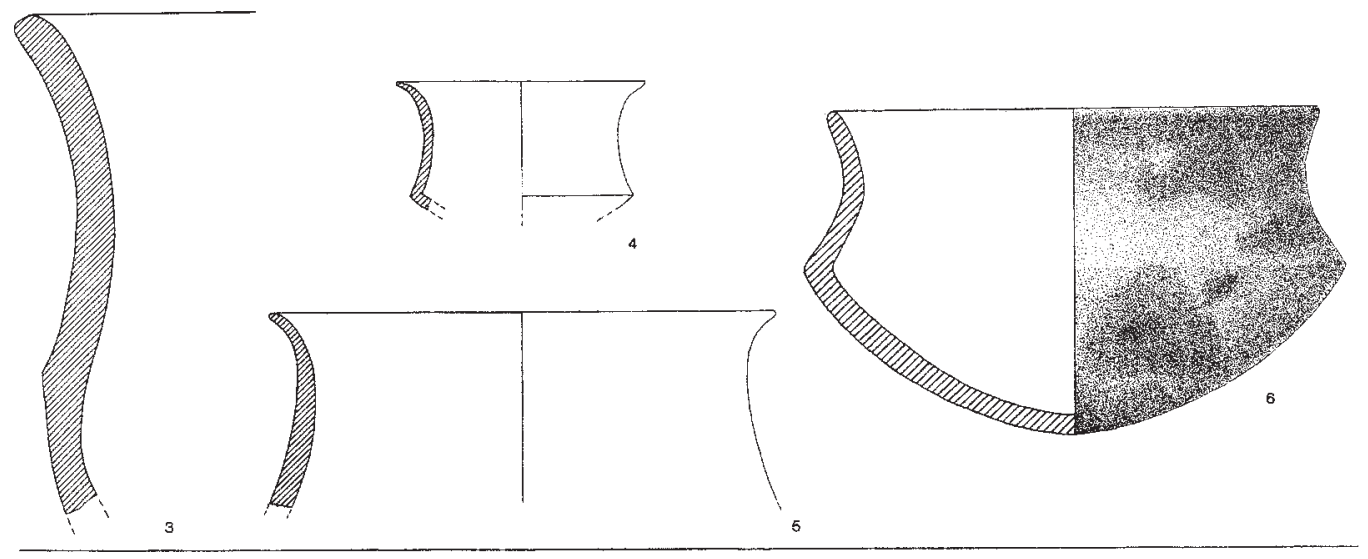

5

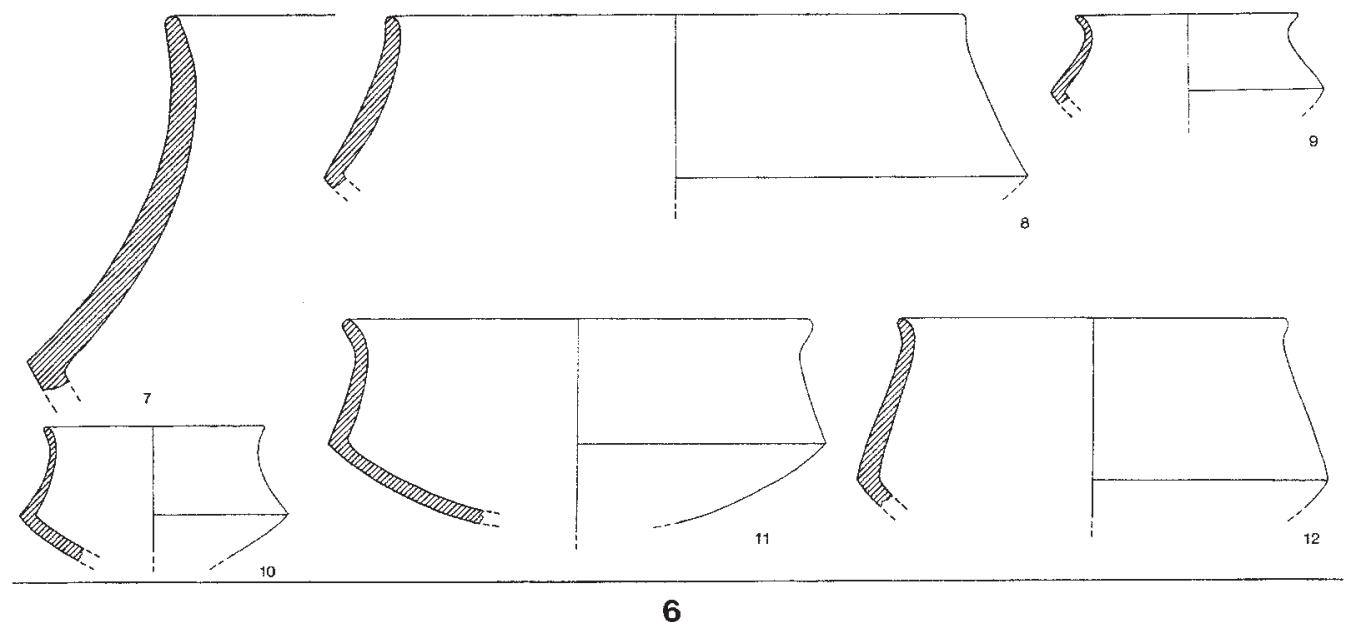

6
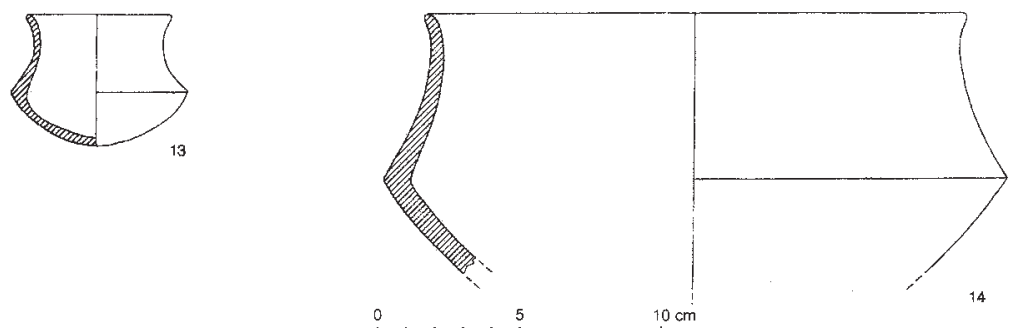

$10 \mathrm{~cm}$

Fig. 8. Fuente Álamo 1977-1982. Hallazgos de vasijas carenadas de la forma 5, ordenados por fases y horizontes estratigráficos.

ISSN: 1133-4525 ISSN-e: 2255-3924

SPAL 13 (2004)

http://dx.doi.org/10.12795/spal.2004.113.02 
II
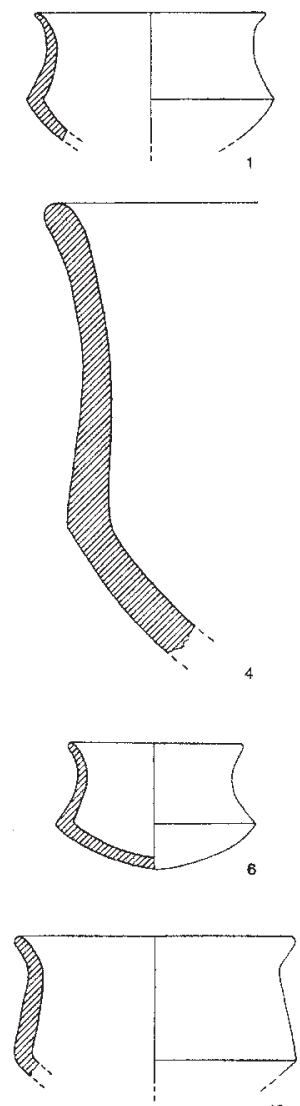
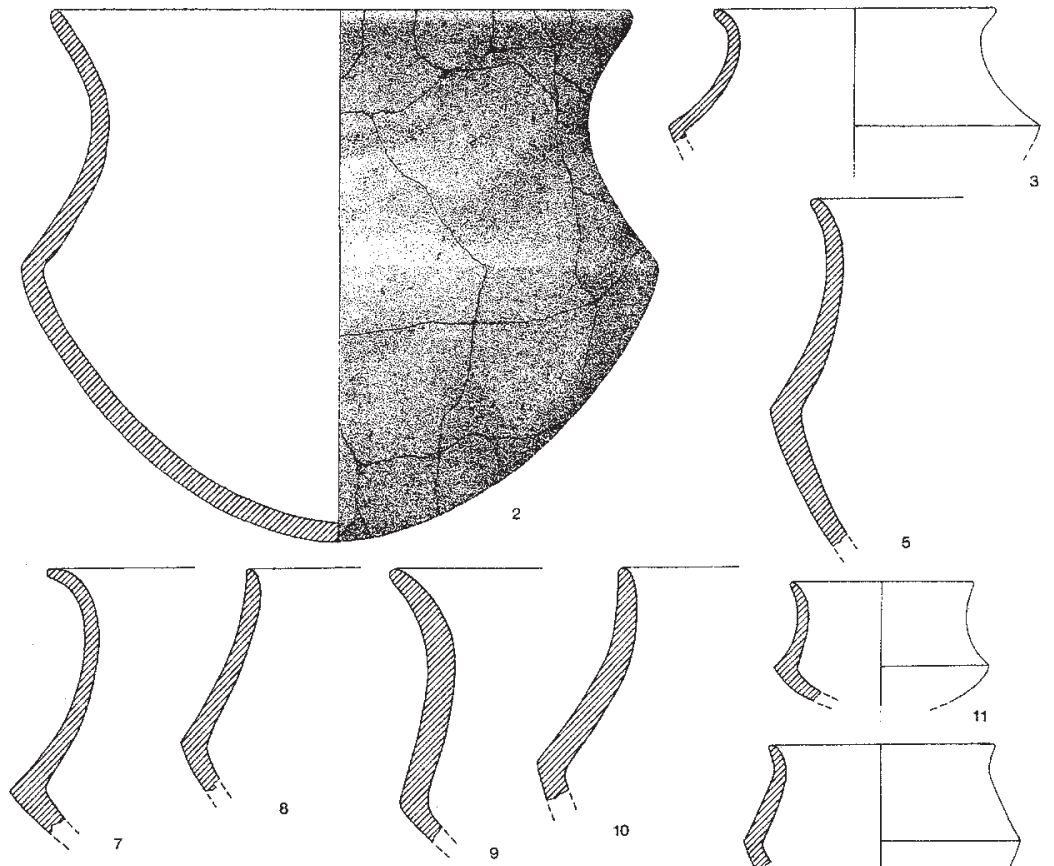

10
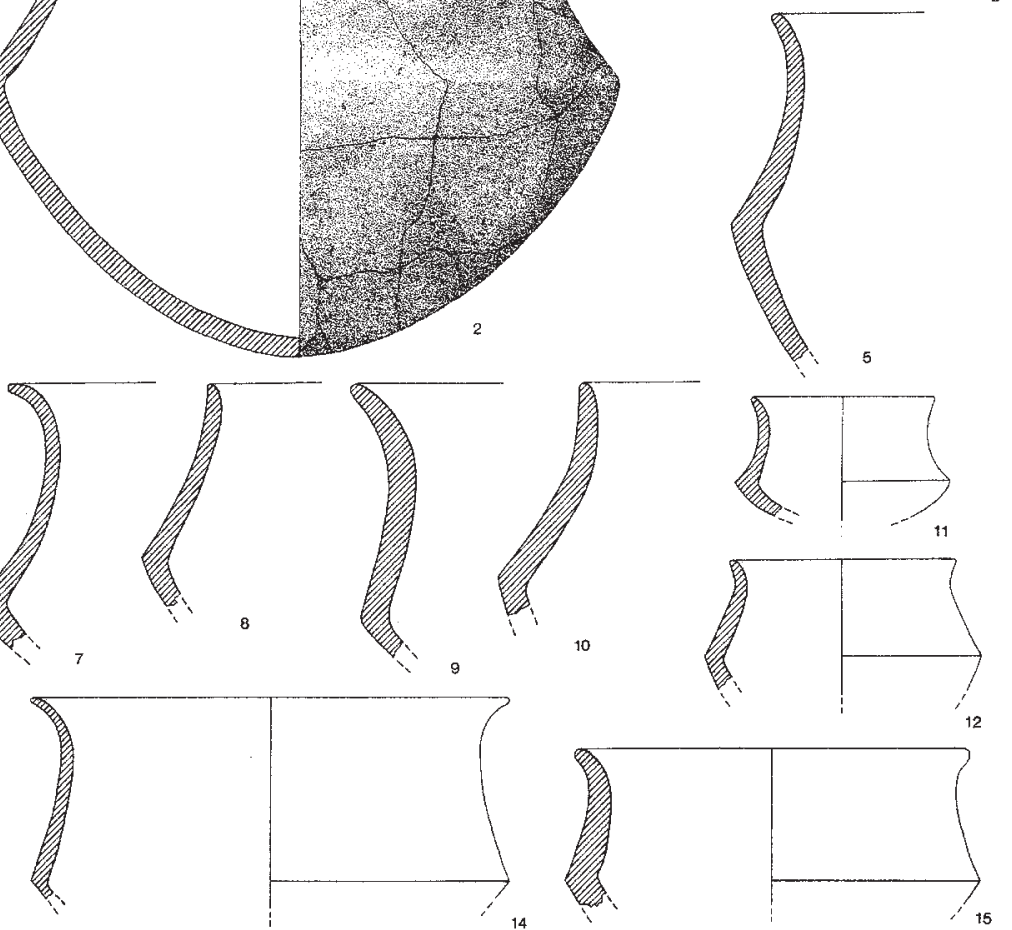

8

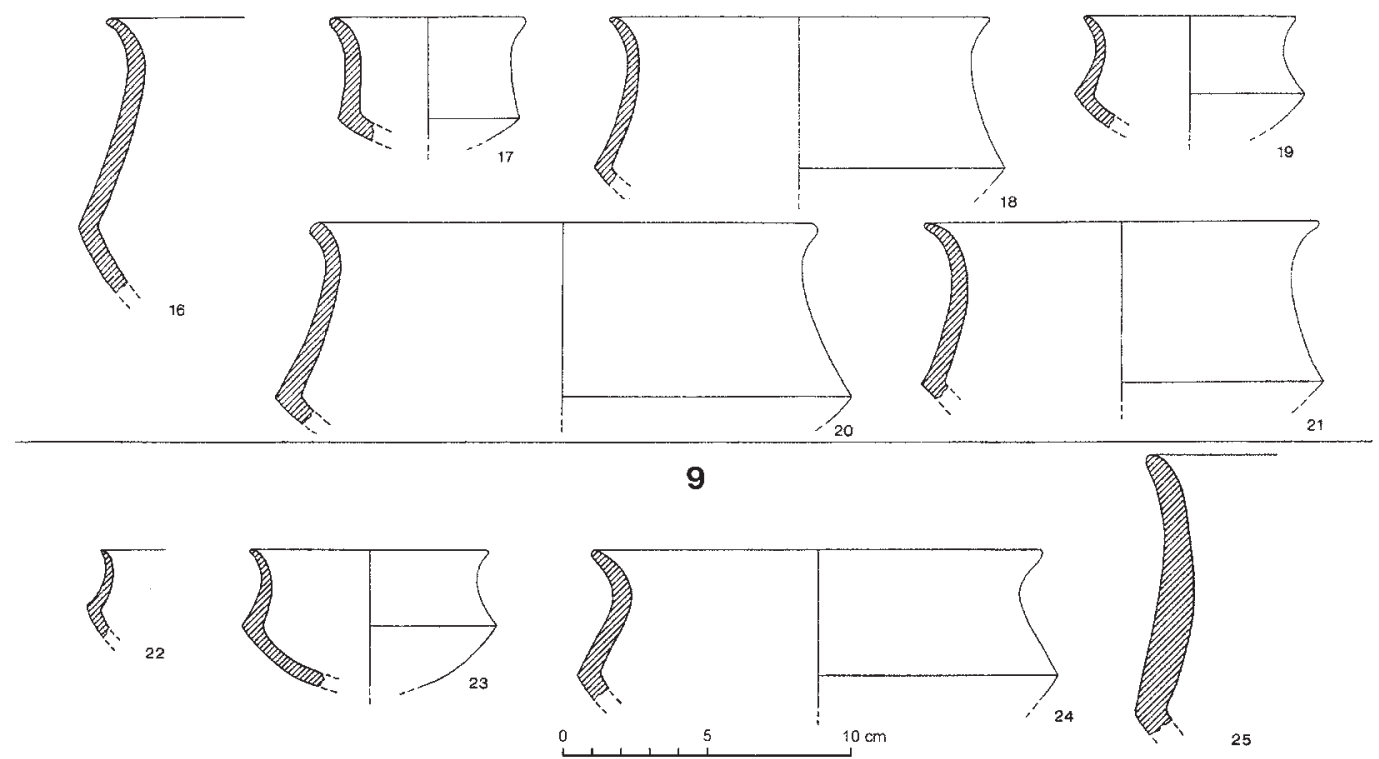

Fig. 9. Fuente Álamo 1977-1982. Hallazgos de vasijas carenadas de la forma 5, ordenados por fases y horizontes estratigráficos. 
III
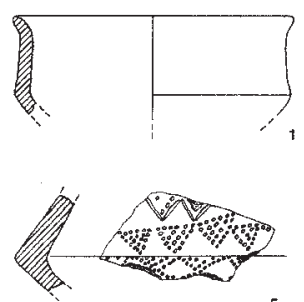

10
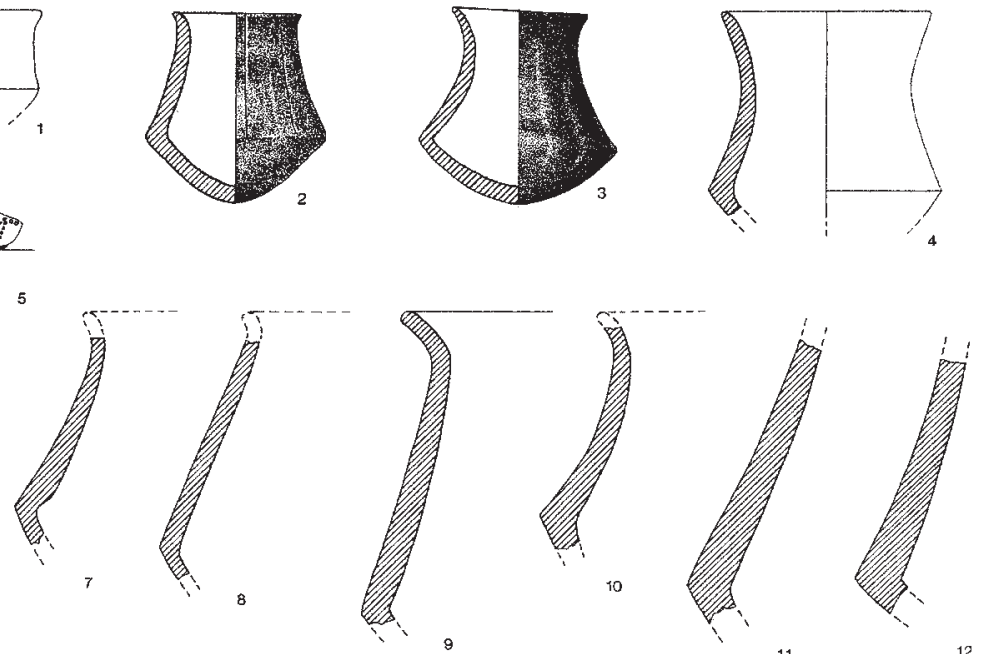

11
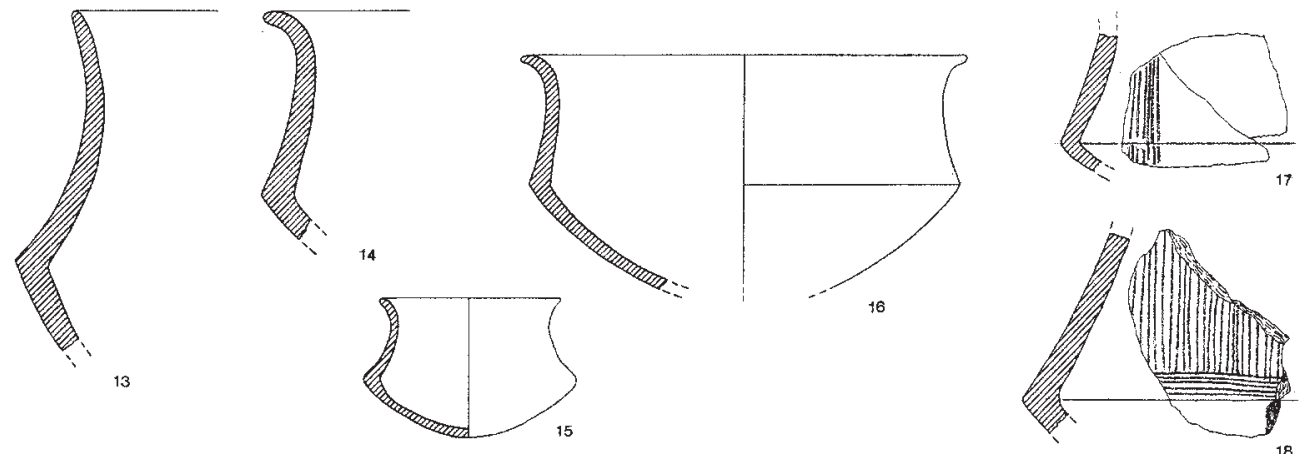

12
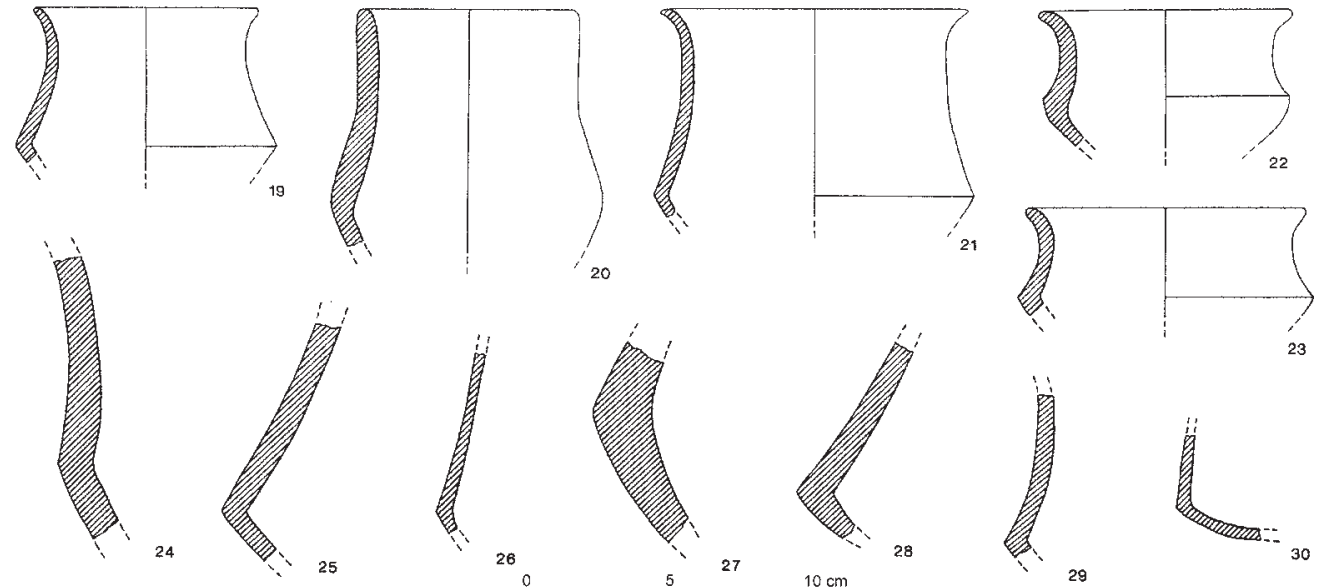

Fig. 10. Fuente Álamo 1977-1982. Hallazgos de vasijas carenadas de la forma 5, ordenados por fases y horizontes estratigráficos. 

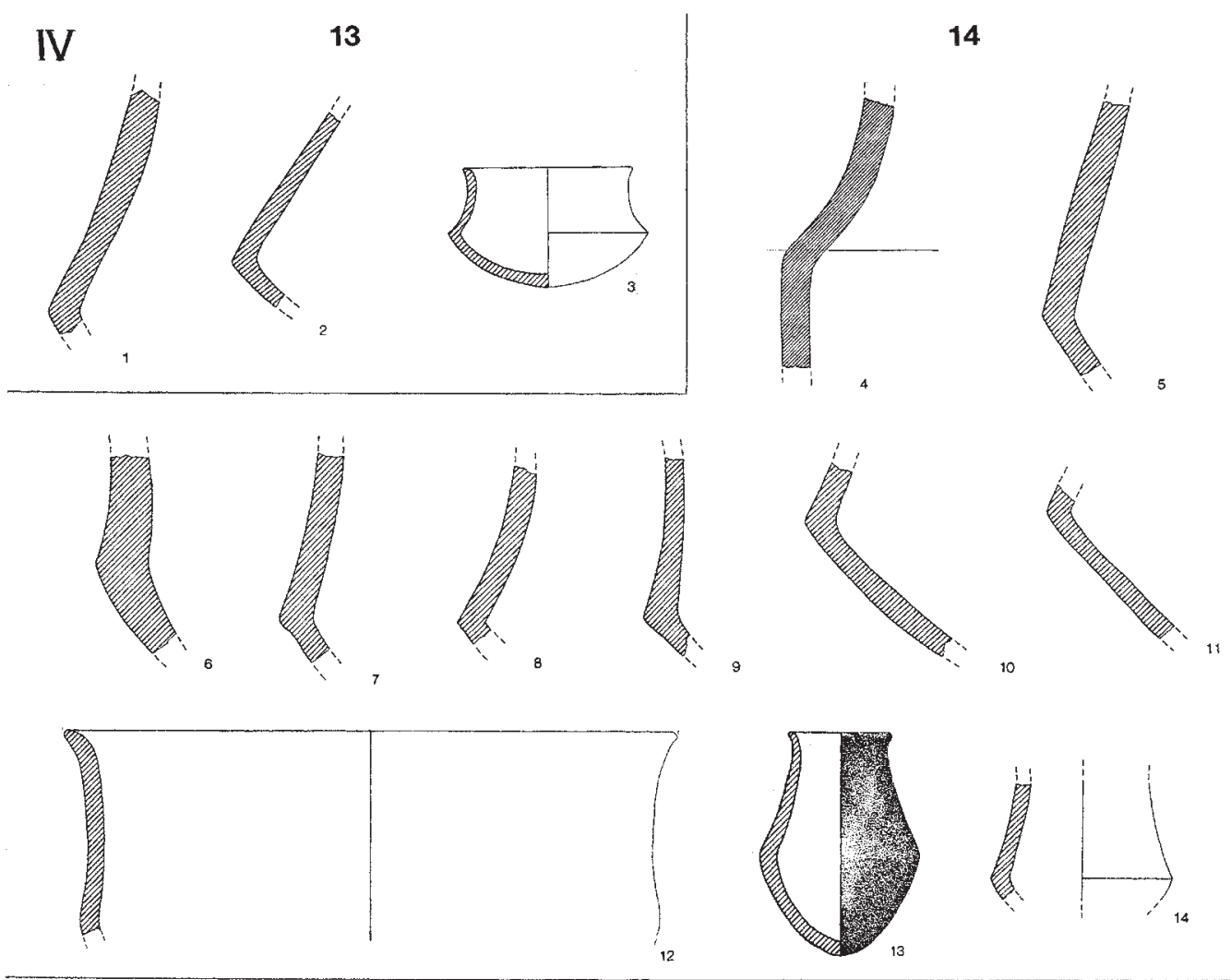

15
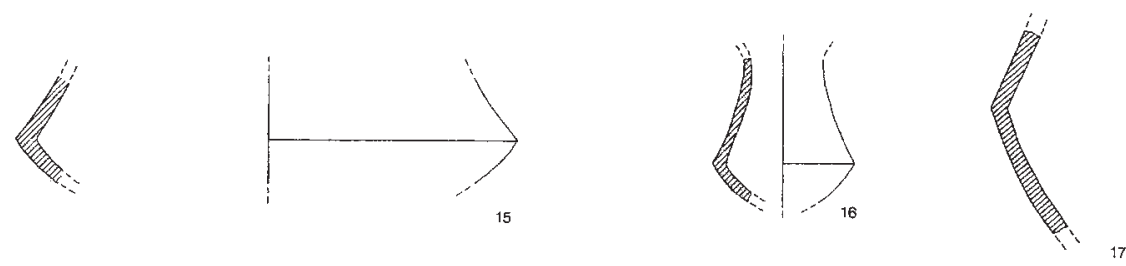

$18 / 20$
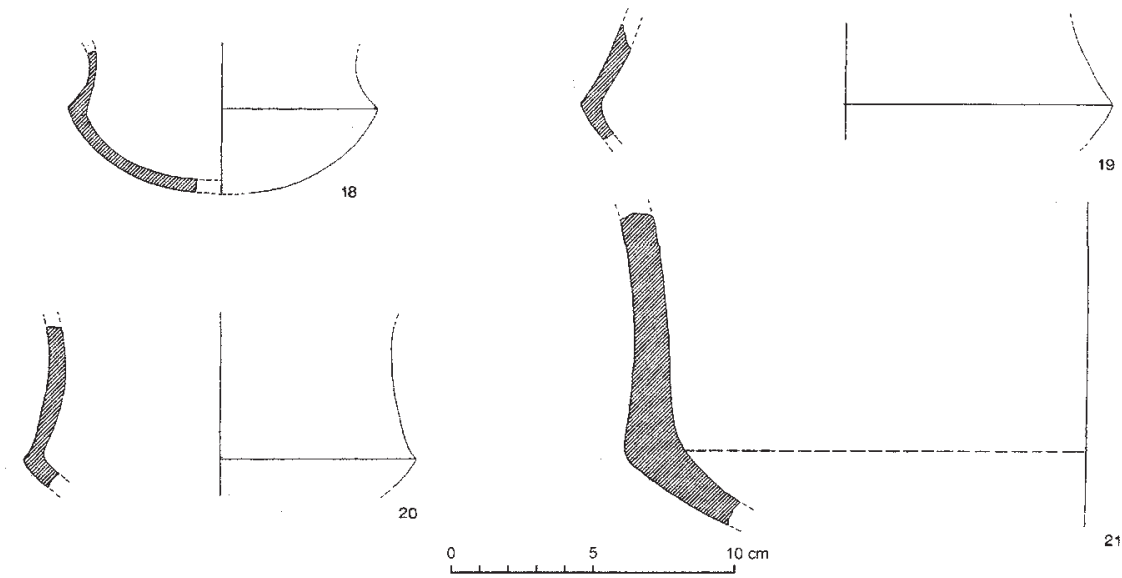

Fig. 11. Fuente Álamo 1977-1982. Hallazgos de vasijas carenadas de la forma 5, ordenados por fases y horizontes estratigráficos. 

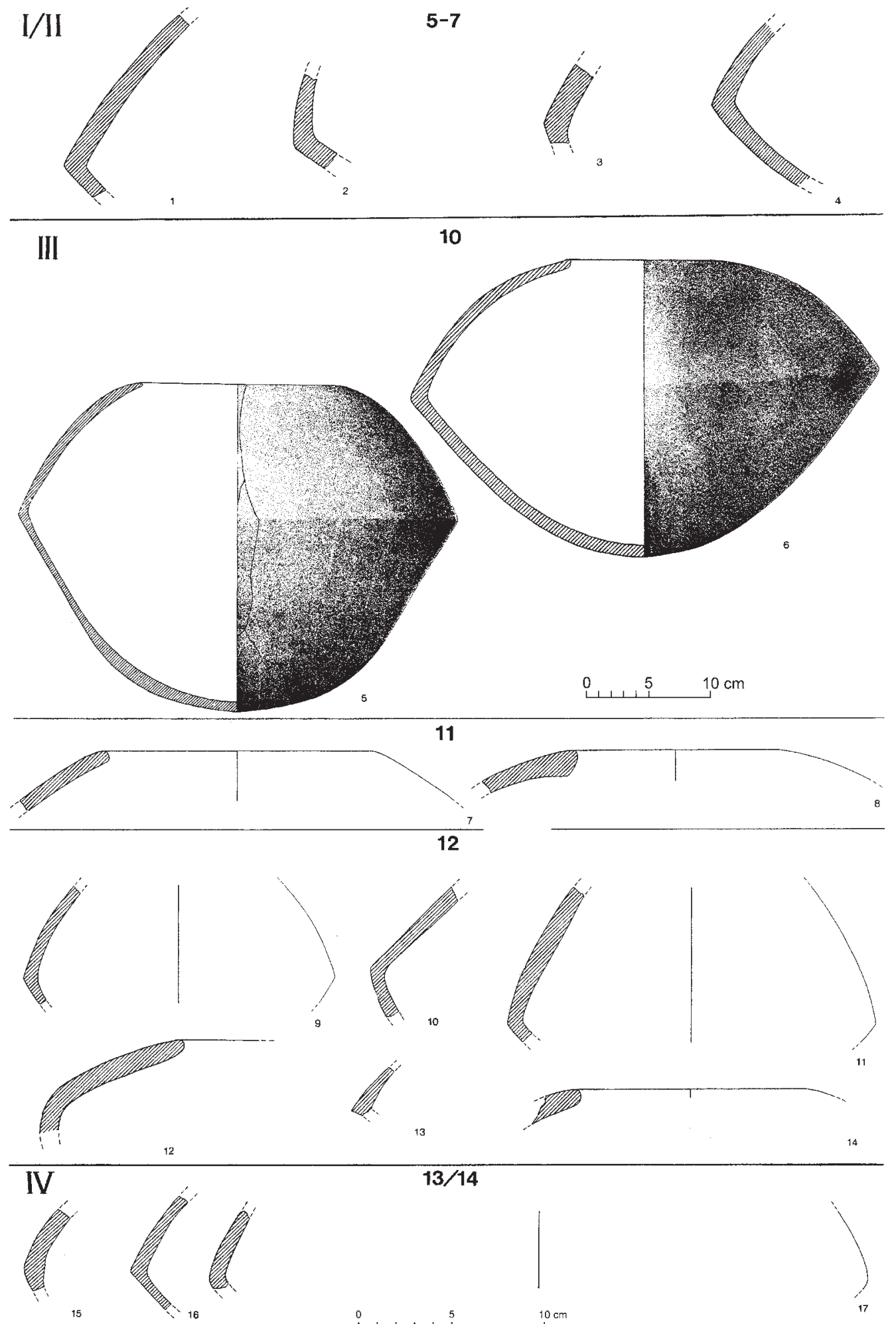

$13 / 14$
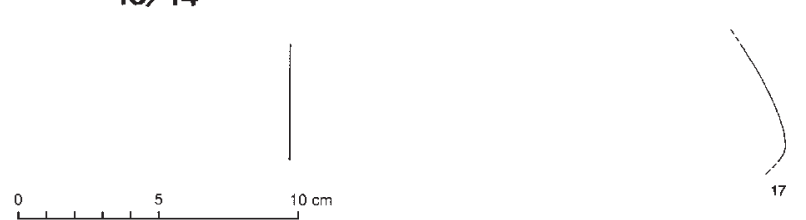

Fig. 12. Fuente Álamo 1977-1982. Hallazgos de vasijas bicónicas de la forma 6, ordenados por fases y horizontes estratigráficos. 

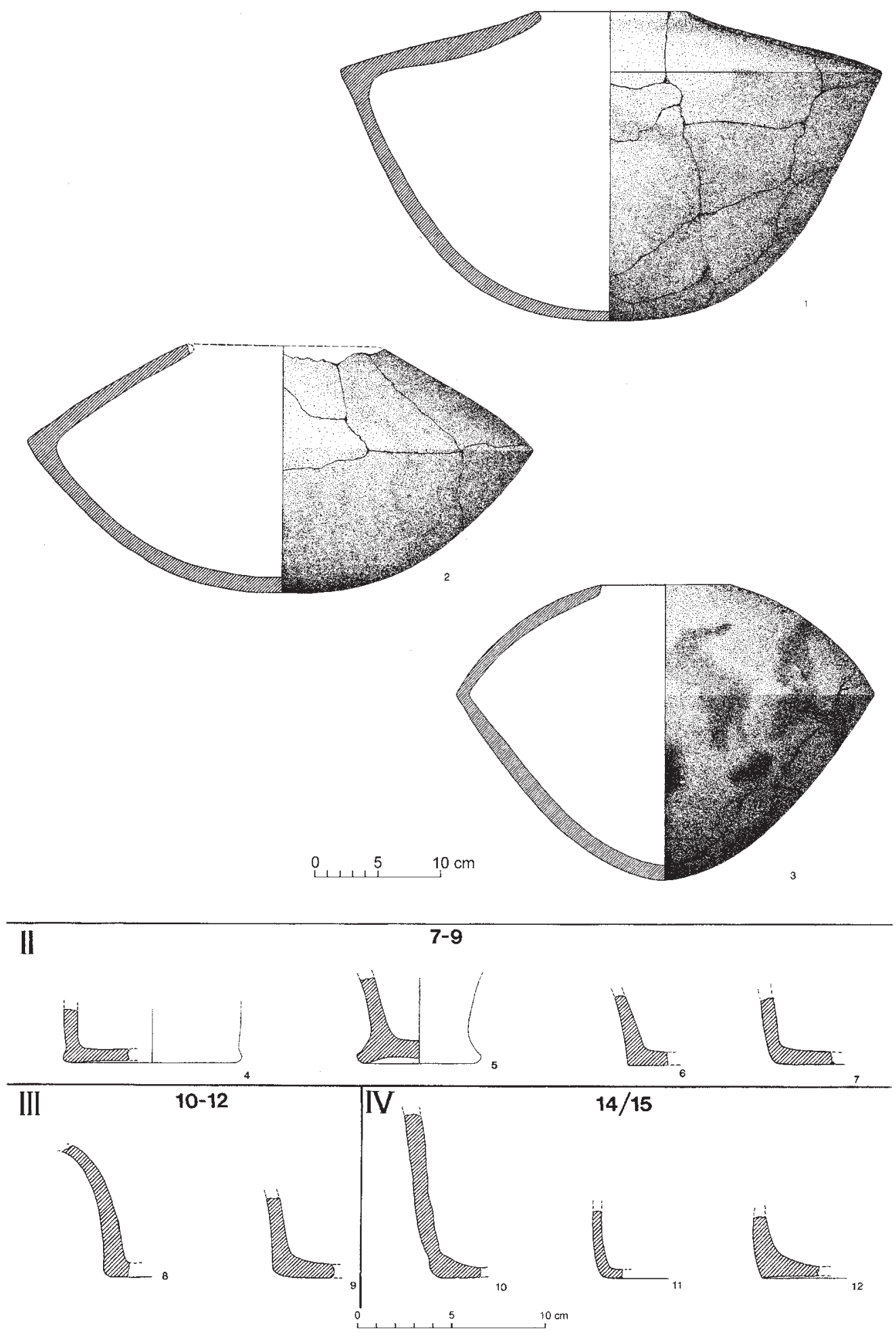

Fig. 13. Arriba: Fuente Álamo. Vasijas bicónicas de la forma 6 procedentes de sepulturas. 1 Tumba 75 (FA 85/1816/4); 2 Tumba 71 (FA 85/2584/1); 3 Tumba 56 (FA 79/1261/1).- Abajo: Fuente Álamo 1977-1982. 4-12 Hallazgos de vasos de la forma 8 , ordenados por fases y horizontes estratigráficos. 

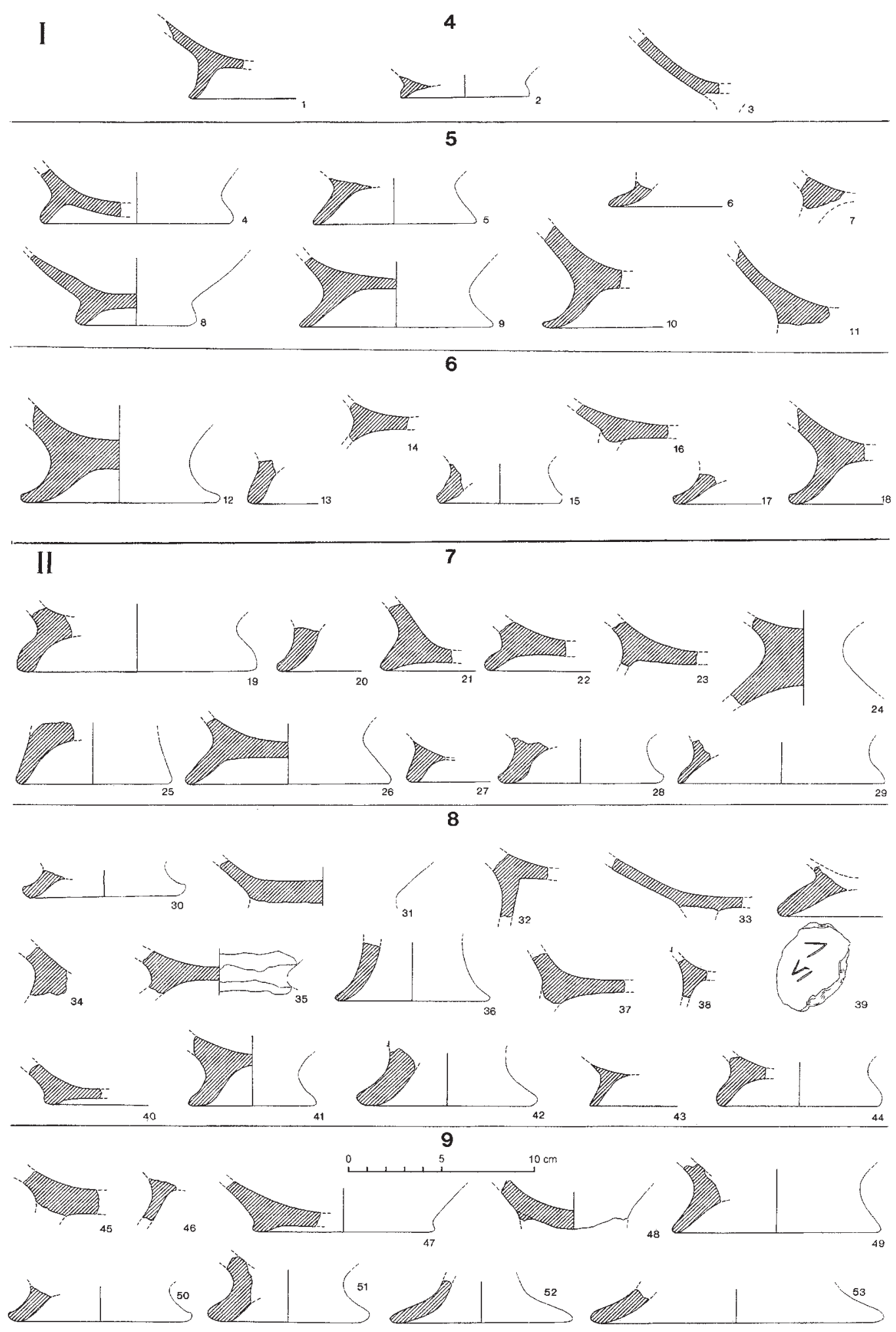

Fig. 14. Fuente Álamo 1977-1982. Hallazgos de copas de la forma 7, ordenados por fases y horizontes estratigráficos. 

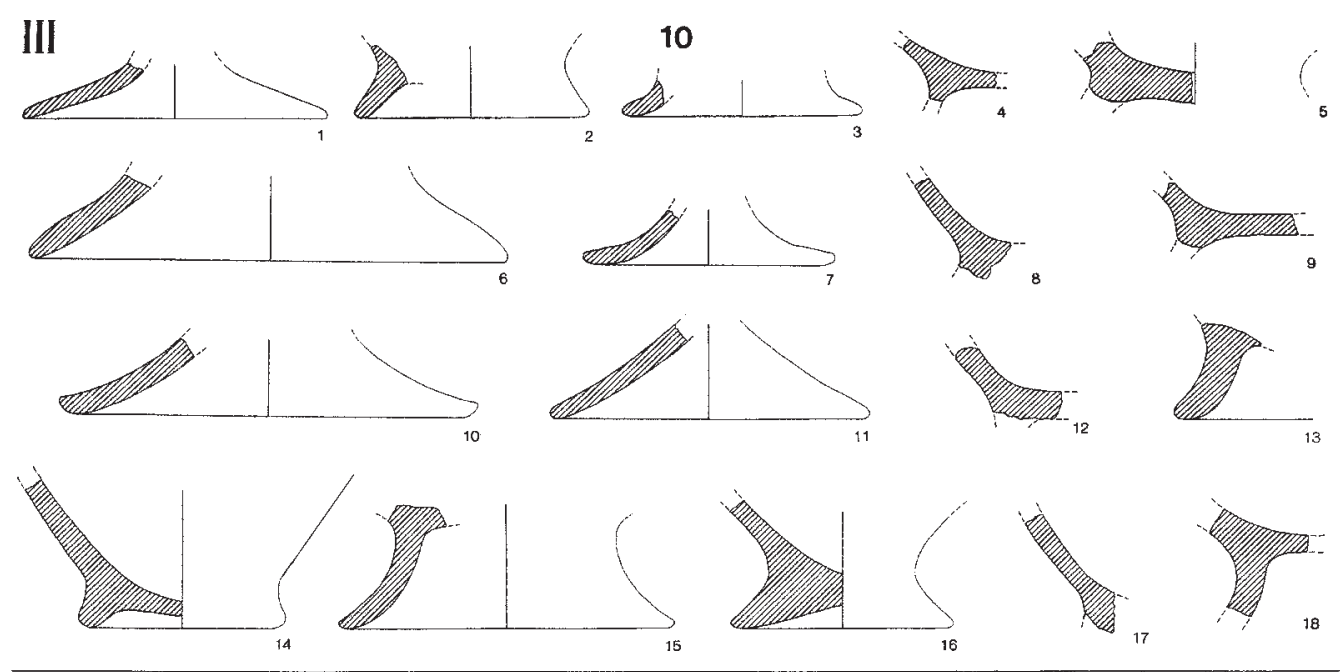

11
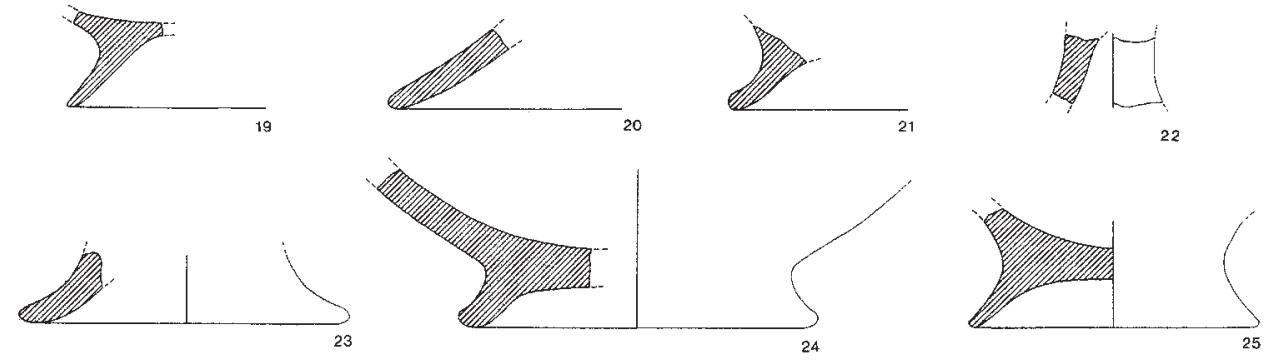

12
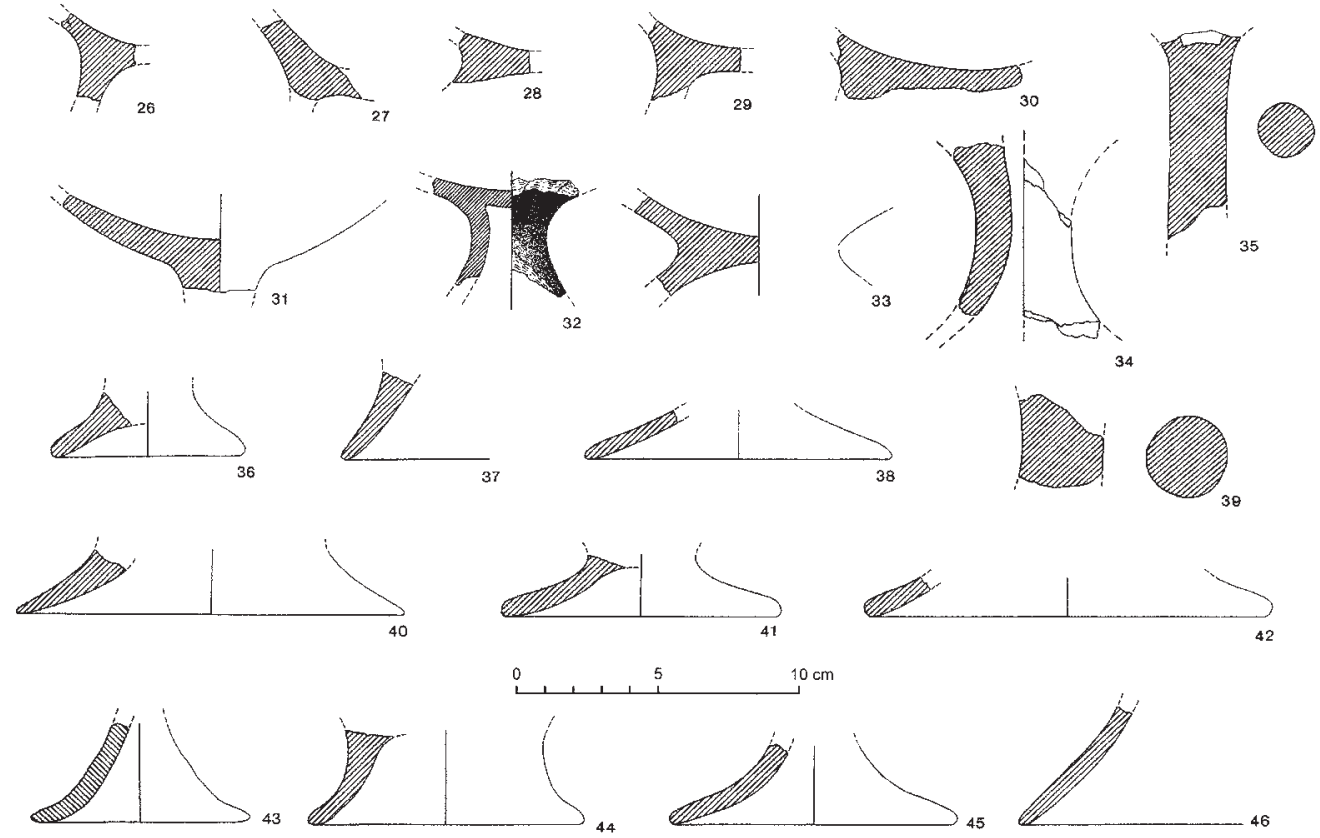

Fig. 15. Fuente Álamo 1977-1982. Hallazgos de copas de la forma 7, ordenados por fases y horizontes estratigráficos. 
IV
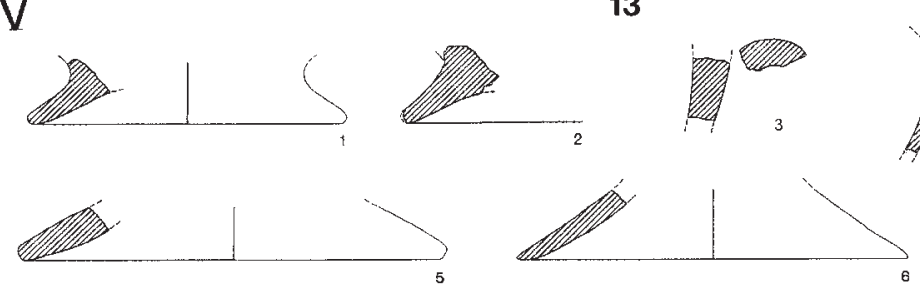

14
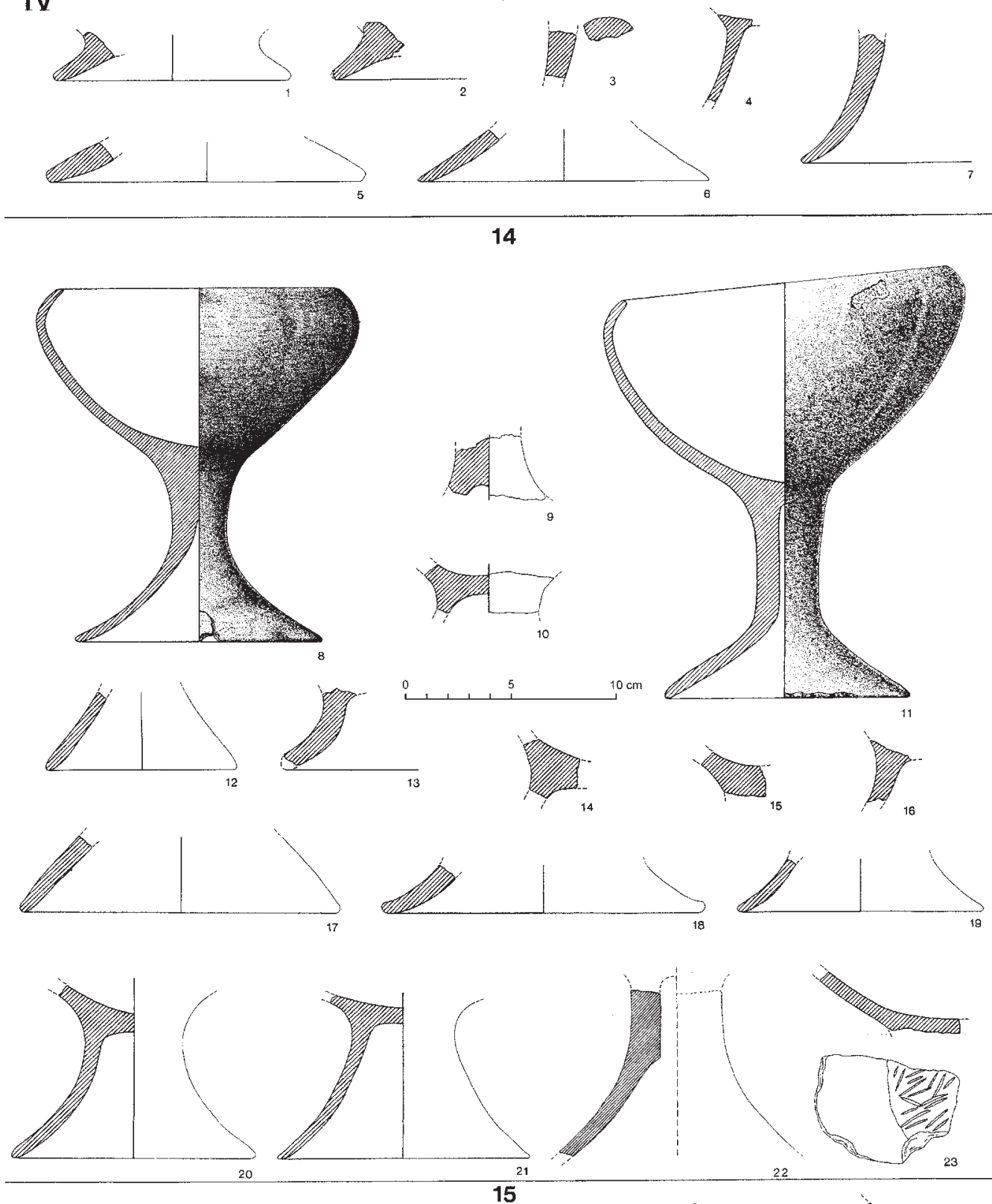

$10 \mathrm{~cm}$
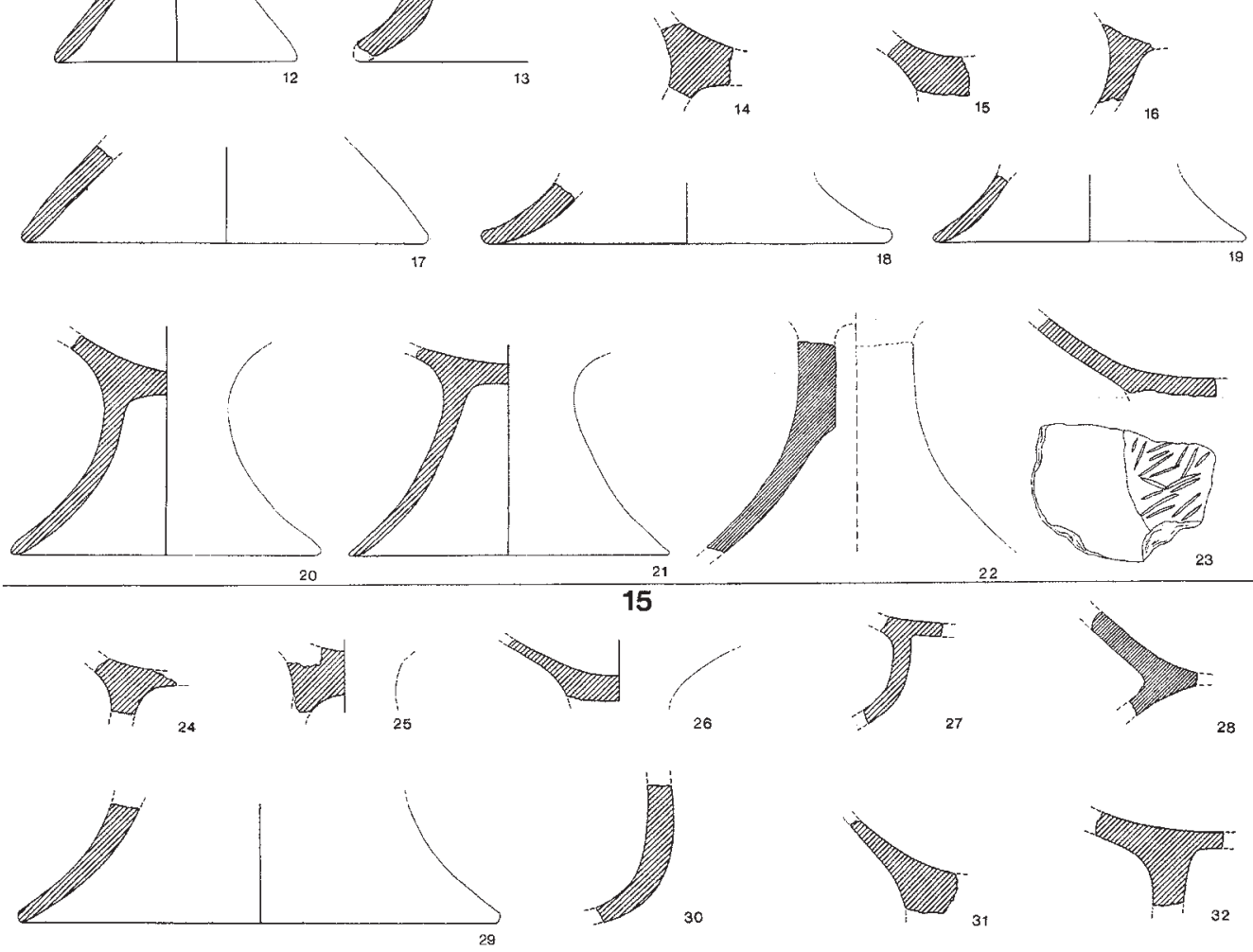

Fig. 16. Fuente Álamo 1977-1982. Hallazgos de copas de la forma 7, ordenados por fases y horizontes estratigráficos. 

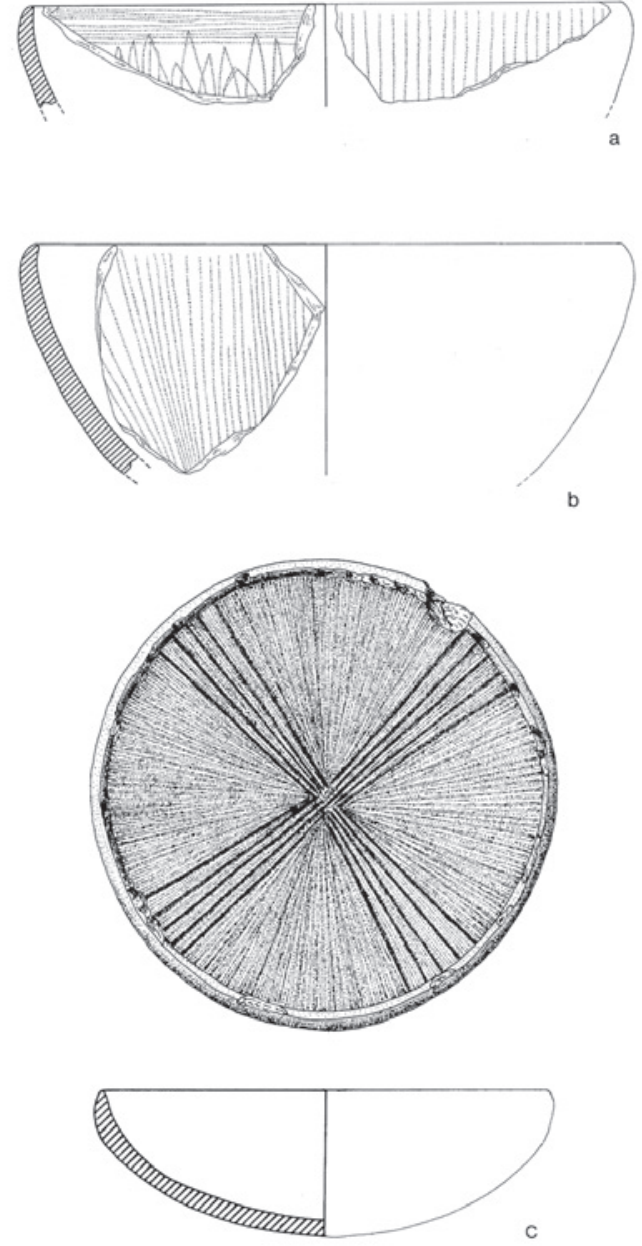

0 $10 \mathrm{~cm}$

Fig. 17. Fuente Álamo. Sector nordeste. Corte 9. a.b Dos fragmentos de borde con decoración bruñida, que pudieron haber pertenecido tanto a cuencos de borde entrante como a las partes superiores de unas copas (a FA 77/68/7; b FA 77/68/11). c Cuenco con decoración bruñida de la tumba 80 de Fuente Álamo (FA 85/2372/1).

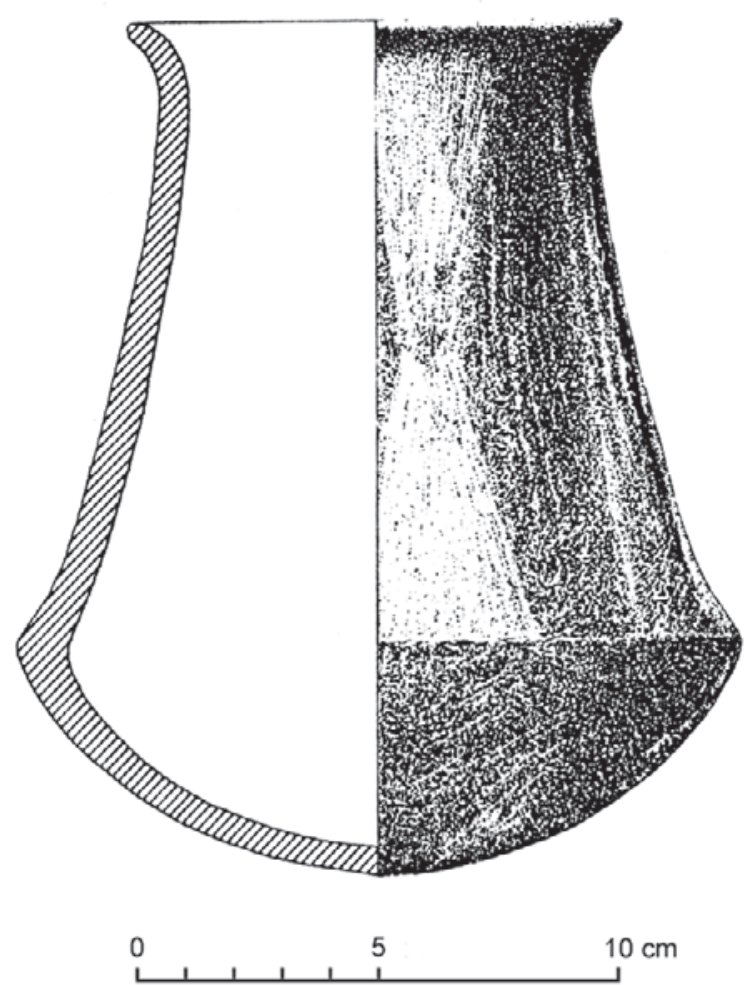

Fig. 18. Museo de Almería (Inv. 13095). Vasija carenada con decoración bruñida en forma de reloj de arena. Como lugar del hallazgo se barajan El Argar o La Bastida de Totana (Murcia). 

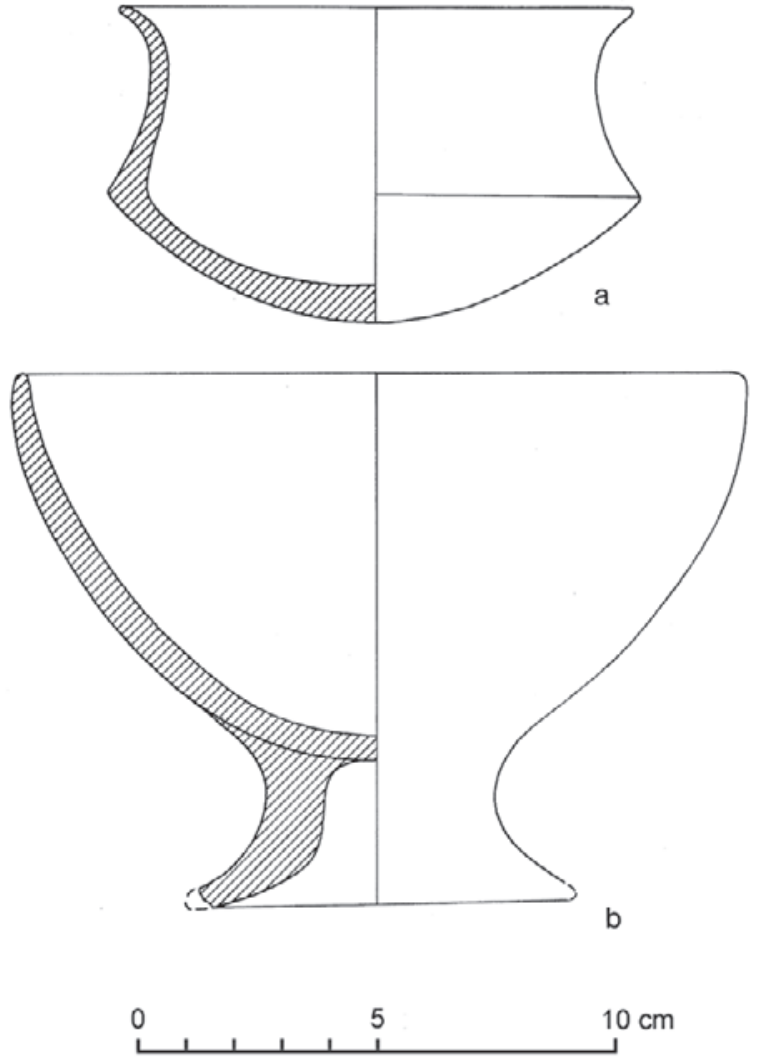

Fig. 19. Fuente Álamo 1988. Dos recipientes procedentes de un contexto cerrado de la fase 9 , adscrito a la tumba 95. a Vasija carenada (FA 88/3077/1); b Copa (FA 88/3078/1).

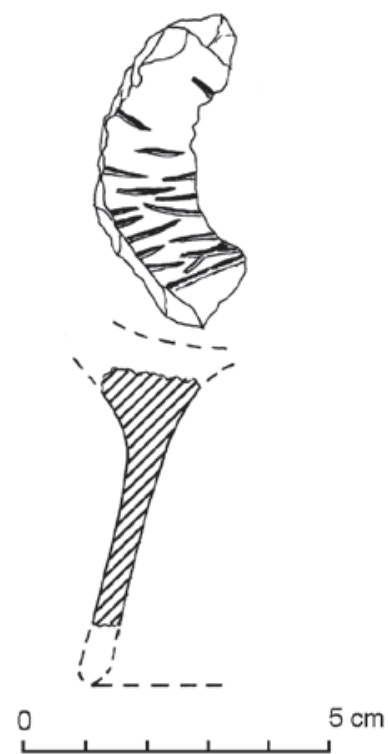

Fig. 20. Fuente Álamo. Ladera oeste. Testigo entre los cortes 17 y 32 . Fragmento de un pie de copa con el arranque del cuenco superior (FA 96/4152/6). 


\section{Forma 4b Forma $5 \quad$ Forma 6}

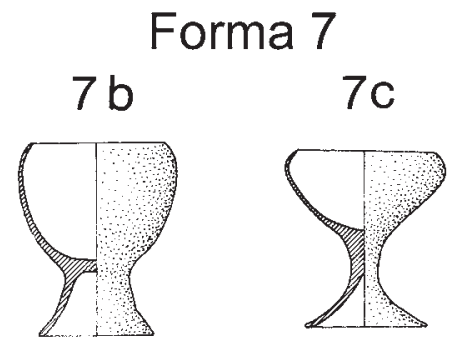

\section{El Argar B}
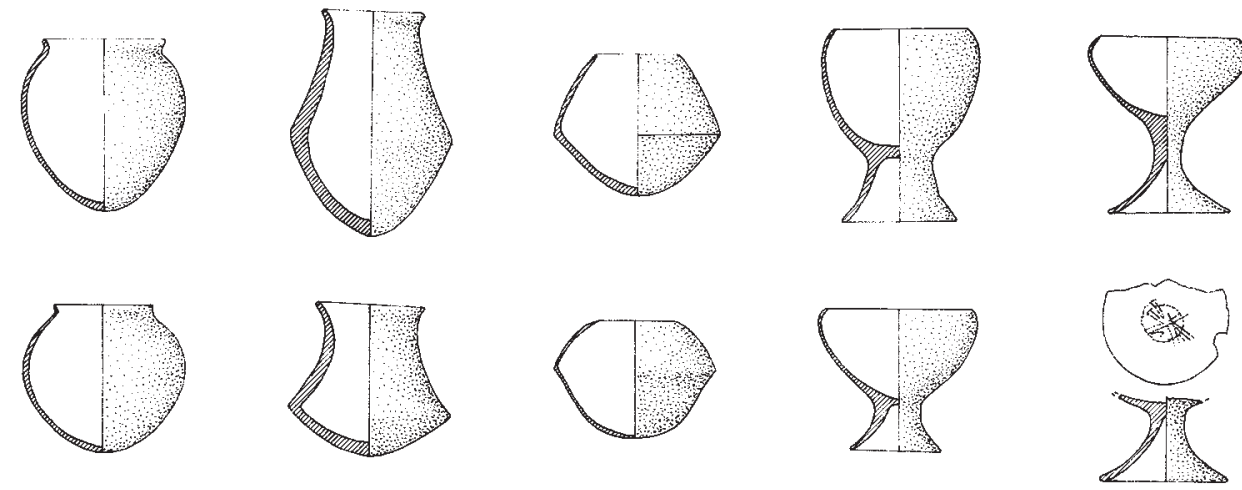

\section{El Argar A}
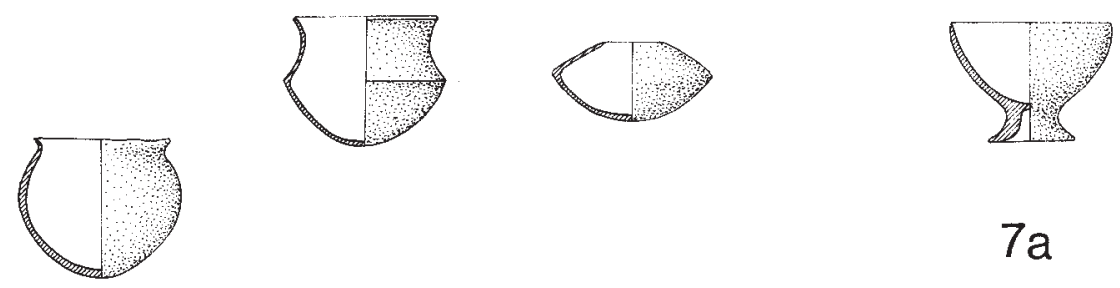

$7 a$
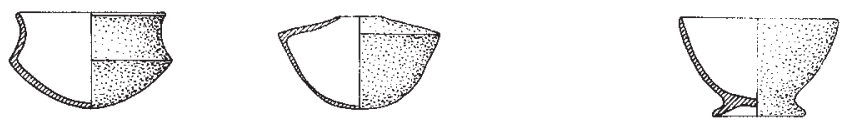

Fig. 21. Comparación de antiguas formas características con otras tardías de la cerámica argárica. Aunque los dibujos de las formas 4-7 no estén a escala, se aplica un mismo formato a las mayores anchuras de los exponentes, respectivamente, de modo que - visto desde abajo hacia arriba - se manifiesta la evolución de la forma original desde un aspecto más ancho hasta un acabado más estirado.- Los ejemplos se tomaron sobre todo de Fuente Álamo y de algunos otros asentamientos argáricos. Forma 4b (siempre desde arriba hacia abajo): Fuente Álamo, tumba 9; El Argar, tumba 398; El Oficio, tumba 9. Forma 5: Fuente Álamo, tumba 68; Fuente Álamo, tumba 52; Fuente Álamo, tumba 54; Fuente Álamo, tumba 69. Forma 6: El Argar, tumba 678; Fuente Álamo, tumba 52; Fuente Álamo, tumba 71; Fuente Álamo, tumba 75. Forma 7b: Fuente Álamo, tumba 111; El Oficio, tumba 164; Fuente Álamo, junto a la tumba 95. Forma 7c: Fuente Álamo, tumba 102; Fuente Álamo, fase 10 (Schuhmacher 2003: lám. 9, 2). Forma 7a: El Argar, sin contexto estratigráfico o funerario (Schubart y Ulreich 1991: lám. 78, 169), sin embargo, algunos de los fragmentos de fondo de la forma 7a procedentes de Fuente Álamo (fig. 14 arriba) podrán ser reconstruidos como vasijas semejantes. 